\title{
'Technology of Freedom' or 'Technology of Inequality'? Smartphones, Activism, and the Digital Divide in Senegal Tamara Gupper
}

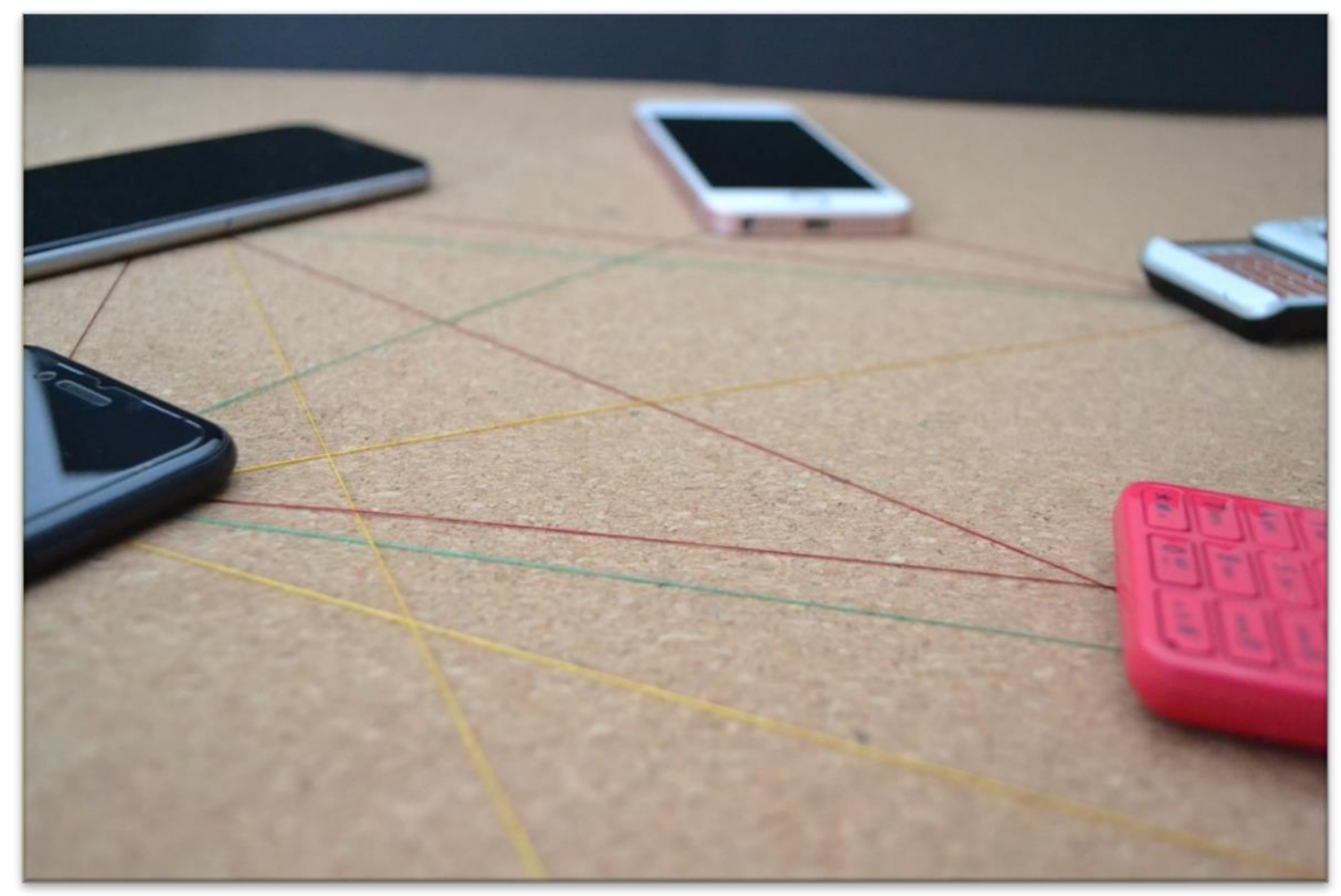

A master's thesis presented in partial fulfillment of the requirements for the degree of Master of Arts

Department of Social and Cultural Anthropology Goethe University Frankfurt am Main

First examiner: Prof. Dr. Hans Peter Hahn Second examiner: Prof. Dr. Mirco Göpfert 


\begin{abstract}
The internet has often been considered a 'technology of freedom' - a nearly revolutionary tool believed to flatten social hierarchies and democratize access to media by 'giving voice' to everybody equally. Contradictory to this point of view, research has shown the existence of a 'digital divide,' the phenomenon that access to and use of the internet, as well as the outcomes derived from this use, correlate with pre-existing inequalities.

Based on ethnographic fieldwork among activists in Dakar, Senegal, this thesis analyzes how inequalities shape and are shaped by the relationships between activists and smartphones. Do smartphones indeed flatten social hierarchies, or are inequalities rather reproduced - or even reinforced - through them?
\end{abstract}




\section{Acknowledgements}

My research, the writing of this Master thesis, as well as its publication, would not have been possible without the various forms of support I received throughout the entire research and writing process.

I am extremely grateful to my academic advisor, Prof. Dr. Hans Peter Hahn who helped me with advice and guidance from the conceptualization of my research project up until the finished thesis. Without the various forms of support you offered me this work would never have taken its current form. I would also like to extend my gratitude to Prof. Dr. Mirco Göpfert for his support throughout my degree, and in particular for his feedback and advice on this thesis. I am equally grateful to all lecturers who taught me both at the Goethe University Frankfurt am Main and the EHESS in Paris. It were your lessons and advice that helped me transform from a student into an anthropologist.

I am deeply indebted to everybody who participated in my research, in particular towards Aziz, Cheikh and Coumba. It was an honor for me to learn more about your activism and the ways you used your smartphones in your engagement. Your open-heartedness and the warm welcome you offered me were truly inspiring and gave me an impression of what the term teranga really means. Our conversations remain the best memories I retain from my time in Senegal.

My particular thanks also go to my friends, particularly Kira Kreft, Tuovi Mäkipere, and Kelan Mc Donnell, who not only read and gave me feedback on several versions of this thesis, but also stood by my side throughout the more difficult periods of my research and writing process. Particularly you, Marko Hermsen, supported me in so many ways that I can't even mention them all. Thank you for being there whenever I needed you. I would also like to extend my thanks to Laura Thurmann for supporting me in the very last steps of the publication process. 


\section{Table of Contents}

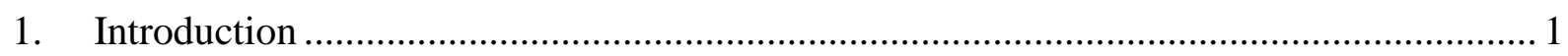

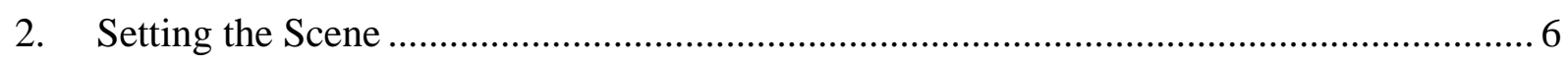

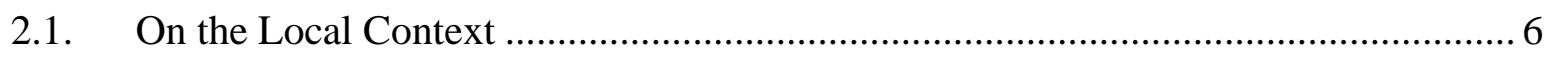

2.2. On Political and Apolitical Activism ……………............................................ 8

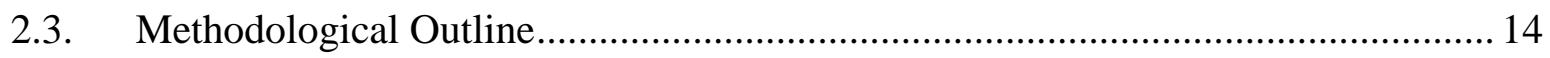

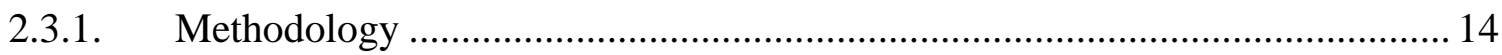

2.3.2. Being a Tubaab among Senegalese Activists ……………………………….. 16

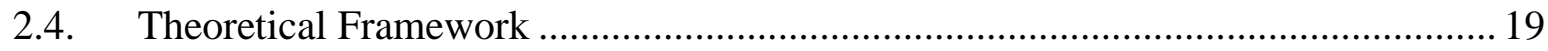

2.4.1. The ‘Technology of Freedom' Discourse …………………………………..... 19

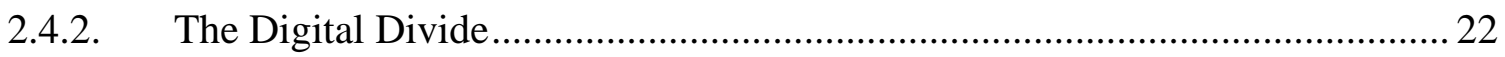

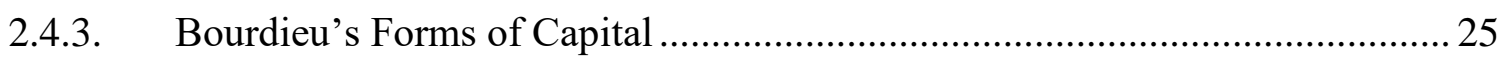

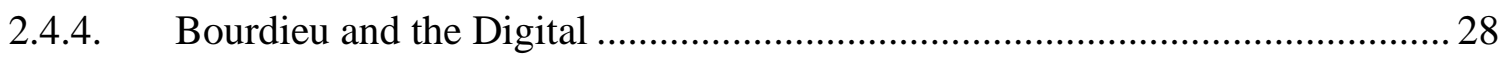

2.5. State of the Art: Internet, Activism and Inequalities in the African Context...........29

3. The Stuff (Digital) Activism is Made of - The Materiality of Smartphones and their Role in the Everyday Lives of Senegalese Activists ......................................................................... 33

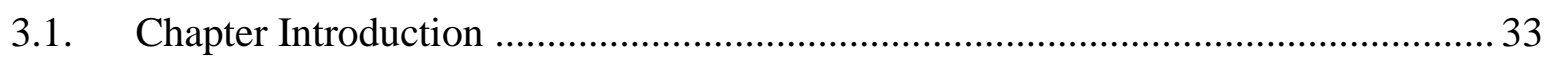

3.2. Gaining and Maintaining Physical Access to a Smartphone and the Internet.......... 35

3.3. Aspects of Time and Space in Smartphone Use................................................... 42

3.4. Valuations Ascribed to Smartphones and their Use.................................................. 47

3.5. Chapter Conclusion: A Life without a Smartphone? ................................................ 49

4. Practicing Activism through Smartphones - Communication, and the Production and Publication of Content ................................................................................................... 51

4.1. Chapter Introduction ………………………………………………………. 51

4.2. Production and Editing of Content .................................................................... 53

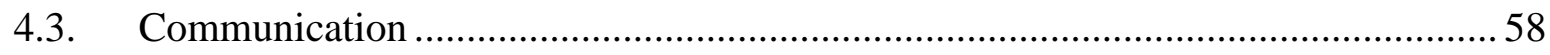

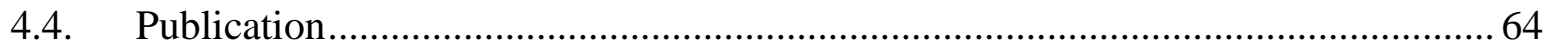

4.5. Chapter Conclusion: A Technology that 'Gives Voice' to Anybody?......................69 
5. The Perks of Being a Digital Activist - The Advantages Smartphones Bring and the

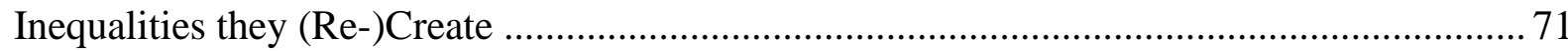

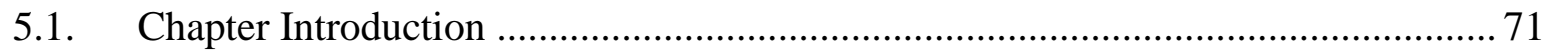

5.2. The Risks and Chances of 'Being Exposed' .......................................................... 72

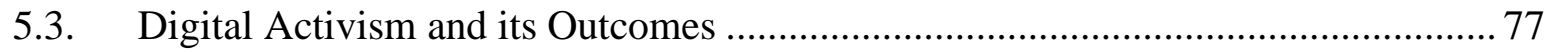

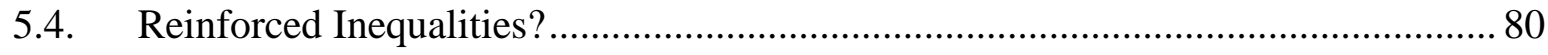

5.5. Chapter Conclusion: A Revolution through a Tap on the Touchscreen?................. 85

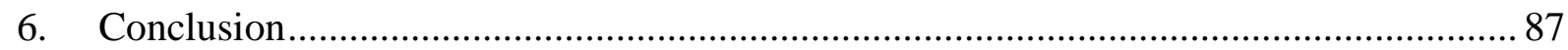

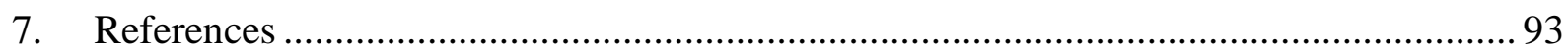




\section{Introduction}

One afternoon, Cheikh ${ }^{1}$ had invited me to his shared student room in one of the dormitory buildings on the campus. I was sitting on one of the two mattresses on the floor, which together covered most of the room, leaving but a small passage between them to reach a small fridge and a desk. Cheikh, the speaker of an activist student group, and Ismaila, one of its members, were watching a Senegalese reality TV show on a small tube TV on the desk. On the mattress across from me, half sitting, half lying, was Oumar, another member. My smartphone lay between us, recording what we were saying.

The interview had already ended, all the questions I had noted in my booklet had been asked and answered. Then, Oumar suddenly said with a sigh: "Tu sais, mon iPhone, on me l'a volé. Mais ça me manque trop !". ${ }^{2}$ At first, I was surprised, given that we had just talked about his smartphone, and he had not mentioned that he had not owned one in more than two months. As we continued talking about the theft, Oumar became angrier and angrier. He described that he felt terrible, because the thief had not only taken his iPhone, which he had enjoyed using and felt very proud of, but had also robbed him of opportunities. Now, he could no longer access information shared online, nor could he share anything for that matter. He had to ask fellow members of the activist group about ongoing discussions and decisions, because those processes mostly took place in a WhatsApp group. His contacts were all gone, and for some people, their telephone numbers were his only way to contact them. Also, everyday tasks for university had become a lot more laborious, given that he read and wrote most of his assignments on his phone. "Il m'a détruit! Il m'a détruit !", ${ }^{3}$ was what Oumar repeated with a strong voice, clearly showing his anger, when Cheikh interrupted him with a laugh. "C'est juste un téléphone, calmetoi". ${ }^{4}$

This ethnographic scene, ${ }^{5}$ which took place during my three-month ethnographic fieldwork in Senegal from July to September 2019, highlights some of the main aspects this thesis will address. Not having a smartphone was a terrible thing for Oumar because he was very attached to the material object which used to be his iPhone, but also because not having one deprived him of several functionalities this device had offered. He had used his smartphone in different domains, such as for university or for his activist engagement. Through this use, Oumar had

\footnotetext{
${ }^{1}$ All names in this work have been changed.

2 "You know, my iPhone, it was stolen. But I miss it too much".

3 "He destroyed me. He destroyed me".

4 "It's just a telephone, calm down".

${ }^{5}$ Interview, 21/07/2019, Dakar - Cité Universitaire.
} 
benefited from his smartphone in multiple ways. He was kept informed about discussions within his activist group and could participate in them. He could also pursue his education more effectively by doing research for his assignments on his phone any time he wanted to, not just when he was lucky enough to get access to one of the library computers. While Cheikh belittled Oumar's strong emotion by reducing his iPhone to its pure materiality, calling it "just a phone", it will be shown that Cheikh's relationship to his own smartphone was stronger than this scene might suggest. It is this relationship between Senegalese activists and their smartphones which will be at the centre of this thesis, and in particular whether and how these relationships shape and are shaped by social inequalities.

Particularly when it comes to the domain of activism, the internet has been considered a nearly revolutionary technology believed to simplify the engagement for a specific cause (see for example Bosch 2018). One of the main arguments in this viewpoint, which I will call the 'technology of freedom' discourse throughout this thesis, is that content such as text or pictures can be published relatively inexpensively and without having to rely on traditional media, where marginalized voices are often underrepresented (see for example Tettey 2017, 688; Bosch, Admire, and M. Ncube 2020, 360-61). The internet, which in Africa is mostly accessed through smartphones $^{6}$ (see for example Alzouma 2019, 251), is thus seen as a technology that flattens social hierarchies and can democratize activism by 'giving voice' to everybody equally.

However, what this 'technology of freedom' discourse ignores is that access to and use of the internet, as well as outcomes derived from this use, are not equally available to everybody but correlate with pre-existing inequalities (see for example Mutsvairo and Ragnedda 2019b; van Dijk 2020). This phenomenon, often called the 'digital divide,' has been observed since the beginnings of commercial use of the internet in a variety of contexts (van Dijk 2020, 7-14), including in African countries (see for example Alozie and Akpan-Obong 2017; Mutsvairo and Ragnedda 2019b).

In the case of Oumar, for example, it was a lack of financial means which meant he could not access the technology at the time of our conversation detailed above. Other factors which have been shown to correlate with access to the internet are geographical location, meaning both the

\footnotetext{
${ }^{6}$ During my research, smartphones were the main technology my interlocutors used to access the internet. Thus, I will mostly refer to the activists" devices with the term "smartphone". I use other terms, such as "mobile phone" and "phone" interchangeably with the term "smartphone", unless I specifically state that I refer to a button phone. The term "ICT" (= Information and Communication Technology) is an umbrella term which also includes other devices than mobile phones, such as tablets, laptops, mp3 players, etc. In this thesis, I will use the term "ICT" to refer to devices which allow access to the internet.
} 
country one lives in and whether it is a rural or an urban region (see for example Mutsvairo and Ragnedda 2019a, 18; L. Ncube 2019, 124), education (see for example Alozie and AkpanObong 2017), gender (see for example Alzouma 2005, 347; Ragnedda 2019, 31-32) and age (see for example Chitanana 2019, 53).

The conceptualization of the connection between the digital divide and pre-existing inequalities has changed over time within the research tradition. From the mid-1990s to the mid-2010s, digital divide research focussed on access to and use of the internet (van Dijk 2020, 7-12). Inequalities in access to and use of the internet were thereby seen as reflections of pre-existing inequalities (van Dijk 2020, 133). Since the focus of digital divide research has also included outcomes of internet use, a new theory of the relationship between inequalities regarding the digital divide and pre-existing inequalities has become popular (Ragnedda 2017, 84 ff.). This theory is that pre-existing inequalities are not only recreated, but reinforced through the digital divide, because advantages from internet use combine with pre-existing inequalities in a vicious cycle (see for example van Dijk 2020, 31).

The theory that inequalities are reinforced through a digital divide directly contradicts the main claim of the 'technology of freedom' discourse. Instead of providing an egalitarian point of entry for everybody, reinforcement of inequalities by a digital divide would increase the gap between those who can be activists and those who cannot.

Based on three-month ethnographic fieldwork among Senegalese activists in Dakar, this thesis will analyse how inequalities shape and are shaped by the relationships between activists and smartphones. Through my research, I want to answer the question whether smartphones and the internet, the proposed 'technology of freedom,' have made practicing activism more accessible by flattening existing social hierarchies, or whether inequalities are reinforced through them instead. The focus will thereby lie on the challenges the activists faced, and the strategies they employed, in order to overcome the digital divide, particularly concerning the practices associated with their activist engagement.

To analyse whether and how inequalities influence and are influenced by smartphone use in the activist context, this thesis will be constructed on the basis of a three-level model of the digital divide. This three-level model differentiates between physical access to ICTs and the internet (first level), different uses of ICTs and factors that account for this difference (second level), and the outcomes for individuals and society based on internet use (third level) (Ragnedda 2019, 35-36). My focus will be on everyday practices of being an activist and using a smartphone in 
this context. The smartphone will thereby be considered both as a material object, the acquisition and handling of which underlies certain restrictions, norms and values, and as an ICT, a device that offers access to the internet.

Special consideration must be attributed to the fact that the activists I worked with were not marginalized in society. Rather, given that all of them had a university education or were in the process of receiving one, and because all of them, excluding Oumar, owned at least one smartphone at the time of my research and had mobile internet access through it, ${ }^{7}$ they need to be considered the more privileged members of society. ${ }^{8}$ The challenges the activists I worked with could overcome thus need to be viewed against the backdrop of those who might not have had the means to do the same. In the context of activism in Senegal, can smartphones thus be considered a 'technology of freedom' or rather a 'technology of inequality?'

The decision to place inequalities at the centre of this work was not something I had planned from the beginning. However, the more I delved into the topic, the more I realised that there was no ignoring inequalities when examining smartphone use in the activist context. The contradiction of the discourse of smartphones as enablers of activism for everybody, regardless of pre-existing inequalities, and the observation that even the more privileged in Senegal struggled to use their smartphones in activism, was so prominent that I decided to make it the core argument of this thesis.

While activism and digital media have been researched before in Sub-Saharan Africa (see for example Mutsvairo 2016a), and while the concept of the digital divide has been used as a theoretical point of departure for research in African countries (see for example Mutsvairo and Ragnedda 2019b), to my knowledge, my work will be the first to combine them. In this work, Pierre Bourdieu's (1983) concept of capitals will be used as a theoretical foundation to further analyse the preconditions and benefits the activists I worked with possessed in relation to their ICT access, use, and resulting outcomes. ${ }^{10}$

\footnotetext{
7 The activists were thus part of the only 48 percent of the Senegalese population who owned at least one smartphone, and the 28 percent who were mobile internet subscribers in 2019 (GSM Association 2020).

${ }^{8}$ Others have also noted that particularly in the activist context, it is mostly the urban elite that is online (see for example Tettey 2017, 690).

${ }^{9}$ Throughout this thesis, the concepts of 'technology of freedom' and 'technology of inequality' need to be seen as different lenses through which to look at technology, rather than strictly dichotomous categories. The same technology can be both in different - or even the same - context. Yet, as will be elaborated below, some aspects of these two concepts are contradictory to each other, which is why I have chosen to contrast them throughout this work.

${ }^{10}$ As will be elaborated below, some literature on activism in the context of African countries have mentioned inequalities, but to my knowledge none have put inequalities at the centre of their work.
} 
The thesis will thereby be structured as follows: In the chapter "Setting the Scene", I will give a more in-depth description of the context of my research, including key terminology, my methodological approach, as well as the theoretical foundation of this work. The following chapters will then be structured along the lines of the three-level model of the digital divide. The different levels do not describe entirely different phenomena, but rather need to be seen as a continuum of the embeddedness of inequality in the relationships between activists and smartphones. What changes in the different chapters is the perspective on these inequalities.

In the chapter "The stuff (digital) activism is made of - The materiality of smartphones and their role in the everyday lives of Senegalese activists," I will focus on the first level of the digital divide, on physical access to the internet through smartphones. Through the experiences of Senegalese activists, I will discuss different aspects of the embeddedness of these material objects in their everyday lives.

In the following chapter "Practicing activism through smartphones - Communication, and the production and publication of content," the focus will lie on the different ways in which the activists use their smartphones in the context of their activist engagement. The focus on how technology is used, and what resources, including skills or specific technology, are needed for this use, correlates with the second level of the digital divide. The chapter will thereby elaborate both the practices performed through smartphones, as well as the different resources the activists required in order to perform them.

In the chapter "The perks of being a digital activist - The advantages smartphones bring and the inequalities they (re-)create," the focus will lie on the outcomes of smartphone use in the activist context, which relates to the third level of the digital divide. The chapter will thereby focus on the outcomes of the practice of publishing activist content, which is more often referred to as 'digital activism.' The main arguments of this thesis will then be summarized in the conclusion. 


\section{Setting the Scene}

\subsection{On the Local Context}

Senegal is a country situated in West Africa with a population of 16.2 million, of which 3.7 million live in the capital Dakar, the main site of my research (Direction des Statistiques Démographiques et Sociales 2020, 4). Since gaining its independence from France in 1960, Senegal has been considered one of the most politically stable and democratic countries in Africa (see for example Bernardini 2018). The success of activist movements to influence political decisions through protests has duly contributed to this reputation. Examples include the 1968 protests which forced then-president Léopold Sédar Senghor to reintroduce a more diverse political landscape (Ndiaye 2000, 129; Thioune Diop 2017, 108), or the 2011 protests which caused then-president Abdoulaye Wade to withdraw a bill which aimed to permit him to run for a third term (Harsch 2012, 45). ${ }^{11}$ The election victory of Wade's opponent Macky Sall in the 2012 presidential elections was also largely attributed to the wave of protests against Wade (Harsch 2012, 46-47). ${ }^{12}$

Since then, several activist groups have made headlines because of large-scale protests in Senegal. One of the most well-known is $Y$ en a marre, ${ }^{13}$ a group composed of journalists and rappers which first became active in the 2011 protests and which has played a pivotal role in the Senegalese activist scene ever since. (Harsch 2012, 45; Thioune Diop 2017, 111). Another well-known group is FRAPP - France Dégage, ${ }^{14}$ a pan-African activist movement against the global marginalization of Africa and in particular of neo-colonial structures. Occasionally, individual groups join forces in larger collectives such as Aar li nu bokk, ${ }^{15}$ which came together following the revelation of a corruption scandal involving Macky Sall's brother in June 2019. While this collective was mostly underpinned by groups without political affiliation, including $Y$ en a marre and Frapp-France Dégage, it was also supported by opposition parties (Prentice 2019; Soumaré 2019).

\footnotetext{
${ }^{11}$ Other examples of such protest waves include the "garbage crisis" in the spring of 2007 (Fredericks 2018), or the "food riots" in late 2007 and early 2008 (M. Schneider 2008; Harsch 2012, 53; Sneyd, Legwegoh, and Fraser 2013).

${ }^{12}$ After winning the presidential elections in February 2019, Macky Sall remained the current president of Senegal at the time of writing.

13 „Fed up".

${ }^{14}$ FRAPP is an acronym for Front pour une révolution anti-impérialiste populaire et panafricaine (= Front for an anti-imperialist, popular and pan-African revolution) and can be understood as a wordplay with the French word "frape", which means "hit" or "strike". France Dégage (= Buzz off, France).

15 „Let's preserve what belongs to all of us” in Wolof.
} 
Senegal's population has different ethnic affiliations, with 85 percent of the population belonging to the five largest groups Wolof, Pulaar, Jola, Serer, and Mandinka (L. Beck 2008, 231). Ethnicity has been shown to influence, for example, voting patterns in presidential elections, although this phenomenon is less observable in Senegal than in other West African countries (Gottlieb and Larreguy 2015, 25). Concerning infrastructure expansion, there is a noticeable difference between northern and southern Senegal, as well as urban and rural areas. The southern region Casamance has thereby been disadvantaged since colonial times because of the French investing more in northern Senegal, with the differences being reinforced by a separatist conflict that has raged in Casamance since 1983 (Trzciòski 2005, 171; Kohnert and Marfaing 2019, 10). Furthermore, people living in urban areas tend to have better access to basic amenities than people living in rural areas (Crossouard and Dunne 2015, $56 \mathrm{ff}$.).

While there are a number of languages spoken as native languages in Senegal, Wolof has developed into a conversational lingua franca, with about 80 percent of the population speaking this language proficiently either as a first or second language (Cisse 2005, 103-5). French, which is the language used in education and administration, is estimated to be spoken fluently by about one quarter of the population, and carries a formal and elitist connotation (Cisse 2005, 105; B. Beck et al. 2018, 35). As in most African countries, Senegal's population is young, with 52,1 percent of the population being under 20 years old (Direction des Statistiques Démographiques et Sociales 2020, 20). About 52 percent of the overall population over the age of 15 are estimated to be literate (Kemp 2019).

About 95 percent of the Senegalese population are Muslim, with the particularity that the religion is organized in four main brotherhoods, which are associated with different cities or villages across Senegal (Wane 2010, 2). ${ }^{16}$ Each of these brotherhoods is further associated with one family and led by a khalif (Wane 2010,22). These families are not only very influential in the religious domain, but also in the political and media spheres (Wittmann 2008, 484). This influence can be demonstrated through the fact that Macky Sall, the currently ruling president, started his 2019 presidential election campaign with a visit with the General Khalif of the Mourides brotherhood, and made the modernization of religious cities one of his main electoral promises (Kohnert and Marfaing 2019, 7).

\footnotetext{
16 The Qadr brotherhood is associated with Ndiassane, the Tijân brotherhood with Tivaouane, the Layène brotherhood with Thiaw in the Cap-Vert, and the Mouride brotherhood with Touba, Senegal's largest city outside the metropole region (Wane 2010, 2).
} 
Senegal's telecommunication sector is relatively diverse, with four major mobile operators (Lancaster 2020). ${ }^{17}$ As other African countries, Senegal has seen a sharp rise in the use of smartphones and the internet in the past decade. For example, the percentage of mobile internet subscribers relative to Senegal's population has risen from 22 percent in 2018 to 28 percent in 2019 (GSM Association 2019, 2020). About 48 percent of Senegal's population owned at least one smartphone in 2019 (GSM Association 2020).

\subsection{On Political and Apolitical Activism}

The activists I worked with were engaged in a variety of different organizations and groups, each of which concerned itself with wildly different topics. Likewise, the individual practices they employed in their activism were not the same. However, because they all considered themselves to be activists, I have chosen to use the term as a way to highlight the similarities between them. In this section, I will thus try to undertake the difficult task of finding a conceptualization of the term 'activism' which is specific enough to give a clear idea of what my interlocutors associated with the term, and what I mean by it in this thesis, as well as broad enough to encompass all the phenomena I could observe.

Although the term 'activism' is used in many scientific works, an exact definition of the term is hardly ever given. This is particularly true concerning activism specific to an African context (see for example Medie 2016; Volpi and Clark 2019). In his introduction to the seminal anthology "Digital Activism in the Social Media Era - Critical reflections on Emerging Trends in Sub-Saharan Africa," Mutsvairo cited Yang who defined activism as "action for social, cultural, political, and nationalistic change" (Yang 2009 in Mutsvairo 2016b, 9). His choice of citing Yang, who came up with his definition based on his work on activism in China, is particularly interesting against the backdrop that in the sentence just before this citation, Mutsvairo $(2016 \mathrm{~b}, 9)$ highlighted the importance of understanding the concept in an African context. Evidently, also Mutsvairo struggled with finding a definition of the term specific to or derived from the African context.

While there are definitions of the term based on ethnographic work in African countries, for example Stafford $(2013,8)$ who defined activism as "coordinated, organized student group activity that serves the purpose of voicing disagreement with governmental decisions or actions" based on her research on student activism in Dakar, they are too narrow to describe the variety of forms of activism I observed.

\footnotetext{
${ }^{17}$ These four operators are Orange Senegal, Tigo Senegal, Expresso, and Hayo Telecom (Lancaster 2020).
} 
Other definitions of the term, stemming from the field of psychology, seem more promising. Curtin and McGarty (2016, 228), for example, defined activists as "people who actively for social or political causes and especially those who work to encourage other people to support those causes." Van Zomeren $(2015,1)$ defined activists as "members of social movements or action groups."

While most of the activists I worked with were part of groups or organizations in which they operated, some of them had started their engagement single-handedly. Aliou, for example, an entrepreneur in his mid-30s who managed a Facebook page through which activist content was regularly published, started his engagement when one day, he witnessed a driver going the wrong way down a road in Dakar. He filmed the incident on his smartphone and posted it on his personal Facebook page, denouncing the act of driving the wrong way and asking his Facebook contacts to be more diligent when it came to respecting the rules of the road. Because of the positive resonance he received, he decided to get more involved in promoting respect for the rules of the road and a variety of other aspects including food hygiene and consumer rights on a Facebook page he opened for this purpose. ${ }^{18}$ At the time of my research, six other people had joined Aliou as managers of the page.

While van Zomeren's definition is thus too narrow to describe my observations, Curtin and McGarty's definition which focusses on activist causes seems more appropriate. All activists I worked with had certain causes they pursued and goals in connection to these causes they wanted to achieve. Often, this goal involved changing a certain status quo, such as existing social hierarchies. An example of this would be when students took action to obtain more decision-making power on campus. Denouncing common practices deemed negative by the activists, such as driving the wrong way or habits that contributed to the piling up of disposable plastics in Dakar, were also common goals.

When I asked my interlocutors when and how they decided to be activists, I noticed three commonly occurring responses. First, the activist goal itself, such as in the case of Aliou. Second, group structures were named as the reason to get engaged, as for example Ismaila, ${ }^{19}$ one of the members of the student movement told me. He had decided to join the activist student movement after Cheikh had added him to the movement's WhatsApp group chat in his first

\footnotetext{
${ }^{18}$ Greijdanus et al. $(2020,49)$ have called the work on platforms on which norm transgressions are publicly displayed as 'digilantism.' Another famous example of this form of digital activism is the blog "Ushahidi”, which was first introduced by a Kenyan activist to document election violence in 2007/2008 (Wachanga 2012).

${ }^{19}$ Interview, 21/07/2019, Dakar - Cité Universitaire.
} 
semester at university. Because he felt very welcome in the group, and also recognized the importance of the goals the group fought for, he decided to get engaged in the group himself. Third, the activists were very passionate about their activist engagement and regarded becoming and being an activist as a morally good activity. More so, some of them saw being an activist as one of their inherent character traits. ${ }^{20}$ Cheikh, ${ }^{21}$ the speaker of an activist student movement, ${ }^{22}$ for example, said he was born an activist and knew that he would be active to fight global and local injustice from an early age on.

A definition that can do justice to the activists I worked with thus needs to include the pursue of an activist goal, the social dynamics in which activism is embedded, as well as allow for 'activism' to be a character trait itself and not only an activity they felt passionate about. Also, because not all of these factors were equally important to the activists I worked with, my concept of the term needs to be flexible enough to account for these differences.

Despite the fact that all of the activists I worked with referred to themselves as activists, they would not see each other's activities in this context as similar to their own. A particularly important distinction my interlocutors regularly brought up was between political and apolitical activism. I first realized the importance of this distinction when, one night, I was sharing a taxi home with Coumba, ${ }^{23}$ a journalist in her late forties and active member of multiple activist organizations in the domains of women's rights, migration, and the environment. We were casually chatting when I asked her for how long she had been politically active. I had not understood the emic significance of the term 'political' yet and what I had actually intended to ask was for how long she had been an activist in the fields she had previously mentioned. To my bafflement, Coumba immediately replied that she was not politically active, had never been and did not intend to ever be. Her engagement, so she explained, was purely apolitical.

In the emic conceptualization, I learnt that night, 'political' meant an affiliation to a political party. Given that political transhumance, defined by Kohnert and Marfaing $(2019,360)$ as the "political nomadism from one party affiliation to another, depending on the attractiveness of 'pastures"” was relatively common in Senegal (Kohnert and Marfaing 2019), it usually meant

\footnotetext{
${ }^{20}$ This aspect was also mentioned by young activists in Chad (Bruijn 2016, 94).

${ }^{21}$ Informal conversation, 05/08/2019, Dakar - Fann.

${ }^{22}$ The student movement was engaged in representing the students' rights, for example when it came to the payout of scholarships, which was a topic that often led to violent protests on campus. The movement presented itself as 'voice of the students,' trying to enforce the students' rights and preventing violence on campus. They were equally active in different art forms, for example graffiti and hip-hop, which have a history of connections with social activism in African countries (see for example Karam 2018, 34).

${ }^{23}$ Informal conversation, 19/07/2019, Pikine.
} 
an affiliation to the party currently in power, or to successful opposition parties. Apolitical activism would then, negatively defined, be any type of activism that is not linked to a political party.

The distinction between the political and the non-political has previously been discussed. Ferguson (1996), for example, analysed how technocrats in a development project in Lesotho used the label of 'not being political' to strengthen their own position in making decisions concerning resources. Also Göpfert (2019) discussed the non-political as a strategy to maintain rooms for action in places where 'being political' entailed personal dangers, naming a Nigerian gendarme and an Iranian cartoonist as examples. While I do believe that these insights apply to the situation of the activists I worked with to some extent, a thorough analysis of this aspect would be beyond the scope of this thesis. From now on, I will thus use the terms 'political' and 'apolitical' in their emic meanings as the activists I worked with in Senegal used them.

Among the apolitical activists I worked with, there were also disagreements on what apolitical activism should look like. Some of the apolitical activists I worked with highlighted refusing foreign funding or affiliation to large organizations from the Global North. One of these activists was Cheikh, who identified strongly with Pan-Africanism, a movement which sees African countries as united in their struggle against colonialism and global marginalization. ${ }^{24}$ $\mathrm{Cheikh}^{25}$ rejected both political engagement, as well as engagement within apolitical organizations with foreign funding, because he found both these forms of organizations to be elitist and partisan, and more generally against the interest of Africans. Others, such as Coumba, were mostly engaged in foreign funded organizations.

Particularly apolitical engagement without affiliation to institutions from the Global North was thereby often seen as a transition phase towards political engagement. Aziz, ${ }^{26}$ for example, told me that he had started off his engagement in an apolitical movement which focussed on development aspects of his home locality in Casamance. As will be discussed below in more detail, it was through this apolitical engagement, and particularly through his smartphone use in its context, that the leader of a political movement with similar activist goals took notice of him and asked him to join. ${ }^{27}$ At the time of my research, Aziz ${ }^{28}$ had been engaged in this

\footnotetext{
${ }^{24}$ For a more detailed definition of the term 'Pan-Africanism' and its history see (Malisa and Nhengeze 2018).

${ }^{25}$ Informal conversation, 05/08/2019, Dakar - Fann.

${ }^{26}$ Interview, 12/07/2019, Dakar - Point E.

${ }^{27}$ Many political parties support movements affiliated with them on the level of villages or smaller localities, particularly given that most campaigns concerning electoral targeting take place on this level (Gottlieb and Larreguy 2015, 4).

${ }^{28}$ Interview, 12/07/2019, Dakar - Point E.
} 
political movement for approximately nine months, and also reported being criticized for it by fellow activists in the apolitical movement. They mainly reproached him for choosing to switch to the political movement for his own benefit rather than the activist goals, which he strongly denied. Rather, he said, the political movement, because it was better funded and better connected to other movements affiliated to the ruling party, would allow him to pursue his goals even more effectively, in addition to having some personal benefit. For example, Aziz ${ }^{29}$ interpreted his finding a job with a long-term contract in a cultural institution in Dakar as a result of his political engagement. Cheikh ${ }^{30}$ also told me that he had been asked to join a political movement, but he reported having declined the offer because he considered it an attempt to divert him from his activist goals. ${ }^{31}$

The activists I worked with were thus engaged in three different forms of organizations: Firstly, political movements affiliated with a political party. Secondly, apolitical organizations which received foreign funding, typically from institutions from the Global North. ${ }^{32}$ And third, apolitical organizations which did not receive foreign funding. While the activists I worked with saw these different forms of organizations as inherently different, at a second glance, the distinctions were often blurred. This was particularly the case because for many, being engaged in one or the other form of organization was not considered to be mutually exclusive. ${ }^{33}$ Aziz, ${ }^{34}$ for example, was not only engaged in the previously mentioned political movement, but also in an apolitical movement which had ties to institutions from the Global North, where he was engaged in a project about the environment. This particular organization was internationally well-connected, being the West African branch of a globally known organization, and received foreign funding from several sources for its different projects. ${ }^{35}$ This also enabled the organization to offer the activists certain benefits, such as training courses, among them one on

\footnotetext{
${ }^{29}$ Informal conversation, 26/09/2019, Dakar - Fann Hock.

${ }^{30}$ Informal conversation, 05/08/2019, Dakar - Fann.

${ }^{31}$ The political system in Senegal is highly marked by clientelism (see for example L. Beck 2008; Ndiaye 2000). The terms 'clientelism' and 'corruption' are not synonymous, with the first one describing the distribution of resources for political support, whereas the second one describes the accumulation of resources for one's personal benefit (L. Beck 2008, 38) The definition of 'clientelism' thereby describes Aziz' role in the political movement very well. As the previously described scandal involving Aliou Sall, Macky Sall's brother, demonstrates, corruption is also an issue in Senegal's political sphere.

${ }^{32}$ All the organizations that will be cited in the course of this thesis which fall in this category receive funding from the Global North. While movements which are financed through South-South relations most probably exist, I have not met anybody engaged in such an organization during my research.

${ }^{33}$ Volpi and Clark $(2019,6)$ could also observe the affiliation of individual activists to different forms of organizations in their research on activist groups in the Middle East and North Africa.

${ }^{34}$ Interview, 02/07/2019, Dakar - Point E.

35 Not only large, internationally well-known NGOs receive foreign funding, but also many smaller local organizations. Many community radios, which are often considered grassroot media channels in West Africa, are funded from foreign sources (see for example Hames 2017; Salgado 2016, 193-94).
} 
the activist use of smartphones and social media in which $\mathrm{Aziz}^{36}$ took part, or the participation at networking meetings in several locations in West Africa and beyond. Aziz, ${ }^{37}$ for example, told me with great pride that he had taken part in a reception in the embassy of the European Union in Dakar because of his engagement in this organization. That the distinction between the different forms of activist organization drawn by my interlocutors is blurred is both true in the context of the activists I worked with, as it is in larger contexts. For example, as previously mentioned, the protests organized by the collective Aar li nu bokk, which itself was apolitical, were actively supported and attended by opposition parties. ${ }^{38}$

The activists and their practices in relation to activism were thus entangled in a global and local power structure, in which the different forms of organizations occupied distinct positions. In the case of Senegal, similarly to many other African countries, these power structures are marked by post- and neo-colonialism, in which African states continue to be marginalized (see for example Ndlovu-Gatsheni 2014; Willems and Obadare 2014, 7). As I will argue, the position of the activist group within these power structures ultimately influenced both the impact the activists' engagement would most likely have, and the activists' position vis-à-vis the digital divide. Trying to formulate a definition for the term 'activism' that does justice to the activists I worked with, I would thus define activism as the passionate pursuit of one or more activist goals, which are often in connection to changing a certain status quo, and often pursued together with fellow activists in more or less formal groups and organizations. Also, activism is a locus where international and national power structures play out, which influence and are influenced by activist practices. My own focus will thereby not lie on large protests or actions that are necessarily successful, but on the everyday practices of people who aimed to make a change, and particularly on the way they used their smartphones in this process.

Given that this thesis focusses on smartphone use in activism, another important concept is that of 'digital activism.' As I will elaborate below, I will use the term 'digital activism' to refer to the practice of publishing activist content online, which is but one of the ways smartphones were used in activism. What I would like to mention at this point, however, is that among the activists I worked with, online and offline activism could not be discerned from each other. While there has been a debate about the difference in efficacity of online and offline activism, ${ }^{39}$

\footnotetext{
${ }^{36}$ Interview, 02/07/2019, Dakar - Point E.

${ }^{37}$ Interview, 02/07/2019, Dakar - Point E.

${ }^{38}$ Demarest (2016) has also shown how opposition parties, including Macky Sall's party Alliance pour la République (APR), have profited from supporting the 2011 protests.

${ }^{39}$ Gerijdanus et al (2020) reviewed literature on the connection between online and offline activism, collecting arguments for a negative, a neutral, and a positive correlation between the two. Their conclusion was that the
} 
I found that the distinction between the two was not expedient, given that all activists I worked with practiced activism both online and offline and found practicing both forms vitally important, if not necessary, in order to achieve their respective goals. Digital activism alone, without further offline practices, was viewed negatively, with $\mathrm{Cheikh}^{40}$ claiming that people who solely practiced digital activism were imposteurs ${ }^{41}$ whose activism was not effective and mainly about their own presentation rather than for the cause. ${ }^{42}$ Also, being an activist without any online presence was viewed negatively because not being reachable through social media and not publicly documenting one's actions was equated with less visibility for one's activist cause. $^{43}$

\subsection{Methodological Outline}

\subsubsection{Methodology}

The information presented throughout this thesis was obtained through semi-structured interviews, participant observation and informal conversations. The interviews were recorded with the consent of the interviewees and later transcribed. The transcriptions serve me as a point of reference to increase the accuracy of my analysis and will not be attached to protect the privacy of the interviewees. All of my interlocutors were informed about my research project and agreed to participate. I also told them that their names would be changed to protect their anonymity. In this thesis, all names have thus been changed ${ }^{44}$ and activist groups and organizations will not be named explicitly.

In this way, I conducted nine semi-structured interviews with a total of eleven activists and one expert in IT consulting specialized in the field of activism, most of them lasting between two and three hours. Despite my initial goal to reach a gender balance among my interlocutors, they ultimately comprised nine men and three women, a fact which I attribute both to the time restriction of my research, as well as on my own gender, as will be elaborated below. The interviews were often followed by either the possibility to observe activist practices, such as a meeting of the activist student group on July $4^{\text {th }}$, or a more informal conversation, such as with

current state of research rather suggests that online and offline measures are closely interrelated. For more on this debate, see for example Wasserman $(2011,146)$ or Bosch, Admire, and M. Ncube $(2020,352)$.

${ }^{40}$ Interview, 04/07/2019, Dakar- Cité Universitaire.

41 "posers".

42 Mare $(2016,64)$ has coined the term 'armchair activism' to critically refer to activism that is solely digital. Also Mutsvairo $(2016 \mathrm{~b}, 11)$ argued that the success of online activism also depended on how it was coordinated with offline actions.

${ }^{43}$ Among others Cheikh (interview, 04/07/2019, Dakar - Cité Universitaire) and Awa (interview, 26/07/2019, Dakar- S.I.C.A.P. Sacré Cœur).

${ }^{44}$ When changing the names, I tried to find aliases that carried a similar connotation to the original ones. 
Aziz on July $12^{\text {th }}$ when the conversation simply continued informally when I had asked Aziz all the questions I had prepared. With some, I also held more informal conversations at meetings not formally related to my research, such as walks along the Corniche or visiting the public viewing of the Africa Cup of Nations together, which gave me the opportunity to gain a better understanding of the activists' lives outside of and in connection with activism.

During interviews and instances of participant observation, I noted down details which I would rewrite and recontextualise in my field diary soon after. My field diary and the interview transcriptions are now a corpus of 39 text documents, out of which 30 are diary entries and nine interview transcripts. In addition to these documents, I also have a corpus of pictures, mostly produced by the activists I worked with. These are pictures they took during our meetings and then sent me, and screenshots of the content they had published through the "status" function of WhatsApp I took and saved. I systematically saved all publications of the activists from the day I got their phone numbers until the end of my stay in Senegal. My corpus comprises a total of 1458 pictures of this kind. While I did take some photographs myself, I am generally not a person who takes many pictures and found it in most situations rather disruptive, particularly because taking out a smartphone to take a picture often causes people to change what they are currently doing. The third type of data are snapshots of the activists' Facebook pages that I saved regularly during the three months of my research. I have a total of 45 saved snapshots of 12 different Facebook pages. Again, these documents will not be shared to protect the privacy and anonymity of the activists.

The interviews and observations I obtained will thereby be the main source for my argumentation, because they give a better insight into the activists' engagement and their relationships with their smartphones than the other types of data. Throughout this thesis, I will indicate the method used, the date and the place in the footnote whenever I refer to ethnographic details. The pictures and snapshots will sometimes be referred to if particular publications of the activists are described. Also in these cases, details relating to these publications will be given in the footnotes.

In the different chapters, I will not always refer to the same activists, and generally I will not refer to all the activists I worked with. While my analysis will thus be based on ethnographic examples from few activists, I have chosen the examples to elaborate on aspects I could generally perceive among all or most of the activists I worked with. Whenever there were contradictions or differences in a certain aspect between activists that are relevant for my analysis, they will be mentioned explicitly. Because my insights are derived from eleven 
activists and one expert on IT consulting specialized in the use of social media in activism, I do not claim that my analysis is valid for all activists in Senegal, but only for their specific cases. However, I do argue that their experiences give a larger insight into the use of smartphones in activism in Senegal.

My three-month stay in Senegal can be divided in periods that were highly relevant for gaining insights into my research topic, and periods which were less so. Particularly in the first five weeks of my stay, I had an immense restlessness to conduct interviews, take part in events, note all my observations down, transcribe the interviews, analyse what I had learned and look for new leads that could prove fruitful. This exceptionally productive period came to an abrupt halt before Tabaski, ${ }^{45}$ a religious holiday, in which almost all the activists I worked with left Dakar for their home localities, and some of them did not return to Dakar before the end of my stay. An even heavier blow to my ability to conduct research came on August $21^{\text {st }}$, about eight weeks into my research, when I was robbed close to where I lived in Dakar. This robbery left me with both physical injuries, as well as an emotional shock that significantly hampered my further research and everyday life in Senegal.

I would describe the main impact of this incident for the remaining time of my stay in Senegal as an immense increase in my inhibition threshold to do all sorts of activities. Things that were easy before, such as calling one of the activists or buying drinking water from the convenience store next to the apartment building in which I lived, cost a large amount of energy and willpower afterward. The aggression has thus also had an influence on my research process, in basically reducing it to activities I could manage to do, such as documenting publications and answering calls and messages from my interlocutors.

\subsubsection{Being a Tubaab among Senegalese Activists}

Basing my research on ethnographic methods ultimately entails accepting that both the accounts of my interlocutors, which are their own interpretations of their life experiences, and my own interpretation of their accounts are subjective perceptions which are anchored in a certain time and place. Ethnographic data is thus always context-dependent, as well as relational, meaning that it stems from the interaction between my interlocutors and myself. Because of this, the next few paragraphs will be dedicated to give a better understanding of the context and particularly of my own role in the field.

\footnotetext{
${ }^{45}$ Tabaski is the name for Eid ul-Adha, the Muslim Feast of the Sacrifice, in Senegal. In 2019, it took place on August $12^{\text {th }}$.
} 
Asking people about their smartphones, or mentioning that I was conducting research on smartphones, was often a good conversation starter. That was both because of the omnipresence of smartphones and the overall consensus of their relevance in everyday life, and because most people enjoyed talking about their own devices and how they used them. One of the reasons for this was surely that smartphones were relatively expensive objects, and owning one, particularly if it was an expensive brand, was a source of great pride for the owner. Also, as will be elaborated below, there was a discourse on smartphones as objects that had the potential to significantly enhance one's living conditions, and on a macro-level the living conditions of Africans in general. Reporting on how one used one's smartphone in a 'good' way was thus also something people were keen on telling me, also in the context of activism.

In some cases, their enthusiasm of telling me about their smartphone use could be described as 'bragging,' which, as I believe, had a lot to do with the way people, including the activists I worked with, perceived me in Senegal. Being a tubaab, ${ }^{46}$ a white person of European descent, and to be more exact a young female tubaab, influenced the way people approached me and surely also what people told me about themselves and about their smartphones. While overly enthusiastic accounts of people's smartphone use might in some cases have been made more as an attempt to create a certain impression than to report a series of facts, they still give valuable insight into the valuation of smartphones, the relationships the activists led with these objects, and the role the devices played in activism.

During my stay in Senegal, I found that being a tubaab had several implications for my everyday life in general, and my research project in particular. It surely facilitated my access to the field, but also produced a number of challenges on a day-to-day basis. The category tubaab is a racial distinction which goes along with the essentialist idea of an innate "origin," which for white people would be Europe, and for black people Africa (see also Barry 2017, 167). Because of colonialism and the ongoing marginalization of countries in the Global South by countries in the Global North, my skin colour represented an unequal power relation, in which I was considered superior in the current neo-colonial power structure.

The more advantageous aspects of this association was that many people thought of me as a valuable social capital. As a tubaab I was expected to be wealthy and influential, which was probably one of the reasons why I received such rapid access to the field - to the extent that I

\footnotetext{
${ }^{46}$ For a deeper analysis of the term in the local context of Dakar see Barry's (2017) "Die Bedeutungen von tubaabité. Rassismuskritische Perspektiven auf das postkoloniale Dakar.“
} 
held three interviews in the first four days of my research stay. Doing research on a quite popular topic, as well as having a good portion of luck to have made contact with people who were incredibly welcoming and readily agreed to be involved in my research project, also contributed to this easy access to the field.

However, because my skin colour represented this unequal power structure, and identified me as the beneficiary of it, I also ended up in situations that were unpleasant at best, and outright dangerous at worst. Once, for example, a taxi driver threatened he would not let me leave his car until I would call somebody to arrange him a visa for France. Luckily, there was a traffic jam and I managed to leave the taxi without further consequences. Incidences like this one, and the fact that I constantly felt people noticing my presence whenever I was in public spaces, led me to an awareness of my own vulnerability which I had not known to this extent before my stay in Senegal.

During the interviews and other incidents where I met the activists I worked with, I felt that the aspect of 'bragging,' which I have previously mentioned, was not only confined to them telling me about their smartphones, but also to telling other people that they had met me, a young female tubaab, to discuss their smartphone use. Most of the activists took pictures of me and published them either through the WhatsApp status function, or on their Facebook pages. One of the activists I worked with also had a picture of him and me taken the first time we met as his WhatsApp profile picture for a week, ${ }^{47} \mathrm{a}$ fact that one his fellow activists later mentioned with a suggestive undertone.

I found that even with the activists that I had most contact with, the aspect of me being a tubaab never really receded into the background. This became most clear in moments when they expressed that there were features they observed on me that were inconsistent with their images of what a tubaab was like. An example would be my own smartphone. Most people who saw it expressed their astonishment in me owning a rather low-budget, worn-out looking smartphone and not the newest, shiniest iPhone.

My smartphone was in several ways probably the most relevant object I took to Senegal. Just as in activism, as will be discussed in more details below, smartphones turned out to be necessary objects in my research project. I got to know most of my interlocutors by contacting them through my smartphone, and I also arranged all of my meetings with them through it. Just

\footnotetext{
${ }^{47}$ This particular picture was the activist's profile picture on WhatsApp from 07/07/2019 to 14/07/2019.
} 
like the activists could not imagine how to practice activism without a smartphone, I cannot think of a way I would have coordinated my research without one.

Apart from the possibility to communicate across distance, which helped me both organize my research while still in Europe and to fix meetings while I was there, I used my smartphone to record interviews and take notes. In the first few days I realised that taking notes with pen and paper often caught people's attention up to a point where I would seriously disrupt, for example, the meeting of an activist group by writing down notes. However, typing something on a smartphone was much more discreet, as most other participants were also holding their smartphones in their hands for most of the time. I also sometimes recorded voice memos on my smartphone when I wanted to describe situations that would take too long to write down manually - speaking to one's phone also did not draw much attention.

While I found it astonishing how passionately people spoke about their smartphones, particularly after it had been stolen or broke, I cannot claim that my personal emotions to my smartphone were any less, particularly during my stay in Senegal. I found it very difficult during these three months to establish a friendship in Senegal which would have allowed me to share both the positive and negative aspects of my everyday life as a tubaab, which often made me feel quite lonely. It was ultimately my smartphone that provided me with the assistance and companionship I needed in the rather difficult times of my research. Through it, I was connected with friends in other parts of the world that had made similar experiences and listened to and understood my struggles. My emotional dependence on my smartphone, and access to the internet, was so strong that I always had an 'emergency scratch card' with me, usually of a value of $1000 \mathrm{FCFA},{ }^{48}$ with which I could reload my pre-paid SIM card in case I accidentally ran out of credit. ${ }^{49}$

\subsection{Theoretical Framework}

\subsubsection{The 'Technology of Freedom' Discourse}

Since the beginning of its commercial usage in the 1990s, and even before, the internet has been imagined to drastically change the way societies function (Uimonen 2015, 600; Schradie 2019,

\footnotetext{
${ }^{48}$ Approximately 1.52 EUR.

${ }^{49}$ My SIM card was from the provider Orange. There were several data packages that could be bought with prepaid credit on the SIM card, which were either limited in duration or data volume, or both. With my emergency airtime of 1000 FCFA, I could for example have bought one hour of unlimited data volume for 400 FCFA, or 3 gigabyte of data volume over the duration of 24 hours for 1000 FCFA. Also weekly and monthly packages were offered.
} 
263-64). Utopian accounts ${ }^{50}$ of science fiction novelists, journalists and scientists alike predicted a new age of egalitarianism, revitalised democracies, and educational possibilities of unprecedented scale (Howcraft and Fitzgeralt 1998, 3-5; Uimonen 2015, 601).

One of the most influential theorists who advocated the view that the introduction of technology would drastically change society is Manuel Castells (Uimonen 2015, 601-2). In his famous trilogy first published in the late $1990 \mathrm{~s},{ }^{51}$ his main claim was that rapid innovations in microelectronics, computer technology and telecommunication have caused a new era for humanity and the organization of society, which he calls the information age (see Castells 2017a, $14 \mathrm{ff}$ ). In this information age, society and all social processes are built on networks which work on a binary logic of inclusion and exclusion (Castells 2017a, 568). Castells thereby considered being included in the network as a precondition to having access to wealth, power and knowledge (Castells 2017b, 104). In the second volume of his famous trilogy, he drew quite a devastating picture of the economic and societal prospects of African countries, which were at that time in most cases completely excluded from access to the internet (Castells 2017b, 104).

A few years after the publication of Castells' trilogy, an unsuspected phenomenon gave new hope for the inclusion of African countries to the global network society - the unexpectedly rapid adoption of mobile phones (Alzouma 2005, 343). The reception of this development was so enthusiastic that "only superlatives seem[ed] appropriate to describe" it (Etzo and Collender 2010, 659). Still today, mobile technologies, particularly smartphones, are the main device for mobile communication and internet access in most African countries, among other reasons because of their affordability and the fact that no constant source of electricity is needed to operate them (Alzouma 2019, 350; Musa 2019, 74).

Particularly since the unexpected success of mobile phones, the inclusion of African countries in the network society has become a major development goal (Alzouma 2005, 341). The United Nations, for example, named providing access to the internet as a way to solve some of the most urgent problems of our time in 2015 (Ragnedda 2019, 28). Also the current minister for digital economy and telecommunication of Senegal, Ndéye Tické Ndiaye Diop, expressed her belief in the developmental advantages of a wide provision of internet access, stating that ' $L$ 'Afrique se développera par le numérique" ${ }^{, 52}$ (Ministère de l'économie numérique et des

\footnotetext{
${ }^{50}$ Also dystopian visions of surveillance and control of humans through technology were predicted from the implementation of the internet onwards (Howcraft and Fitzgeralt 1998, 5-6).

${ }^{51}$ The Rise of the Network Society (1996), The Power of Identity (1997), and End of Millennium (1998).

52 "Africa will develop through digital technology".
} 
télécommunications 2019). The general assumption of initiatives which seek to provide access to the internet as a development strategy is that the possibility to obtain information online will lead to improvement in multiple areas, such as healthcare, education, political participation, and the economy. ${ }^{53}$ This technologically determinist approach, called Information and Communication Technologies for Development (ICT4D), is still common among policy makers (see for example Heeks 2018).

Particularly since the start of the Arab Spring in early 2011, social media, mostly accessed through smartphones in the African context, have become the new flagship of the liberating potential of the internet (Uimonen 2015, 602; Alzouma 2019, 265). Both public opinion and scientific analysis credited access to the internet through smartphones as a main enabler of the protests in North Africa and the Middle East, by presenting a stage, 'giving voice,' to the marginalized (Schradie 2019, 263-64). Because mobile phones had spread so rapidly across African countries, hopes for a new democratic wave through sub-Saharan African countries, an “African Spring," started to arise (Harsch 2012, 45; Mutsvairo 2016a, 7).

Indeed, protest movements which made use of the internet have been a phenomenon in African countries in recent years, much-cited examples being the South African movements \#RhodesMustFall and \#FeesMustFall (Bosch 2016; Daniels 2016; Frassinelli 2018). Smartphones have, however, not only been acknowledged as tools to organize protests, but also in a number of other activist practices. From a publications point of view, social media are considered to be a platform on which information can be shared and political issues discussed, thereby allowing users to circumvent the gate-keeping of traditional media (Mutsvairo 2016b, 3; Tettey 2017, 688; Musa 2019, 84-85; Bosch, Admire, and M. Ncube 2020, 360-61). Particularly with a highly state-controlled and elite-oriented media landscape, the less privileged are often underrepresented in the media - something expected to drastically change with the wide availability of smartphones (see for example Chuma 2016). With a smartphone and internet access, as Mutsvairo put it, "any computer or mobile phone owner is potentially a news publisher" (Mutsvairo 2016c, 1). In this way, to give an example, evidence of misconduct captured as photos or videos with a smartphone can be published relatively inexpensively without having to pass the threshold of intermediaries (see for example Tettey 2017, 688). From a consumptions point of view, this can potentially lead to a greater variety of information

\footnotetext{
${ }^{53}$ Keja and Knodel (2019), for example, argue against the assumption that potential access to information alone will lead to drastic changes. Rather, aspects such as trust and mistrust, as well as social hierarchies need to be taken into consideration.
} 
available online, which has been linked to greater motivation to participate in public decisionmaking processes (Salgado 2016, 187-88; Aker, Collier, and Vicente 2017). In the long run, a greater variety of information and ways for citizens to participate can be expected to foster democracy (see for example Aker, Collier, and Vicente 2017, 2-3).

The general idea is thus that because the technology is widely available, not only to the privileged, other power inequalities such as control over the media can be outbalanced. In this way, "the dynamics of the situation have been changed," as Ling and Horst $(2011,369)$ claim. In the context of activism, it thus seems that smartphones and access to the internet through them make engaging oneself for a cause much more accessible to the marginalized. Once somebody owns a smartphone, so is the claim, this person can receive information from various sources online and express an opinion on social media for everyone to see (Schradie 2011, 147). Through the claim that an increasing individualization triggered by the internet renders group structures more and more redundant (see for example Castells et al. 2009, 250-51; Mwaura $2017,153)$, the image of a standalone activist is created, who, armed with a smartphone, can spark a revolution independent of other institutions. Owning a smartphone would thus translate into being integrated in a network society where outside inequalities hardly matter and where everybody who wants to be an activist can choose to in fact be one.

In the course of this thesis, I will name the idea of ICTs and the internet as a means to reduce inequality and facilitate activism for everybody the 'technology of freedom' discourse. I have chosen this term used by Sey and Castells $(2004,363),{ }^{54}$ because it accurately represents these very enthusiastic expectations towards the introduction and long-term effects towards ICTs, which are equally present in public opinion, international development initiatives, and scientific research.

\subsubsection{The Digital Divide}

In the course of this thesis, the 'technology of freedom' discourse will be confronted with a research tradition which has focussed on aspects of inequality in the use of the internet ever since the beginning of its commercial use, namely digital divide research. The term 'digital divide' thereby describes the phenomenon that access to and use of the internet are not equally available to everyone, but that pre-existing inequalities, such as age, gender, socioeconomic

\footnotetext{
${ }^{54}$ Sey and Castells used the term in the context of utopian expectations of the internet in the political context. Also note how the United States Agency for International Development launched a project called the "Digital Freedom Initiative" in Senegal in 2003 (Alzouma 2005, 349), and how Greijdanus et al. (2020, 51) used the term 'liberation technology'.
} 
status and geographical location correlate with access and use (Mutsvairo and Ragnedda 2019a, 14).

Digital divide research began in the mid-1990s, when the expectations towards the potential of the internet, among others as a tool that would help reshape access to activism and make it more democratic, were remarkably high (Schradie 2019, ix; van Dijk 2020, 8). From this time on, researchers have observed that the internet, and technology with which to access it, were adopted at different rates correlating with certain factors (van Dijk 2020, 8).

Thereby, privileged groups were observed to adopt internet technologies faster - Factors such as high levels of education, high income, young age, and belonging to the majority ethnicity in a country correlated with a higher adoption rate (van Dijk 2005). In this first research phase, from the mid-90s to approximately 2004, the digital divide was defined in a dichotomic "have" or "have-not" and was considered a technological problem more than a social one (van Dijk 2020, 8-9). ${ }^{55}$ Once the necessary infrastructure was globally available, and once the technology was affordable enough for everyone to purchase it, so the theory, the digital divide would be overcome (van Dijk 2020, 9).

This dichotomic conceptualization was rejected in what has come to be known as the second phase of digital divide research, which started around $2003^{56}$ and in the context of which research is still ongoing (van Dijk 2020, 9 ff.). Here, the focus shifted from physical access to the internet towards the way technology is used, as physical access does not necessarily equate to using it in a way that could be considered 'inclusion' to a network society (Ragnedda and Mutsvairo 2017, 6; Sam 2019, 216; van Dijk 2020, 9). Rather, aspects such as motivation and skills had an influence on what certain people would use the internet for, which research again found to correlate with pre-existing inequalities (Ragnedda 2017, 82; Mutsvairo and Ragnedda 2019a). In this research phase, the dichotomous conceptualization of the digital divide was substituted for a more comprehensive one, and the problem was more understood as societal rather than technological (Ragnedda 2019, 32; van Dijk 2020, 10).

\footnotetext{
${ }^{55}$ Note the similarities between this dichotomic approach to the digital divide and Castells' conceptualization of the network society presented above, which also worked on a binary logic of 'inclusion' and 'exclusion'.

${ }^{56}$ Seminal works that have contributed to this paradigm shift include Mossberger, Tolbert, and Stansbury's (2003) "Virtual inequality. Beyond the digital divide", Warschauer's (2003) "Technology and social inclusion. Rethinking the digital divide" and Selwyn's (2004) "Reconsidering Political and Popular Understandings of the Digital Divide“.
} 
From about 2015 onwards, a new focus has been introduced in digital divide research, namely on the outcomes of internet use (van Dijk 2020, 12). ${ }^{57}$ With this paradigm shift came a dilemma concerning the question of how the digital divide could eventually be closed and whether it could be closed or not. While the digital divide concerning physical access was considered to be closed once everybody owned an internet-ready device, and the digital divide concerning different skills and motivation was considered closable through training opportunities, taking into account that internet use also produces certain outcomes brought another variable into the equation (Ragnedda 2017, 20 ff.). Because the internet can provide positive outcomes, such as job opportunities for example, to users who have overcome the digital divide, the gap between those who have overcome it, and those who have not, is in fact growing (Ragnedda and G. W. Muschert 2018a).

While in the past the idea was that inequalities were reflected in the digital divide but could potentially be lessened through corresponding measures as described above, the idea that outcomes could add up to the inequalities led to the conclusion that the internet in fact reinforced them (Ragnedda 2017, 21; Mutsvairo and Ragnedda 2019a, 14). ${ }^{58}$

Based on these three phases of digital divide research, a three-level model of the digital divide has been established (see for example Ragnedda 2019), along which this work will be structured. This three-level model differentiates between physical access to the internet (first level), different uses of the internet and factors that account for this difference (second level), and outcomes for individuals and society based on internet use (third level).

The assertion that because of a digital divide inequalities would be reinforced rather than flattened is a direct contradiction of what I have named the 'technology of freedom' discourse. Particularly concerning the field of activism, it would mean that access to the internet does not facilitate becoming an activist, but rather increase the gap between those who can be activists and those who cannot. The 'technology of freedom' would thus turn out to be the 'technology of inequality.'

\footnotetext{
${ }^{57}$ A seminal work that introduced most of the aspects currently associated with this phase was Ragnedda's (2017) "The Third Digital Divide." Studies that have focussed on outcomes, albeit solely positive outcomes, have been conducted before (see for example Wei et al. 2011; van Deursen, van Dijk, and Klooster 2015).

${ }^{58}$ While it is theoretically possible for less privileged people to increase their position in the social hierarchy through taking advantage of the positive outcomes of smartphone and internet use, it is more likely that more privileged will use it to maintain or improve their position (Ragnedda 2019, 36).
} 


\subsubsection{Bourdieu's Forms of Capital}

The concept of the digital divide has so far mostly been used to describe the observable phenomenon that inequalities in accessing and using the internet exist (van Dijk 2020, 21). While individual publications have made use of a theoretical underpinning to explain their research results, ${ }^{59}$ only recently have there been attempts to provide a systematic theoretical basis for the concept as such (see for example Ragnedda and G. W. Muschert 2018b).

My choice thereby fell on Bourdieu's approach to inequality because of its relationality and compatibility with both offline and online phenomena (Ignatow and Robinson 2017; Rudolph 2019, 73 ff.). Because it is Bourdieu's concept of capitals that will feature most prominently in the course of this thesis, the different forms of capitals will be described in detail in the next few paragraphs. As the concepts of capitals can, however, only be understood in the framework of two other well-known concepts of Bourdieu, namely the concepts 'field' and 'habitus,' these two concepts shall be defined below.

Bourdieu (1983) conceptualized capital in three basic forms: cultural capital, social capital, and economic capital. People acquire capitals of these forms either by accumulating them over a period of time, or by having them transferred to them (Bourdieu 1983, 197). An important aspect is also that forms of capital can be transformed from one into another (Bourdieu 1983, 197).

Bourdieu defines cultural capital in three forms: embodied, objectified and institutionalised (Bourdieu 1983, 185). Embodied cultural capital describes that over time, a person incorporates certain aspects of education in their way of behaving and interacting with their surroundings (Bourdieu 1983, 186). This form of capital is non-transformable as it is an intrinsic part of each person's individual self and is tied to the environment in which it was acquired - Bourdieu gives the example of a particular way of speaking in the case of embodied cultural capital that was acquired in a particular region (Bourdieu 1983, 187). Whether profit, such as economic profit, can be drawn from this type of capital depends on the person's surroundings - if there is, for example, only one literate person in a certain social setting, the embodied capital of reading and writing can bring certain profits (Bourdieu 1983, 187-88). The accumulation of embodied cultural capital often starts in childhood in the family setting - people from higher social classes, where family members tend to have higher cultural capital themselves, often accumulate more prestigious embodied cultural capital (Bourdieu 1983, 188).

\footnotetext{
${ }^{59}$ Bourdieu's concepts have, for example, been used by Hargittai and Hinnant (2008) and Zillien and Marr (2013).
} 
Institutionalised cultural capital describes educational achievements in the form of academic titles or diplomas (Bourdieu 1983, 190). While skills, which can be regarded as embodied cultural capital, can theoretically be acquired autodidactically, institutionalised capital differentiates between those who underwent institutional education and those who did not. Institutionalised capital is easier to convert into other forms of capital than embodied cultural capital (Bourdieu 1983, 190). Objectified cultural capital is cultural capital that is manifested in objects, such as prestigious paintings (Bourdieu 1983, 188).

The concept of social capital describes the network of institutionalized relationships a person has (Bourdieu 1983, 190). This type of capital is defined both through the number of relationships one entertains, and the power that these relationships have (Bourdieu 1983, 191). Social capital can either develop over the course of one's life, or stem from existing networks into which one was born (Bourdieu 1983, 192). Relationships, once established, need to be reconfirmed over time (Bourdieu 1983, 193).

Economic capital describes monetary resources and assets that a person possesses (Bourdieu 1983, 183). Bourdieu argues that monetary capital presides over the other two forms, because it can easily be turned into social and cultural capital over time (Bourdieu 1983, 196).

In this work, another form of capital described by Bourdieu will play an important role, namely symbolic capital. Symbolic capital is a secondary capital, which builds on and overarches the previously mentioned primary forms of capital (Ihlen 2018, 2-3). The term is connected with the concept of "reputation" or "prestige" and is largely subjective (Ihlen 2018, 3). Through this subjectiveness, it often acts as a justification for the relative amount of capital one has accumulated (Ihlen 2018, 3).

As previously mentioned, Bourdieu's concepts of the different forms of capital cannot be understood outside of his larger framework, and particularly in the context of the concepts 'field' and 'habitus.' According to Bourdieu, people are distributed in a social field in relation to each other concerning the different forms of capital they possess (Bourdieu and Wacquant 1994, 96). What matters is firstly, the amount of capital each person possesses in each of the different forms, and secondly, the ratio of the forms of capital relative to one another (Ihlen 2018, 2; Paccoud, Nazroo, and Leist 2020, 512). Bourdieu names the analogy of a game in this context (Bourdieu and Wacquant 1994, 98-99). Actors in a field are in a relation to each other, whereby the amount of capitals of each of the players is the relative power they can assert in 
the game (Bourdieu and Wacquant 1994, 98-99). Players play to increase or conserve their capital within the rules of the game (Bourdieu and Wacquant 1994, 98-99).

The position one has in a certain field is then connected with what Bourdieu called a 'habitus,' a mental and corporeal unifying principle which translates the position somebody occupies in a certain field into a certain lifestyle (Bourdieu 1998, 8). The general argument is that the more two people resemble each other concerning the forms of capital they possess, the more they have in common also in other areas, including tastes and the valuation of certain practices (Bourdieu 1998, 6 ff.). People with similar amounts and ratios of capital in a similar field thus share a system of classification and valuation (Bourdieu 1998, 8).

Throughout this thesis, I will use these concepts by Bourdieu to analyse inequalities in connection with the digital divide I could observe among the activists I worked with in Senegal. Simplistically stated, the game analogy of the field can be used to describe how the activists, equipped with different forms of capital which determine their position in the field, make moves in the game. These moves are the way the activists use their smartphone, and their new position are the outcomes they experience from their smartphone use. The habitus would then be the way the activists decide to move and act in relation to other players on the field, as well as in their strive to increase their positions. In order to be able to conceptualize my observations more in-depth and more specific to the context of the digital, particularly in the context of embodied social capital which, as will be shown, is highly relevant to the activists' positions, I will complement Bourdieu's framework with the concept of 'digital skills' established by Jan van Dijk (2020).

Van Dijk (2020, 66-67) identified two main categories of digital skills, namely 'mediumrelated skills' and 'content-related skills.' 'Medium-related skills' are thereby the more basic skills regarding the use of the device, such as switching the phone on and off, or being able to open a browser and type a word into a search engine (van Dijk 2020, 66-67). 'Content-related skills' presuppose the mastery of medium-related skills and can be divided into four major types (van Dijk 2020, 66). 'Information skills' include, among other things, the skill to identify reliable information from misinformation. 'Communication skills' describe the skills to successfully contact people online, or to create and maintain an appealing profile on social media platforms. 'Content-creating skills' describe the ability to produce high-quality text, videos or photos to be published on the internet. Finally, 'strategic skills' are needed to use the internet in a way that is beneficial to one's own situation (van Dijk 2020, 67). 


\subsubsection{Bourdieu and the Digital}

In recent years, several of Pierre Bourdieu's concepts have been adjusted to be applied specifically to an online context. For example, Robinson (2009) introduced the concept of the 'information habitus' to describe inequalities in the use of technology among American youth. Hußenöder (2014) referred to, among others, Bourdieu's conceptualization of capitals when analysing Facebook as a 'social capital site.' Nissenbaum and Shifman (2017) introduced the term of 'digital cultural capital' when describing the use of memes on the platform 4chan.

A quite recent adaptation of Bourdieu's concepts to the internet, and in particular to digital inequalities, is the concept of 'digital capital,' elaborated by Ragnedda (2018) ${ }^{60}$ Ragnedda (2018) introduced the concept of 'digital capital" ${ }^{61}$ as a "bridge capital between the offline and online life chances" (Ragnedda 2018, 2367). In this way, Ragnedda proposed to analyse 'offline capitals' and their relation to the digital sphere, in which it is digital capital that is accumulated and which can translate back to offline capitals (Ragnedda 2018,2368). Digital capital thereby entails both physical resources, such as access to an ICT, and accumulated knowledge in connection with the digital domain, such as skills in connection with ICT use (Ragnedda 2018, 2368). Relating Ragnedda's concept of 'digital capital' back to the three-level model of the digital divide, the digital capital of a person would thus quantify the extent to which the first and second level of the digital divide were overcome. With 'digital capital' as an analytical tool, Ragnedda, Ruiu and Addeo (2020) then suggest to measure outcomes of internet use by correlating certain outcomes with the amount of 'digital capital' at an individual's disposal.

I chose not to use the concept of 'digital capital,' or any of the other adaptations of Bourdieu's concepts for the digital sphere. This is firstly because I, contrary to the authors presented above, do not think that offline and online spheres are separable to an extent that new concepts would be needed to describe mechanisms of social phenomena in the digital sphere. While there are differences in the mechanisms of online and offline spheres, I argue that these differences are not drastic enough to require new conceptualizations.

Choosing Bourdieu's forms of capital on phenomena of both the online and offline spheres, without conceptualizing them differently, gives me the opportunity to focus on digital forms of activism as social and cultural practices materialized in the physical world. While smartphones

\footnotetext{
${ }^{60}$ The concept was already elaborated in Ragnedda and Ruiu's (2018) "Social capital and the three levels of digital divide," an earlier publication from the same year. However, I chose to primarily use Ragnedda's (2018) "Conceptualizing digital capital" as a source for the description of the concept, because it is presented in more detail.

${ }^{61}$ Ragnedda (2018) based this concept on a number conceptualizations of capitals, but particularly on Bourdieu's.
} 
and different internet platforms do offer new ways to practice activism, I argue that digital activism and 'offline activism' cannot be seen as two divisible entities. Based on my observations, I argue that online activist practices are embedded in "offline" structures and can only be meaningful when materialized in the physical world.

\subsection{State of the Art: Internet, Activism and Inequalities in the African Context ${ }^{62}$}

The concept of the digital divide has so far mostly been used for research in the Global North (Ragnedda 2019, 29), or to describe the global disparities concerning internet access, use and outcomes between countries from the Global North and the Global South (Uimonen 2015, 603). There are a handful of works which have made use of the concept in an African context, including "The Digital Gender Divide" by Alozie and Akpan-Obong (2017), in which the authors show the correlations between gender and access to the internet in six sub-Saharan African countries, ${ }^{63}$ and the volume "Mapping Digital Divide in Africa" by Mutsvairo and Ragnedda (2019b), which offers both theoretical contributions to adapt the concept in an African context, as well as contributions on the digital divide in contexts such football fandom, film, the media, and among specific groups such as students or illiterate persons.

Africanist cultural anthropology has introduced a concept of significant importance to research in the field of the digital divide called 'partial access.' Uimonen (2012) coined the term to describe the internet access of Tanzanian art students. Uimonen argued that although the students had access to the internet and to specific art-related technology at university facilities, numerous students were obliged to share a small number of devices. This resulted in highly limited possibilities for individual students to make good use of the technology available and consequently rendered their overall access to said technology only partial (Uimonen 2012, 9). With this concept, Uimonen offered a more comprehensive conceptualization of physical access, going beyond the dichotomy of "have" or "have-not" which was usual in the context of the first level of the digital divide.

Oyedemi (2019) further used the concept to describe the internet use of students in South Africa, taking their use of smartphones into consideration. His definition of the term included a "partial" possession of skills to use the internet, which he traced back to the partial access the

\footnotetext{
${ }^{62}$ Because there is a large number of literature on the topic or related topics of this thesis, only a selection of a few relevant titles can be presented in this section.

${ }^{63}$ The countries from which data was analysed in this work are Ghana, Kenya, Nigeria, Senegal, South Africa and Uganda (Alozie and Akpan-Obong 2017, 144).
} 
youth had (Oyedemi 2019, 95). Oyedemi thus expanded the concept to include aspects of the second level of the digital divide.

In his study on the appropriation of mobile phones in Kenya, Waltinger (2019) observed inequalities in access to and use of smartphones in addition to other mobile phones. While inequalities were not the focus of his work, he mentioned them and also referred to the concept of the digital divide when doing so. While Waltinger used the dichotomic conceptualization when saying that he could not observe a digital divide of the first level among his interlocutors (Waltinger 2019, 350), he mentioned that he could observe inequalities concerning which model of phone somebody owned and concerning the internet access the person could afford (Waltinger 2019, 240; 323).

Waltinger could also observe a second-level digital divide among his interlocutors, correlating with age, level of education, and access to help networks (Waltinger 2019, 323). He thereby found that both a difference in skills (Waltinger 2019, 301-6), as well as a difference in how the technology was used correlated with these factors (Waltinger 2019, 309-14). Waltinger equally collected data on the outcomes of mobile phone use, but without linking these outcomes to the digital divide (Waltinger 2019, $286 \mathrm{ff}$.). He categorized these outcomes into neutrally ${ }^{64}$, positively $^{65}$ and negatively ${ }^{66}$ valuated outcomes (Waltinger 2019, 286 ff.).

Another author who has mentioned outcomes of internet use in his work is Fantaw (2013), who worked on the appropriation of smartphones in Ethiopia. Similar to Waltinger's work, inequalities were not his focus and the concept of the digital divide in itself was not mentioned at all in this case, but he thematized inequalities in outcome in the context of his research on married couples (Fantaw 2013, 91 ff). He noticed that mobile phones were often used in controlling one's spouse, whereby Fantaw argued that this would lead to an infringement in freedom in the long run, and more so for women than for men (Fantaw 2013, 105).

When it comes to activism, the use of the internet and mobile technologies in the African context has been widely discussed, but to my knowledge not with a focus on access inequalities. Because a large proportion of the literature focusses on positive aspects of technology for activism, a number of titles have been discussed in the section on the 'technology of freedom'

\footnotetext{
${ }^{64}$ Neutrally valued outcomes included immediacy and omnipresence, mobility and localisation, and the bridging of physical distance (Waltinger 2019, 287-90).

65 Positively valued outcomes include the simplification and acceleration of communication, cost minimization and efficiency enhancement, and the intensification of social relationships (Waltinger 2019, 290-92).

${ }^{66}$ Negatively valued outcomes include the disruption of social relationships, the support of criminal activities, the normative-moral undesirability, as well as health risks (Waltinger 2019, 292-96).
} 
discourse. The works discussed here will thus focus more on negative aspects with regard to activism and the internet.

An important work in this context is the volume "Digital activism in the social media age," edited by Mutsvairo (2016a). Most of the contributions in this volume discussed only positive aspects of the use of the internet for activism, while some negative aspects were mentioned (Wasserman 2016, vii). For example, Currier and Moreau (2016) discussed how LGBTI activist organizations experienced hate speech and mass mobilization against LGBTI rights on social media (Currier and Moreau 2016, 234 ff.). Currier and Moreau do not, however, include access inequalities in their analysis. Other works that deal with negative outcomes of digital activism, but not concerning access inequality, include for example "Du Désert Technologique au Paradis Digital" by Alzouma (2019), whose main claim is that the global marginalization of Africa directly translates into the online space and reinforces, among others, ethnic tensions in Africa. ${ }^{67}$

As shown in the previous paragraphs, the internet and mobile technologies have featured prominently in scientific literature about African countries. While the literature on this topic in connection to activism has so far received a lot of attention, which I can only suspect to be a symptom of the popularity of the 'technology of freedom' discourse, literature which focusses primarily on inequalities in connection to ICTs and the internet in an African context are relatively scarce. As I have shown, inequalities do feature in a number of texts, but tend be mentioned more as side notes than as the focal point of analysis.

When it comes to connecting these research fields, that is to say combining the aspects of activism, mobile technologies and the internet, as well as inequality in accessing and using these technologies in an African context, I failed to find any works that systematically approached all of these aspects together. To my knowledge, my work will thus be the first in this field. Some literature has, however, mentioned aspects of the problematic. For example, when describing the online practices of two Chadian activists in her text "Citizen Journalism at Crossroads," De Bruijn (2016) mentioned that they both had passed through higher education and had gained physical access to the necessary technologies, a barrier which many others could not overcome in Chad (Bruijn 2016, 101). In his paper "Mobile Telephony and Democracy in Ghana," Tettey

\footnotetext{
${ }^{67}$ Note how Alzouma's (2019) findings contradict the discourse which makes Africa more free once 'included' in the network society.
} 
(2017) stated that it is mostly the urban elite who tend to be active in online conversations concerning political or societal issues (Tettey 2017, 690).

The only research I have found which combines all the aspects mentioned, with the exception of not focussing on an African context, was Schradie's (2019) "The Revolution That Wasn't." Schradie conducted her research among activists in the U.S. state of North Carolina, and found that pre-existing inequalities heavily influenced the online practices of activists and their respective groups - a phenomenon she called the "digital activism gap" (Schradie 2019). Her findings suggested that there was indeed a digital divide among activists, which instead of removing barriers towards activism, reproduced and intensified existing power inequalities (Schradie 2019, 7). Her quite devastating verdict was that if this digital activism gap could not be closed, "[t]hat would not just snuff out the dream that technology can be a force for progress; it would extinguish the possibility of a truly democratic society" (Schradie 2019, 279). 


\section{The Stuff (Digital) Activism is Made of - The Materiality of Smartphones and their Role in the Everyday Lives of Senegalese Activists}

\subsection{Chapter Introduction}

This chapter will discuss smartphones as material objects embedded in the everyday lives of Senegalese activists. Aspects that will be considered include the purchase and upkeep of these objects, everyday practices in which they were entwined, in particular concerning their relation to time and space, and the values and norms that were associated with them. All of these aspects will be discussed against the backdrop of the first level of the digital divide, which deals with physical access to the internet through internet-ready devices, in this case the activists' smartphones.

Echoing Castells' (2017a) previously discussed model of inclusion and exclusion to the network society, physical access is often described as a dichotomous phenomenon - either somebody has physical access to the internet, or not. However, this conceptualization falls short of lived realities, because people can also have access only in certain circumstances making them 'partially included,' for example when they access public computers in an internet café or a university library (see for example Uimonen 2012; Oyedemi 2019, 95).

In recent years, the popularity of smartphones has led to a loss in popularity of internet cafés in West Africa - institutions that offered 'partial' access to the internet for many - and many such cafés have closed as a result (Alzouma 2019, 251). Because smartphones are highly personalized and private objects (see for example Archambault 2017), asking friends to access their devices was also very uncommon among the activists I worked with. ${ }^{68}$ For many people in West Africa, having reliable physical access to the internet thus equated to buying and maintaining a smartphone (Alzouma 2019, 248).

The process of gaining physical access to the internet does not, however, end once the smartphone has been purchased. Rather, overcoming the first level of the digital divide must be seen as an ongoing process, as internet access needs to be paid regularly in order to maintain access to the internet. This aspect is of particular relevance when talking about the digital divide in the African context given that mobile data can cost multiple times as much as it does in the

\footnotetext{
${ }^{68}$ Oumar mentioned that he would rather ask a friend to look something up online for him, than ask the person whether he could borrow the device to do it himself (Interview, 21/07/2019, Dakar-Cité Universitaire). Hahn and Kibora $(2008,99)$ argued that in Burkina Faso, the aspect of sharing mobile phones was more common in rural areas than in the city, where they found that devices were only shared with close friends.
} 
Global North while incomes tend to be a mere fraction of those in the Global North (Musa 2019, 75; Mutsvairo and Ragnedda 2019a, 15).

Despite the economic hardships some of my interlocutors reported, gaining and maintaining access to the internet through their smartphones was considered a priority. This was, among other factors, because of an emotional bond the activists described having with their smartphone and its use, which also contributed to the object being kept close to the body at all times. ${ }^{69}$

Smartphones and their use are thereby not neutral, but ascribed with sometimes ambivalent valuations. I thereby argue that valuations ascribed to the objects influenced the way the activists I worked with handled their smartphones, and vice versa. ${ }^{70}$ Notions such as 'good' and 'bad' use, as well as the discussion on where the device is positioned within the global power structure influenced the relationship between the activists and their smartphones, as well as the practices in which this relationship materialized. Analysing the way smartphones were appropriated by the activists I worked with is thus essential to understand activist practices performed through smartphones as such, because they ultimately result from this relationship. ${ }^{71}$

The present chapter will discuss these aspects in three main sections, followed by a chapter conclusion. The section "Gaining and maintaining physical access to a smartphone and the internet" will discuss the consumer choices the activists made in the context of overcoming the first level of the digital divide, as well as the strategies employed to maintain internet access. The section "Aspects of time and space in smartphone use" will focus on the spatio-temporal contexts of smartphone use, as well as the emotional bond between activists and their smartphones which causes the activists to keep their devices close to their bodies at all times. The section "Valuations ascribed to smartphones and their use" deals with the different valuations smartphones are ascribed with, as well as how these ascriptions influence the relationship between the activists and their smartphones. The chapter conclusion will then summarize the main points of this chapter while answering the question whether a life without a smartphone was still imaginable for the activists I worked with.

\footnotetext{
${ }^{69}$ The observation that smartphones are always kept close to the body were made by other researchers, for example by Waltinger $(2019,287)$ during his research on Kenya.

${ }^{70}$ Other literature has analysed this aspect before. Brouwer $(2019,269)$, for example, found that Kenyan farmers incorporated the international and local discourses about technology and themselves into their use of technology.

${ }^{71}$ For a more in-depth analysis of the term "appropriation" and all the aspects it entails, see Hahn (2011).
} 


\subsection{Gaining and Maintaining Physical Access to a Smartphone and the Internet}

To begin this section, I would like to return to the scene at the very start of this thesis' introduction. Oumar, ${ }^{72}$ a student engaged in an activist student movement, told me about his struggle of not owning a smartphone after his iPhone had been stolen months before. While he aired a number of grievances pertaining to his not owning a smartphone any more, one in particular stood out when it came to his activist engagement: he could no longer access the group's WhatsApp chat.

The WhatsApp group chat was used in a variety of ways in this student movement. During my first interview with the group, ${ }^{73}$ the members present enumerated, for example, the discussion on whether to take action concerning current events on campus, the allocation of tasks to different members of the movement, the organization of hip-hop concerts on campus, ${ }^{74}$ as well as the discussion of whom to invite to perform, the announcement of press conferences and the decision on what should be discussed with the press, as well as the occasional organization of group meetings. Because most of the group's daily activities were coordinated through the WhatsApp group, the group meetings took place only from time to time, and usually when it had previously been decided in the WhatsApp group to organize one.

In Oumar's ${ }^{75}$ case, not having a smartphone meant not taking part in many of the activist group's discussions and decision-making processes. This lack of physical access meant he was not informed about what happened in the group unless he personally met other activists to ask them, or used his button phone to contact them. Because it was such a given that everybody had a smartphone, though, Oumar ${ }^{76}$ reported finding it difficult to ask about things that other people took for granted he knew already.

Not owning a smartphone thus seriously hampered Oumar's access to the group's communication, and ultimately to activism as such. ${ }^{77}$ The reason he did not own a smartphone was, as he said, ${ }^{78}$ his difficult financial situation, which meant he could simply not afford one

\footnotetext{
${ }^{72}$ Interview, 21/07/2019, Dakar - Cité Universitaire.

${ }^{73}$ Interview, 04/07/2019, Dakar - Cité Universitaire. At this particular meeting, Abdoulaye, Cheikh, Lamine and Mamadou were present.

${ }^{74}$ As described above, hip hop has been considered an activist art form in different African countries before (see for example Karam 2018, 35).

${ }^{75}$ Interview, 21/07/2019, Dakar - Cité Universitaire.

${ }^{76}$ Interview, 21/07/2019, Dakar - Cité Universitaire.

${ }^{77}$ De Bruijn $(2016,101)$ described a similar phenomenon when she mentioned that 'political agency' changed for two Chadian activist in relation to their access to the internet through ICT.

${ }^{78}$ Interview, 21/07/2019, Dakar - Cité Universitaire.
} 
at that moment. What Oumar was lacking was thus economic capital, both in the form of a smartphone and in the form of money to be able to buy a new smartphone.

The theft, damage or wear and tear of a smartphone was something most of the activists I worked with had experienced. Also for Cheikh, ${ }^{79}$ the spokesperson of the activist student movement Oumar was engaged in, his worst-case scenario had taken place in October 2018, about nine months prior to my arrival in Senegal. His BlackBerry's screen had broken to the point that he could no longer use the device. He explained that he lost access to much important data, including contact details and messages, as a result. Similar to Oumar at the time of my research, Cheikh ${ }^{80}$ did not immediately have the means to buy a new smartphone, but acquiring the necessary financial means became a priority for him.

The activists I worked with mentioned different places where smartphones could be purchased, including show-rooms, ${ }^{81}$ smaller shops where electronics were sold, markets, or smaller street vendors. Cheikh, ${ }^{82}$ for example, told me that despite the cheapest option being to purchase a used smartphone from a street vendor, he had saved longer to buy a new one from a show-room. Cheikh told me that while he could have bought a model he liked for about $10,000^{83}$ FCFA from a street vendor who usually sold smartphones just off the campus, he preferred to buy a new one for $55,000^{84}$ FCFA from a show-room.

The reasons Cheikh ${ }^{85}$ opted to buy the smartphone in the show-room, despite of the higher price, was the official payment confirmation and the two-year guarantee on the device that would be included when buying it there. Purchasing the device second-hand would carry the risk that the device did not work at all. Also, the serial number of the devices stated on the official payment confirmation could prove ownership in case the device was stolen. Through this serial number, so Cheikh $^{86}$ said, the telecommunication providers could track the stolen phone and help retrieve it. ${ }^{87}$

\footnotetext{
${ }^{79}$ Informal conversation, 05/08/2019, Dakar - Fann.

${ }^{80}$ Informal conversation, 05/08/2019, Dakar - Fann.

${ }^{81}$ The term 'show-room' described a shop from either mobile providers or smartphone brands, which, as Cheikh told me, where climatized and always had the newest smartphone models on sale (Interview, 21/07/2019, Dakar Cité Universitaire).

${ }^{82}$ Interview, 21/07/2019, Dakar - Cité Universitaire.

${ }^{83}$ About 15.25 EUR (The exchange rate between EUR and FCFA is fixed at 1 EUR = 655.86 FCFA).

${ }^{84}$ About 83.85 EUR.

${ }^{85}$ Interview, 21/07/2019, Dakar - Cité Universitaire.

${ }^{86}$ Interview, 21/07/2019, Dakar - Cité Universitaire.

${ }^{87}$ Neither in Oumar's case, nor in Aziz' case which will be discussed below, did the payment confirmation help to retrieve the phone.
} 
While Cheikh ${ }^{88}$ managed to pay this sum within two weeks, others, like Oumar, took much longer to obtain the necessary economic capital. Despite the fact that having difficulties gaining physical access to a smartphone was commonplace, owning one was considered the norm and people were generally expected to be reachable through WhatsApp. ${ }^{89}$ Also, both Cheikh ${ }^{90}$ and Oumar ${ }^{91}$ mentioned that saving money to buy a new smartphone had become their main priority after they had lost physical access to one.

Cheikh $^{92}$ explained the urgency he felt to buy a new smartphone in two ways, the first being for emotional reasons. He said he had got used to having his smartphone around him and he reported, for example, having problems sleeping at night because not owning one made him feel nervous. His nervous feelings, he explained, were due to a certain feeling of guilt he felt towards the people who might try to reach him - after all, he had lost their contact information and could not inform them of the reason why he did not respond to their messages. Also, he missed reading the news or playing games on his smartphone in his free time.

Second, Cheikh ${ }^{93}$ repeated several times that as the spokesperson of the activist student movement, it was very important that he be reachable at all times because the position entailed great responsibilities. Because he could never know when a student or a member of the university authorities would contact him with essential information, or need essential information from him, he saw it as his responsibility to have his smartphone with him at all times. For example, he ${ }^{94}$ told me that one day shortly before faculty elections on campus he received the information that students from one student party had brought thrust weapons onto the campus and intended to use them in confrontations with members from another party. He thus called one of the university authorities responsible for security on campus, who was in Egypt for the African Cup of Nations at the time, and who arranged the rooms of the respective students to be searched. In this way, the thrusting weapons could be secured without any further damage. Also in Cheikh's case, not owning a smartphone would thus seriously hamper his capabilities to work towards his activist goals.

\footnotetext{
${ }^{88}$ Interview, 21/07/2019, Dakar - Cité Universitaire.

${ }^{89}$ This paradox of the high number of people who cannot afford to overcome the first level of the digital divide, and the self-evidence with which physical access to the internet is expected from everyone, has also been observed by other researchers (see for example Musa 2019, 79).

${ }^{90}$ Informal conversation, 05/08/2019, Dakar - Fann.

${ }^{91}$ Interview, 21/07/2019, Dakar - Cité Universitaire.

${ }^{92}$ Informal conversation, 05/08/2019, Dakar - Fann.

${ }^{93}$ Informal conversation, 05/08/2019, Dakar - Fann.

${ }^{94}$ Informal conversation, 05/08/2019, Dakar - Fann.
} 
Cheikh $^{95}$ was also a member in several WhatsApp groups of activist groups outside of the university context, notably one he joined during a large protest against the corruption scandal involving Aliou Sall, the president's brother, in late June 2019. ${ }^{96}$ Cheikh sometimes took information shared in this WhatsApp group and reposted it in the WhatsApp group of the student movement, for example when it came to announcements of new anti-corruption protests. Cheikh ${ }^{97}$ saw this as a logical extension to his engagement on campus - he saw himself as a young leader whose fight for people's rights ultimately had to face greater challenges than the ones on campus.

Because being a responsible leader also entailed being reachable at all times for Cheikh, ${ }^{98}$ owning a smartphone and having access to the internet at any given moment was part of the identity Cheikh constructed for himself. ${ }^{99}$ The way Cheikh handled his smartphone was a material manifestation of his self-image and the reputation he wanted to have. He saw it as his duty to have his smartphone around at all times, because it meant that he could be the "voix des étudiants"100 day and night. Maintaining this reputation, or this symbolic capital to use Bourdieu's terms, was important for Cheikh, and so was making sure he could maintain physical access to the internet.

So far, I have shown how owning a smartphone, which presupposed the necessary economic capital to buy one, was essential to fully participate in the activist student group among which I conducted my research, as well as to fulfill all responsibilities held as an activist. There is, however, another important precondition to taking part in activist WhatsApp groups apart from owning a smartphone, namely social capital in the form of members who can add a person to this chat ${ }^{101}$. As I have mentioned in the section "On political and apolitical activism," joining an activist WhatsApp group was how some of the activists had started to engage themselves, as

\footnotetext{
95 Informal conversation, 05/08/2019, Dakar - Fann.

${ }^{96}$ In early June 2019, the BBC had published evidence that Aliou Sall, the brother of Senegal's president Macky Sall, benefited from secret payments in connection to the licence for extracting oil off Senegal's coast (Prentice 2019).

${ }^{97}$ Informal conversation, 05/08/2019, Dakar - Fann.

${ }^{98}$ Informal conversation, 05/08/2019, Dakar - Fann.

99 Mutsvairo and Ragnedda $(2017,117)$ also mentioned the identity construction through production and consumption processes in the internet. 100 ,voice of the students”.

${ }^{101}$ During my research, I could only observe people being added to these online communities through prior (offline) contacts. However, as for example Seto (2017, 79ff.) has shown, contacts made online can also be an access point to join offline communities.
} 
was, for example the case with Ismaila. ${ }^{102}$ Also Cheikh ${ }^{103}$ could only join the WhatsApp group chats of the larger activist organizations after having met members at a large protest. ${ }^{104}$

As mentioned above, physical access to the internet cannot be considered achieved once a smartphone has been bought, but it needs to be seen as an ongoing process, because mobile data volume needs to be purchased on a regular basis in order to access the internet through it. In the case of the student group, paying for mobile internet subscriptions was less of an issue, because they could access wifi ${ }^{105}$ on campus. Although the rather meagre quality of this campus wifi made the access more 'partial,' to use Uimonen's (2012) term, sending text messages and calling through WhatsApp did not come at an additional cost to the students. Other activists who could not benefit from the campus wifi, however, had to make sure they would not run out of prepaid data volume in order to maintain physical access to the internet. ${ }^{106}$ Because maintaining physical access to the internet through prepaid data volume also strained some of the activists' budgets, some had intricate strategies in place to ensure they always had enough data volume to access the internet with as little expenditure as possible. ${ }^{107}$

One of these activists was Aziz, who was engaged in a political movement associated with the then-ruling party. For Aziz ${ }^{108}$, being connecté $e^{109}$ non-stop was equally important as to Cheikh, because first, he considered it would hamper his engagement in the movement if he were not connected at some point, and second, because he was sure that people would immediately notice if he were not online for some time. Aziz ${ }^{110}$ thus also saw running out of data volume as damage to his symbolic capital of being a reliable leader.

In the political movement, Aziz ${ }^{111}$ took responsibility for the movement's Facebook page and its WhatsApp groups ${ }^{112}$. The WhatsApp groups differed in their purposes and members - There was one WhatsApp group for the core members of the movement, several for people who were

\footnotetext{
${ }^{102}$ As mentioned above, Ismaila only joined the activist movement after Cheikh had added him to the WhatsApp group chat.

${ }^{103}$ Informal conversation, 09/07/2019, Dakar - Cité Universitaire.

${ }^{104}$ Also Ncube (2019) found that in the case of Zimbabwean football fans, social capital was crucial in gaining access to WhatsApp and Facebook groups in which certain football memes were shared.

105 (= Wireless fidelity LAN). The university provided a wireless internet connection the students could use instead of buying mobile data themselves.

${ }^{106}$ Wifi access points were very rare in Dakar, I in fact only know of the university campus, a European research institute, and some hotels that had wifi access.

${ }^{107}$ Waltinger $(2019,243)$ has also described similar strategies he observed during his fieldwork in Kenya.

${ }^{108}$ Interview, 12/07/2019, Dakar - Point E.

109 "connected", meaning connected to the internet.

${ }^{110}$ Interview, 12/07/2019, Dakar - Point E.

${ }^{111}$ Interview, 02/07/2019, Dakar - Point E.

${ }^{112}$ In West Africa, WhatsApp and Facebook are the two most popular social media platforms (see for example Alzouma 2019).
} 
active members but did not have decisive roles within the movement, and even more for people who wanted to stay informed about the movement's activities. In these groups, he would regularly share news in relation to the movement, for example when an event was being organized, or in relation to the locality, such as a message of condolences when a well-standing inhabitant of the locality had passed away.

In order to make sure Aziz ${ }^{113}$ had physical access to the internet to manage these WhatsApp groups and the Facebook page at all times, even on the tight budget that he was on, he used four different SIM cards from four different providers, two in his smartphone and two in his button phone. He chose which SIM card to put in which phone depending on the cost of airtime and prepaid data volume of each provider - he put the two which offered better deals on mobile communication into his button phone, which he would then use to call people and send SMS, and the two which offered better deals on data volume into his smartphone. Concerning calls and SMS, it also made a price difference whom he would want to contact - usually, calls between SIM cards of the same provider were cheaper than calling somebody of another provider. Which card would be used thus also depended on whom to contact. While it was possible to recharge a SIM card using coupons that were sold either in the shops of the mobile providers or by street vendors, Aziz ${ }^{114}$ said he usually paid for his using mobile payment services.

Concerning the data volume, which SIM card to use also depended on the deals the providers offered. Some providers would offer better deals on long-term data packages, in which, for example, $5 \mathrm{~GB}$ could be bought to be used within one month. By buying one of these deals, Aziz could ensure that he would be connecté at all times, as WhatsApp messages and messages on Facebook would reach him continually. However, if Aziz knew that he would need a large data volume within limited time, for example if he wanted to live stream a video on Facebook, it would be cheaper to buy a deal which allowed him to use unlimited data volume over a limited time frame of just 60 minutes, for example. Additionally, all providers regularly proposed promotions on certain offers and informed the users via SMS. According to Aziz ${ }^{115}$, it was worth it to always keep track of these promotions, and he sometimes also switched the SIM cards between his smartphone and his button phone if one happened to have an offer which

\footnotetext{
${ }^{113}$ Interview, 02/07/2019, Dakar - Point E.

${ }^{114}$ Interview, 02/07/2019, Dakar - Point E.

${ }^{115}$ Interview, 02/07/2019, Dakar - Point E.
} 
would be more beneficial in the other device. Aziz would thus choose the data deal which would be the cheapest for his current needs.

Despite Aziz' intricate strategies to maintain physical access to the internet, he had lost this access in May 2019, when his smartphone was stolen by a man on a motorcycle while walking along a street in Dakar. At this point, Aziz ${ }^{116}$ did not have the economic means to buy a new smartphone, particularly not one that was sufficient for his needs. ${ }^{117} \mathrm{He}$ had no other device with which to access the internet and particularly his activities in the different WhatsApp groups of the movement were rendered impossible by the theft.

Luckily, Aziz ${ }^{118}$ was able to buy a new smartphone about two weeks after the theft because the leader of the political movement Aziz was engaged in gave him 300 EUR to buy a new one. ${ }^{119}$ This leader had just come back from a trip in Europe and decided to give Aziz the money because, so was Aziz' interpretation, the movement would not be successful if it was not Aziz who coordinated the social media accounts and groups. Aziz particularly put this down to his high symbolic capital as a young local leader whom the inhabitants of his home locality knew they could trust, as well as the fact that he was always available and active in the WhatsApp groups and on the Facebook account. Aziz ${ }^{120}$ thus spent around $150.000^{121}$ FCFA on a new phone, and the remaining sum on prepaid data volume. Like Cheikh and Oumar, Aziz ${ }^{122}$ reported buying his smartphone in a show-room in order to receive the guarantee and the payment confirmation.

Aziz $^{123}$ told me that when buying the smartphone, he already knew that he wanted a model of the brand techno, because he had had good experiences with this brand concerning the camera quality and memory, which were the two most important aspects for him. When I met Aziz ${ }^{124}$ again, about three weeks after he had told me about purchasing this techno phone he seemed to prefer at that time, Aziz owned a different smartphone. When I asked him about it, he said that he had exchanged the smartphone he had bought in the show-room for another one of the same

\footnotetext{
${ }^{116}$ Interview, 12/07/2019, Dakar - Point E.

117 Aziz repeatedly said that he needed a smartphone with particular functionalities and of good quality for his activist practices. This aspect will be elaborated in the next chapter.

118 Interview, 12/07/2019, Dakar - Point E.

119 The case of Aziz, who got the money to buy a new smartphone from the leader of the political movement he was engaged in, is a good example to demonstrate the transformability from one form of capital to another - In this case, it was social capital that turned into economic capital for Aziz.

${ }^{120}$ Interview, 12/07/2019, Dakar - Point E.

121 About 228.67 EUR.

${ }^{122}$ Interview, 02/07/2019, Dakar - Point E.

${ }^{123}$ Interview, 12/07/2019, Dakar - Point E.

${ }^{124}$ Informal Conversation, 07/08/2019, Dakar - Fann, Cité Universitaire.
} 
brand with a better camera and even more memory for a small surcharge. He had made this deal with a student who was short of money and posted the offer online, and so Aziz decided to take it because owning a better smartphone would be beneficial to his activism.

The last time I met Aziz ${ }^{125}$ during my research stay, about three months after I first met him, Aziz was looking for another such deal - he had decided that the smartphone he was currently using did not offer a camera of sufficient quality. He said that he sometimes needed to take photos of a quality that would enable him to print the picture as a poster or a flyer, and his techno phone did not provide adequate enough photo quality. He was thus looking to exchange his techno smartphone for an iPhone because he was certain that an iPhone would have a camera with the quality he required.

While the need for specialized equipment for specific usage in the activist context will be discussed in the next chapter, I briefly want to mention that smartphones, particularly models of expensive brands, can be considered objectified cultural capital, because they represent the wealth of the activists. Owning an iPhone would thus also contribute to Aziz' symbolic capital. Contrary to Waltinger's (2019, 233 ff.) observations on mobile phone users in Nairobi, Kenya my interlocutors were not ashamed when their smartphone was not expensive. ${ }^{126}$ They were, however, particularly proud when it was an expensive brand, such as an iPhone.

\subsection{Aspects of Time and Space in Smartphone Use}

One of the main advantages named by the activists in connection to using smartphones in activism was that they enabled communication anywhere, free of spatial constraints. Already in the early 2000s, Geser (2004) noted the detachment of communication from spatial constraints as an "evolutionary" innovation of mobile communication devices. Smartphones have taken this point further - not only has communication become free of spatial constraints, but also all the other functionalities smartphones offer, such as taking photos, recording videos, writing notes, or using a mobile banking service for example, have become possible from anywhere, provided that physical access to the internet is present.

As has been shown in the previous section, being able to access the internet at all times was considered a necessity despite the difficulties the maintenance of this constant access entailed.

\footnotetext{
${ }^{125}$ Informal conversation, 26/09/2019, Dakar - Fann Hock.

${ }^{126}$ Waltinger $(2019,280)$ noted, for example, that people would not use cheap phones in front of their friends out of shame. I could not observe the same among the activists I worked with. Rather, it was normal to own a smartphone and a (cheap) button phone and to use the button phone for mobile communication, also in the presence of others.
} 
Given the great importance the activists I worked attributed to keeping their smartphones with them at all times and to having the necessary airtime and data volume to use it at any given moment, communication and the other functionalities of smartphones have not only become detached from spatial constraints, but also from temporal constraints. In this section, two main aspects of smartphone use connected to time and space will be discussed. First, their omnipresence and the urge people described to keep their smartphones close to their bodies at all times, and second, aspects of activist engagement across large distances.

In late July, about two weeks before the religious holiday Tabaski, Cheikh had invited me to join him and some of his fellow students, including Fatou, the spokeswoman of the female branch of the activist student group, ${ }^{127}$ to a village about a five-hour bus ride from Dakar. ${ }^{128}$ The trip was organized by a professor and several students of a modern languages institute of the university, with the purpose of distributing donations collected from the group throughout the year, including clothes, cooking oil and rice, among the villagers. ${ }^{129}$

On the bus ride home, I was sitting between Cheikh and Fatou, ${ }^{130}$ when at some point she mentioned that she felt sad because the phone's charging port had broken. While the smartphone did still have some battery left, it would most likely not hold up until the following evening, the earliest possible time she could go to the repair shop to have it fixed. Fatou had already published a WhatsApp status to inform her contacts that she would not be available until then during the bus ride in the morning, but still anxiously commented her battery's weening percentage during the bus ride. She mentioned feeling distressed at the thought of probably not being able to access the smartphone's functions until it would be fixed the next day.

\footnotetext{
${ }^{127}$ While the movement itself was open to both genders according to Cheikh (Interview, 04/07/2019, Dakar - Cité Universitaire), there was a need for a female branch because one part of the campus was reserved for dormitories for women. Because the students' rights in this particular part of the campus also needed to be taken into consideration, there was a group of female students who organized together with the rest of the group, but separately when it came to issues regarding this part of the campus and its residents.

${ }^{128}$ During our one-hour stay in the village, I noticed that both the students and the villagers were filming the speeches given by villagers, as well as the professor and students who had participated in the project, with their smartphones. While I could observe that all of the about twenty students had their smartphones in use in the village, I could only observe three villagers using their smartphones, from a group of around 70. All of the villagers who used their smartphones were men.

${ }^{129}$ The professor told me that this project had been done for several years and that he saw it both as a humanitarian project, with the goal of reducing poverty among villagers in Senegal through these donations, and as an educational project for the students to learn that foreign funding was not needed to work towards a more developed country. The project per se can thus also be considered an activist practice in my definition.

${ }^{130}$ Informal conversation, 27/07/2019, village close to Nguéniène.
} 
Because the topic of emotions towards smartphones had come up repeatedly in conversations with Cheikh, for example in the scene where Oumar was angry about the theft of his smartphone and described feeling desperate about not having one, Cheikh ${ }^{131}$ mentioned having thought about this aspect, coming to the conclusion that it was a negative sign that so many people were emotionally dependent on a material object. He pointed out that most of the students on the bus were using their smartphones instead of talking to each other, which Cheikh used as an example to critique that virtual contact through the internet seemed to be considered more important than 'real' relationships and conversations. ${ }^{132}$ Fatou, on the other hand, pointed out that by not being able to use her smartphone, she might miss out on contacting or being contacted by people she had a 'real' relationship with. This contact, so she claimed, actually enabled her to maintain 'real' relationships, for example with her family in the countryside, but was now threatened by her smartphone's sinking battery. It was thus not only the device itself which Fatou was afraid of not accessing, rather it was potentially missing contacts she might have through it.

The omnipresence of smartphones, and the negative emotional outcomes in case this omnipresence was interrupted, needs to be seen as a material indicator of the objects' importance in the activists' everyday lives. ${ }^{133}$ As the discussion between Fatou and Cheikh has shown, not having a functioning smartphone available was connected with negative feelings, particularly because of the missed opportunities to contact or be contacted through it. It thereby seems to be considered equally terrifying when the smartphone itself is not within reach, or when it is not functioning because it has run out of battery. ${ }^{134}$

As has previously been described in the prior section, being constantly available through the smartphone had also formed part of Cheikh's ${ }^{135}$ symbolic capital. Because he wanted to be recognized as a leader, it was important for him to show others that he was trustworthy and reliable, and that he could live up to the responsibilities he had taken upon himself - which, for

\footnotetext{
${ }^{131}$ Informal conversation, 27/07/2019, village close to Nguéniène.

${ }^{132}$ See for example Anyanwu $(2019,178)$ for a similar argumentation using more general examples.

133 The emotional bond to smartphones has previously been described as 'companionship' in other literature (Carolus et al. 2019). Carolus et al. argue that because of the variety of possibilities to interact with smartphones, the devices themselves have come to be seen as "social actors" (Carolus et al. 2019, 4). Fantaw (2013, 64-65) also documented his Ethiopian interlocutors comparing their mobile phones to their children in terms of emotional closeness.

134 The discussion between Fatou and Cheikh also disclosed an ambivalence concerning the valuation of having a (functioning) smartphone at close hand at all times. This aspect will be taken up in the next section.

${ }^{135}$ Informal conversation, 05/08/2019, Dakar - Fann.
} 
him, included having a smartphone with internet access accessible at all times in order to be reachable at any given moment. ${ }^{136}$

That smartphones are material objects which are available for use at all times could also be observed in the context of the activist practices performed through them. While documenting the activists' WhatsApp statuses and Facebook posts, I noticed that most of the activists did not seem to have specific times during the day when they posted content. When I asked Aziz ${ }^{137}$ about some of his recent publications, he said that he had posted a picture informing people that security guards were needed for an event in the morning at his home while eating breakfast. ${ }^{138}$ Before that, he had posted a picture of a dish typical for his home locality which he had eaten the weekend before, shortly after waking up while still lying in bed in the morning. ${ }^{139} \mathrm{He}$ had also posted pictures of an event organised in his home locality in connection with his engagement together with a text of about ten lines while he was hanging out with friends in Dakar. ${ }^{140}$ And still another one was a live-stream filmed from his home locality, where he voiced critique about the local infrastructure while filming how strong rain made an unpaved road essentially unusable. ${ }^{141}$

While all the activists I worked with reported using their phones to communicate over large distances, Aziz was probably the one who valued this feature most, given that the locality his activism was directed towards lay at about $500 \mathrm{~km}$ linear distance from Dakar, where he lived at the time of my research. ${ }^{142}$

As previously mentioned, some of Aziz ${ }^{143}$ friends had criticized him for joining the political movement and shirking his duties in the apolitical movement with similar activist goals he had founded years earlier, accusing him of doing it more out of his own self-interest than out of engagement for the cause. Moreover, people had criticized that he could not claim political

\footnotetext{
136 The entanglements between online and offline practices and identities have previously been described by Cover and Doak $(2015,549-50)$.

${ }^{137}$ Interview, 12/07/2019, Dakar - Point E.

${ }_{138}$ Published on Facebook on 12/07/2019 at 12:02, 11 likes, six comments (documented on 15/07/2019).

139 Published on Facebook on 11/07/2019 at 09:29, 58 reactions (57 likes, one laughing), 17 comments (documented on 15/07/2019).

140 Published on Facebook on 09/07/2019 at 19:37, 40 likes, 3 comments, 1 time shared (documented on 15/07/2019).

${ }^{141}$ Livestream on Facebook on 06/07/2019 at 09:31, 2 minutes 38 seconds, 392 views, 33 reactions (31 likes, 1 heart, $1 \mathrm{sad}$ ), 16 comments, 4 times shared (documented on 15/07/2019).

142 The phenomenon that emigrants who moved to the city have played a role in the development of their home localities in different West African countries has been observed for over two decades (see for example Lachenmann 1993), but I argue that through smartphone use the intensity of this local engagement over large distances has increased. This has particularly been observed for the involvement of diaspora in local and national matters (see for example Tettey 2017, 691; Alzouma 2019, 251-52).

${ }^{143}$ Interview, 12/07/2019, Dakar - Point E.
} 
involvement in his home locality if he lived in Dakar the vast majority of the time. In order to establish and maintain his reputation as a leader, Aziz ${ }^{144}$ employed strategies with the intention to prove the critical voices wrong and demonstrate that he was present and involved in the locality through his smartphone.

One of the strategies was regularly posting pictures from his home locality to his personal Facebook page and as WhatsApp statuses. It was thereby important that these pictures were taken recently and showed specific events in the locality, such as a flooding or a festivity. When he was in Dakar, which was the case for most of the time, he did not take these pictures himself, but rather posted pictures that friends from his home locality had sent him. He then usually commented on the pictures to add his personal note. Concerning the accounts of the political movement, members living in Aziz' home locality sent pictures and news for Aziz to post on the official accounts. Aziz sometimes also posted this information on his personal accounts, which for him was a demonstration and proof of his trustworthiness and level of involvement in local matters.

Aziz' engagement in his home village, where he wanted to be seen as a leader, was thus based on his smartphone use, as well as on the smartphone use of friends who lived in his home locality and provided Aziz with the content he could then publish. Aziz ${ }^{145}$ stated multiple times during my research that this high level of involvement in the political matters of his locality would not be possible if he and his friends did not have access to the internet through their smartphones. By detaching communication, as well as other features, from spatial constraints, smartphones enable local activism to be carried out by actors who are not physically present.

During my research, there was one functionality which seemed particularly in vogue, namely live-streaming events on Facebook. Aziz ${ }^{146}$ said that he live-streamed whenever he could, particularly when he was in his home locality, because it added "authenticity" to the publication. Live-streams could not be edited afterwards and they, in contrast to other posts, anchored the user to a very high degree in a specific time, the time of the live-stream, and a specific place, which was usually marked next to the live-stream and specified through scenes that could be seen in the live video. Live-streams can thus be seen as a counter-development towards the detachment of time and space from publication processes of content.

\footnotetext{
${ }^{144}$ Interview, 12/07/2019, Dakar - Point E.

145 Interview, 02/07/2019, Dakar - Point E; Interview, 12/07/2019, Dakar - Point E; Informal conversation, 07/08/2019, Dakar - Fann/ Dakar - Cité Universitaire.

${ }^{146}$ Interview, 12/07/2019, Dakar - Point E.
} 


\subsection{Valuations Ascribed to Smartphones and their Use}

Smartphones, just like other material objects, are ascribed with valuations in a process often referred to as appropriation (see for example Hahn 2011). These valuations are often ambivalent, as could also be shown in the conversation between Cheikh and Fatou on the bus ride back to Dakar which I have previously described. Their conversation, just as it was a demonstration of the emotional bond people have towards their smartphones, also revealed an ambivalent valuation of the constant closeness and use of these objects. In this section I argue that these valuations ascribed to the objects also influence the relationship between the activists and their smartphones, and ultimately physical access to and use of the devices.

While we were on the bus driving towards the village, I asked Cheikh ${ }^{147}$ what associations he had with the term tubaab. ${ }^{148}$ Cheikh answered that he mostly associated colonialism with it, and the continuing economic exploitation from countries of the Global North, particularly from France. He then proceeded to tell me how he was once insulted as tubaab while he was in his home village, in the North East of Senegal. As he was used to do in the city, Cheikh kept his smartphone with him at all times, checking it regularly for messages and answering if he had received one. He then described how, while writing a message on his smartphone, he heard one of the village youth call him tubaab $b^{149}$ in front of several other youth. Cheikh was very hurt by this remark and felt compelled to justify his smartphone not as a symbol for tubaabité, ${ }^{150}$ but as a tool for his activism in international black resistance and pan-Africanism.

This situation recounted by Cheikh, in which two contradictory interpretations of Cheikh's smartphone confronted each other, shows the ambivalent valuations of smartphones in different contexts. The village youth saw Cheikh's smartphone as a symbol of the Global North ${ }^{151}$ and associated Cheikh with the tubaabs because he regularly used it. Cheikh, however, who saw tubaabs as the beneficiaries of the unequal global power structure he was actively engaged against, had appropriated his smartphone in the context of his activism. For Cheikh, his smartphone thus represented this activist engagement against the privileges of tubaabs, not his

\footnotetext{
${ }^{147}$ Informal conversation, 27/07/2019, bus ride to village close to Nguéniène.

148 As described in the methodological outline, the term tubaab is used to refer to people of white skin colour in Senegal.

${ }^{149}$ While the term tubaab usually describes white people of European descent, black people can also be called tubaabs when they do certain things or look a certain way that is associated with white people, such as going to the mall, wearing Western clothes or having an expensive smartphone (see for example Barry 2017, 166).

${ }^{150}$ The term 'tubaabité' was coined by Barry (2017).

${ }^{151}$ Others have noted before that technology is generally associated with the Global North in African countries. Kusiak (2010) demonstrated the appropriation of technology associated with the Global North in the case of a radioscopic machine in Senegal. Karam (2019) demonstrated that smartphones and other ICTs were used as symbols to mark class differences in several African movies.
} 
affiliation with them. Cheikh ${ }^{152}$ told me that after this encounter, he decided to stop using his smartphone in public in the village. The valuation of smartphones as tubaab technology, which Cheikh refused to be associated with, led to him not having his smartphone with him at all times, which in turn restricted his physical access to the internet. ${ }^{153}$

Apart from the device as such being subject to valuations, so are the different ways a smartphone is used. Many of the activists I worked with thereby differentiated between 'good use' and 'bad use' of the smartphone. I could observe that the criteria the activists put in place to differentiate the two echoed global discourses of smartphones as tools of development, and equally of smartphones as 'technology of freedom.'

$\mathrm{Cheikh}^{154}$, for example, repeatedly said that the smartphone was a tool for development, both for oneself and for the whole continent. 'Good ways' of using the smartphone thus included purposed for education, for economic transactions, to stay in touch with family or friends, or to look for information when needed. ${ }^{155}$ Activism, if practiced along moral principles, was among the 'good' uses of the smartphone, because it brought new skills, insights and contacts for the activists, and would ultimately bring positive change concerning the respective activist goal, according to Cheikh. ${ }^{156}$ All of the above-mentioned arguments are thereby outcome-related, which is particularly relevant given that outcomes are one of the aspects linked to inequalities in digital divide research. The general assertion is thus that if positive outcomes could be achieved, particularly if these outcomes could increase one's own capitals and make a change concerning one's activist goals, the smartphone was used in a 'good way.'

However, these 'good ways' of using the smartphone were also ambivalent at a second glance. 'Good uses' needed to be accompanied with a 'good' and rational handling of the device, according to Cheikh, as well as Oumar and Ismaila. ${ }^{157}$ This was particularly true for determining when and for how long one would use a smartphone. Being scotché $e^{158}$ to one's

\footnotetext{
152 Informal conversation, 27/07/2019, bus ride to village close to Nguéniène.

${ }^{153}$ In order to avoid missing important calls or messages when not constantly checking his smartphone, Cheikh used the strategy to post a WhatsApp status before travelling to the village, stating that he would not be online for some time and giving the phone numbers of his button phone under which he could be reached for calls. He then switched off his smartphone when going to the village and only switched it on about once every day to check whether he had received important messages on WhatsApp despite the status post.

${ }^{154}$ Interview, 04/07/2019, Dakar - Cité Universitaire; interview, 09/07/2019, Dakar - Cité Universitaire; informal conversation, 05/08/2019, Dakar - Fann.

155 The idealization of certain activities as 'good' does not necessarily mean that people will use their smartphones in this way. Research on students in South Africa, for example, suggests that this group privileges entertainment over education purposes in case of limited data volume (Karam 2019, 156; Oyedemi 2019, 92).

${ }^{156}$ Informal conversation, 05/08/2019, Dakar - Fann.

${ }^{157}$ Interview, 21/07/2019, Dakar - Cité Universitaire.

158 ,glued“; this word was used as a critique of excessive use of the smartphone.
} 
smartphone was considered to hinder enhancing different forms of capital or pursuing responsibilities in 'real life,' such as meeting people or paying attention during lectures. ${ }^{159}$ Being scotché was valued particularly badly if the individuals were not using their smartphones to enhance their capitals, for example if they were 'just' watching videos or playing games. However, even Cheikh who viewed being scotché so badly, found it very important to have his smartphone at hand and to be reachable at all times, as previously mentioned. Because the students ${ }^{160}$ related the way they used their smartphone also with how they managed their lives in more general terms, using the smartphone in a 'good' way, and particularly refraining from using it in a 'bad' way, ${ }^{161}$ was particularly important for them. The students thus also described a moral dimension to using a smartphone.

This moral dimension to smartphone use highlighted by the activists, which acknowledges that people can use their smartphone in different ways, can be used as an argument against the 'technology of freedom' discourse. As has previously been elaborated, the 'technology of freedom' discourse sees the internet and ICTs as tools that flatten pre-existing inequalities and thus provide a stage that 'gives voice' to the marginalized, too. Because more people are 'given voice,' so the discourse suggests, more people will pursue activist goals through their smartphones, which will ultimately lead to a more democratic society. However, as the moral dimension to smartphone use highlighted by the students shows, it is just as much about the possibilities smartphones offer as it is about the individual choices made of how smartphones are ultimately used.

\subsection{Chapter Conclusion: A Life without a Smartphone?}

In this chapter, I have analysed aspects of the smartphone as a material object, including the way they were acquired and their upkeep, aspects of time and space in connection to the way they were handled and used, and the valuations the objects and their use were ascribed with.

From my analysis follows that a life without a smartphone was hardly imaginable for the activists I worked with. Smartphones were the activists' constant companions, to which they reported having an emotional connection. Also, many of the activists felt a responsibility to

\footnotetext{
${ }^{159}$ Being 'scotché' as Cheikh called it, was called 'excessive use' in van Dijk's $(2020,96 \mathrm{ff}$.) conceptualization of negative outcomes.

${ }^{160}$ Interview, 21/07/2019, Dakar - Cité Universitaire.

${ }^{161}$ Examples of what the students considered 'bad' use were, among others, insulting people or lying to them, as well as not fact-checking information one would pass along to others. These two aspects have been discussed widely in scientific literature, with some claiming that smartphones are used to revive ethnic tensions (see for example Tettey 2017, 687; Alzouma 2019, 260), or to systematically spread misinformation (see for example Mare, Mabweazara, and Moyo 2019).
} 
have this object close to their body at all times in order to be reachable via their smartphones at any moment. I have shown that ambivalent valuations of the object and its use sometimes caused the activists to adapt the ways they handled their smartphones. Using a smartphone in 'good' or 'bad' ways was thereby connected with a larger conceptualization of making moral decisions and constructing one's identity and reputation. Both Cheikh and Aziz, for example, considered being constantly available through the smartphone important for their reputation as trustworthy and responsible leaders.

Given that, for example in the activist student movement mentioned multiple times in this chapter, most discussions and information exchange happened within a WhatsApp group chat, not owning a smartphone ultimately meant not being able to fully participate in the activist group, as Oumar's experience has proven. Furthermore, the examples of Cheikh's and Aziz' responsibilities within their respective activist groups, and their experiences of not owning a smartphone, have shown that it was not possible to continue their activist practices unless they had constant, or at least partial, access to a smartphone and the internet.

Even though life without a smartphone seemed so unimaginable, it was a situation all of the previously mentioned activists had already faced. Many of them reported that their smartphone broke or was stolen, and also described the difficulties to find the money to purchase a new one. The first level of the digital divide was, however, not overcome once a smartphone had been bought. Rather, maintaining physical access to the internet must be seen as a continuing process which periodically demands economic capital to pay for mobile data. Because it was a lack of economic capital which made overcoming the first level of the digital divide so challenging for the activists I worked with, and because of the necessity smartphones constitute in the context of activism, it can be said that activism in Senegal has a monetary entrance fee - the costs of a smartphone and prepaid mobile data.

As has previously been mentioned, the activists I worked with were all highly educated and did, eventually, all overcome the first level of the digital divide. Because many in Senegal cannot claim similar success, it has to be kept in mind that the difficulties the activists I worked with have overcome remained insurmountable barriers for many others. ${ }^{162}$

162 As described in more detail in the section "Overview of the local context - Senegal", only 48 percent of the Senegalese population owned at least one smartphone in 2019, while 28 percent were mobile internet subscribers (GSM Association 2020). 


\section{Practicing Activism through Smartphones - Communication, and the Production and Publication of Content}

\subsection{Chapter Introduction}

The focus of this chapter will lie on the ways smartphones were used by the activists I worked with in the context of their activist engagement. It needs to be kept in mind that the activists used their smartphones in a variety of domains, of which activism was but one. For example, smartphones were used to stay in touch with family members across large distances, as well as for educational, entertainment, or financial purposes. Out of this variety of domains, this chapter will only deal with the practices employed in the context of activism.

According to my interlocutors, using smartphones in the context of activism was a sheer necessity. ${ }^{163}$ If access to a smartphone was lost for some time, which, as has been demonstrated in the previous chapter, happened to many of the activists I worked with, continuing to be engaged in activism became increasingly difficult - up to the extent that being an activist without a smartphone was considered nearly impossible. I could identify three main activist practices that were preformed through smartphones, which will form the basis of the three following sections of this chapter. The first one is the production and editing of content, which refers to all practices in which content, such as text, pictures, audios, or videos are produced and edited in order to serve the activists and their respective goals. The second one is communication, with which I describe the exchange of content among a relatively small number of people, such as a WhatsApp group chat. The third category, publication, refers to the act of deliberately giving up control of who gets to access certain content by, for example, publishing the content on a public Facebook page.

While all the activists I have spoken with employed these three practices in the context of their engagement, the frequency with which they practiced them differed among them. While for example Aziz published new content at least every other day, Cheikh and other members of the activist student movement hardly ever did so. ${ }^{164}$ Speaking in terms of the digital divide, it can thus be said that a digital divide of the second level, thus differentiating between different ways of using a smartphone, was observable among the activists I worked with.

\footnotetext{
${ }^{163}$ See the previous chapter for a more detailed discussion of the necessity of owning a smartphone for Cheikh and Aziz. Other interlocutors who explicitly mentioned smartphones being a necessity in activism include Coumba (interview, 19/07/2019, Pikine), Aliou (interview, 25/07/2019, Dakar - Nord Foire), Awa (interview, 26/07/2019, Dakar - S.I.C.A.P. Sacré Cœur.), and Immanuel (interview, 06/08/2019, Dakar - Plateau).

${ }^{164}$ In July 2019, for example, Coumba published a total of 43 posts on her Facebook page, Aziz 26, and Cheikh 6.
} 
Generally, it can be said that some of the uses of technology are more complex than others. Consuming online content is, for example, easier than producing the content (Oyedemi 2019, 101). A precondition to using ICTs in a certain way is thus having the necessary skills to do so. As with physical access, research has identified correlations between certain skills in ICT use and factors such as age, gender, education, employment and geographical location (van Dijk $2020,85)$. Given that all the activists I worked with had either obtained a university degree, or were in the process of doing so, their chances of having good skills with respect to ICT usage were higher than that of the average Senegalese person. ${ }^{165}$ The focus of this chapter will thus lie on what kinds of capitals the activists' use of smartphones presupposed, keeping in mind that others might not have had these capitals at their disposal.

Furthermore, the degree of physical access a person has to ICTs and the internet influences their level of skills and the practices that can ultimately be performed (Oyedemi 2019, 101). The type of device, whether it is for example a smartphone or a laptop, makes a difference in what can be achieved online, and devices of low quality, which are broken, have little storage or a short battery life, hinder access as well (Oyedemi 2019, 95; van Dijk 2020, 55 ff.). Moreover, the quality and amount of data volume a person has access to influences how the device can be used (Oyedemi 2019, 100). As discussed in the first chapter, various forms of capital, particularly economic capital, were needed for physical access. Because the second level of the digital divide depends on whether and to what degree the first one has been overcome, the inequalities described in the first chapter also play an important role in the following sections.

The use of ICTs thus corresponds to physical access to the internet through a respective device in two ways: First, one needs physical access to an ICT and the internet in order to use it at all. As I will show in the first section of this chapter, specific uses thereby demand physical access to ICTs with specific functionalities, and to mobile data volume of a certain quantity. Second, as Oyedemi (2019) argued, having more access and superior physical access increases the probability of developing skills that will allow for more complex uses.

Whether or not an activist has learned specific skills will thusly influence the way this person uses their smartphone. Attributing all differences in use to a difference in skills would, however, fall short as an explanation. In order to use a smartphone in a certain way, aspects such as personal motivation and interests play an important role. This is also true in the specific case of

\footnotetext{
${ }^{165}$ Research has found formal education to be the highest correlating factor with skills in connection to using the internet (van Dijk 2020, 70-71). A comparative study of six countries in sub-Saharan Africa, including Senegal, found education to be a stronger indicator to skills in ICT use than gender (Alozie and Akpan-Obong 2017).
} 
activism (see for example Tettey 2017, 689; Bosch, Admire, and M. Ncube 2020, 351). ${ }^{166}$ Using Bourdieu's concept of habitus can explain these differences in the way smartphones are used in relation to the capitals the person has acquired. As mentioned above, the concept 'habitus' describes a unifying principle which explains why people who occupy similar positions in a given field - due to similarities in their amount and ratio of capitals - share interests, motivations and tastes. Ultimately, the interests and motivations to use smartphones in the context of activism can also thus be related back to pre-existing inequalities.

\subsection{Production and Editing of Content}

In this section, I will describe the practices I could observe in the context of the production and editing of content, such as text, pictures, audios, and videos, specifically for activist purposes, and further analyse them through the lens of the digital divide. This section will thereby focus on two relevant aspects - firstly, that specific uses of smartphones require specific physical access, and secondly, that a variety of skills are highly advantageous, if not needed, to produce content for activist purposes.

When I first met Coumba, ${ }^{167}$ an activist and journalist engaged in several national and international organizations, one evening in the first week of my research, I noticed that she had two smartphones. One was already lying on the table between us, when at some point, she pulled the second one out of her bag and put it onto the table, next to the first one. When I asked her about the two smartphones, Coumba told me that she had owned the first device for some time, and had then bought the second one for a particular use, namely for livestreaming videos on Facebook.

Coumba told me that she had started to do as much livestreaming on Facebook as possible, because it was a current trend and because she liked that people could directly participate. ${ }^{168}$ While she livestreamed, she would see the viewers' comments on her screen and could respond to people's reactions directly during the livestream. Buying a new smartphone for this purpose had become necessary for two reasons. First, the camera of her first smartphone was not particularly good and it was important for Coumba to produce content of professional quality, so she needed a smartphone with a better camera. Second, when people would call her while

\footnotetext{
166 As Barbosa Neves and Mead (2018) show, non-use of smartphones does not always entail not having the possibility to use a smartphone, but can be a deliberate choice.

${ }^{167}$ Interview, 03/07/2019, Dakar - Plateau.

${ }^{168}$ Livestreaming onto Facebook has already been discussed in the previous chapter, concerning its anchoring of the produced content in space and time, which makes livestreamed recordings different from other published content.
} 
she was doing a livestream, which happened regularly, the smartphone's ringing would be audible on the recording. Coumba thus decided to buy a second smartphone with a particularly good camera, which she intended to solely use for livestreaming, so that people would not call her on this smartphone during the livestream. This did, however, not work out too well, as I could observe during an event at the Ministry of Environment and Sustainable Development I attended with her, during which she was called multiple times on the phone she used to livestream parts of the event. ${ }^{169}$ Coumba $^{170}$ had decided to use the SIM card of another provider in this new smartphone, because it offered more affordable mobile data packages. As mentioned, calling between providers was cheaper than calling the number of another provider, which ultimately led to the phenomenon that people who used the same provider as the one in her new phone would still call her during livestreams.

Smartphones as such, even though they do offer apps that allow for the editing of pictures and videos, only provide access to basic editing software. Coumba ${ }^{171}$ therefore also owned a laptop on which she used more professional editing software than she could on her phone. While Coumba ${ }^{172}$ reported owning a separate camera with a high resolution, she chose to use her smartphone for the production of her content, because it was easier to transport, more practicable to use, and the smartphone she owned had a sufficiently good camera. ${ }^{173}$ Once Coumba ${ }^{174}$ had taken the pictures or videos on her phone, she would connect her phone to her laptop, transfer the content to it, and edit it with professional software. Once edited, she either transferred the edited content back onto her smartphone to send it via WhatsApp, or she posted it to Facebook directly from her laptop.

From Coumba's example, two important aspects of the first level of the digital divide concerning the use of smartphones in the activist context can be deduced. Firstly, physical access cannot be reduced to owning any smartphone and being able to maintain it - Specific uses require specific functionalities and quality from the devices (see for example van Dijk 2020, 90; Schradie 2019, 16). These specific functionalities do, for the most, go hand in hand with a higher cost of the devices and their upkeep, and do thus presuppose higher economic capital on the part of the activist. In Coumba's ${ }^{175}$ case, it was social capital that ultimately gave

\footnotetext{
${ }^{169}$ Participant observation, 08/07/2019, Dakar - Hann.

${ }^{170}$ Informal conversation, 08/07/2019, Dakar - Hann.

${ }^{171}$ Interview, 19/07/2019, Pikine.

172 Interview, 19/07/2019, Pikine.

${ }^{173}$ In the previous chapter, I have mentioned how Aziz was looking to purchase an iPhone because of his need for a smartphone with a good camera to take pictures with a high resolution.

${ }^{174}$ Interview, 19/07/2019, Pikine.

${ }^{175}$ Interview, 19/07/2019, Pikine.
} 
her access to specialized equipment. She bought her second smartphone in a show-room whose owner she knew and who allowed her to pay for the smartphone in instalments over two weeks given that she did not have the total amount available at the time. The laptop she used was a gift from her older brother who had lived in the United States of America since his youth. Secondly, the insight that specific uses require specific devices directly contradicts assumptions that the wide availability of inexpensive smartphones signify that the first level of the digital divide is in the process of being overcome in countries like Senegal. In fact, it means that the first level of the digital divide is also far from being overcome in wealthier countries where penetration rates are close to reaching 100 percent, contrary to what has been claimed by Ragnedda (2019, 31), among others.

Once the first level of the digital divide has been overcome, also for the specific uses the activists employ their devices for, the necessary skills to use these devices in the most expedient way for the activists' goals are just as much needed. As has been elaborated above, I will use van Dijk's (2020) conceptualization of skills to analyse this aspect in detail. All of the skills that will be mentioned can thereby be considered embodied cultural capital in Bourdieu's (1983) terms. In the following, both medium-related skills, which describe the skills needed to operate an ICT, and content-related skills, including information skills, ${ }^{176}$ communication skills, ${ }^{177}$ content-creating skills, ${ }^{178}$ and strategic skills ${ }^{179}$ will be considered (van Dijk 2020, 66 ff.). It is thereby important to note that the acquisition of these skills is not trivial and while learning them auto-didactically is theoretically possible, most people learn them through the help of others, such as in specialized courses (van Dijk 2020, 69).

Coumba, ${ }^{180}$ for example, has acquired many aspects of these skills in her university studies of journalism and her experience of working as a journalist for many years. Concerning the production and editing of content both for her work as a journalist, and for her activist engagement, Coumba knew a variety of techniques to produce content. When taking pictures, for example, Coumba had learned from which angle to take them, and under which light conditions and surroundings in order to convey a certain message with these images. Also concerning the editing of the content she produced, Coumba not only had specialized equipment

\footnotetext{
176 'Information skills' include, among other things, the skill to identify trustable information from misinformation.

177 'Communication skills' describe the skills to successfully contact people online, or to create and maintain an appealing profile on social media platforms.

178 'Content-creating skills' describe the ability to produce high-quality text, videos or photos to be published on the internet.

179 'Strategic skills' are needed to use the internet in a way that is beneficial to one's own situation.

${ }^{180}$ Interview, 19/07/2019, Pikine.
} 
and software at her disposal, as described above, but also possessed of a variety of skills to edit content strategically for her goals.

Through her engagement in a project on women's representation in the media by the West African branch of an international organization, Coumba ${ }^{181}$ also had the opportunity to participate in a training course in which a variety of skills were taught on how to use smartphones and social media in the context of activism. So did Aziz, ${ }^{182}$ who took part in an environmentalist project in the same organization. According to Immanuel, ${ }^{183}$ the trainer of the course, the lessons were designed on smartphones as the sole device available to the activists, because of its wide availability and the general expectation that 'everybody' had access to a smartphone. ${ }^{184}$ The training course was held over three days and comprised lessons on how to create and edit content with smartphones, how, when and where to publish it using them, as well as general strategies to follow in order to get one's message across while simultaneously avoiding negative consequences. ${ }^{185}$

There were a number of skills that Immanuel ${ }^{186}$ mentioned conveying in the training course. The most basic, he said, were medium-related skills, which included knowing how to use the smartphone to take pictures or record videos and which applications to use in order to edit the content in the best way. Immanuel also named various skills which van Dijk would conceptualize as 'content-related skills.' The training course thereby paid a lot of attention to the acquisition of content-creating skills, including how to take pictures and videos, how to edit them, and how to combine them with text or other content in order to get the respective message across. $^{187}$

However, as Immanuel ${ }^{188}$ suggested, good content-creating skills alone were not enough to produce content that was advantageous for one's activist goals. Rather, the content, such as all

\footnotetext{
${ }^{181}$ Interview, 19/07/2019, Pikine.

${ }^{182}$ Interview, 02/07/2019, Dakar - Point E.

${ }^{183}$ Interview, 06/08/2019, Dakar - Plateau.

${ }^{184}$ As mentioned in the previous chapter, all of the activists I worked with reported struggling to gain and maintain physical access to the internet through their smartphones. However, the general expectation was that everybody owned one and was reachable via it at any given moment. The expectations of this training course for everybody to have a smartphone available is another example of this phenomenon.

${ }^{185}$ Strategic skills to avoid negative outcomes of activism were seen as essential by many of the activists I worked with, as will be elaborated in the next chapter.

${ }^{186}$ Interview, 06/08/2019, Dakar - Plateau.

${ }^{187}$ Immanuel also mentioned including a lesson on how important it was that content needed to be well-researched and fact-checked before being published, which would be considered an 'information-skill' in van Dijk's conceptualization. He also mentioned teaching the importance of the way the activists addressed their target group through their content, which van Dijk would consider a 'communication skill'. However, the two main categories of skills treated in the training course were content-creating skills and strategic skills.

${ }^{188}$ Interview, 06/08/2019, Dakar - Plateau.
} 
other aspects of one's engagement, needed to be planned strategically and fit together to give an authentic and convincing general impression. In this context, it was also vital to know one's target group and adapt one's approach accordingly. Particular attention was thus also put on the acquisition of strategic skills or, as Immanuel called them, marketing strategies.

When I asked Awa, ${ }^{189}$ the president of one of the projects in the aforementioned organization which offered the training course, what the most important skills taught in it were, she answered that it was the ability to evaluate one's own content and publication habits according to certain criteria, which would then allow the activist to see where there was room for improvement. Thus, for Awa the most important skill to be learned as an activist was the strategic skill to analyse and adapt one's content according to the content's success.

She explained that there were two types of criteria to be observed, thematic criteria and technical criteria. Thematic criteria included the relevance of the subject addressed by the content, the relatability of the content and whether the claims made were properly substantiated. Technical criteria, for example concerning the production of videos, would be sound quality, video quality, and whether the camera work, cutting technique and overall atmosphere of the video fit its thematic.

In this context, I asked Awa whether the skills to produce and edit content really needed a training course, and could not be learned auto-didactically by anybody with physical access to a smartphone, as the 'technology of freedom' discourse seems to suggest. Her answer was that basic smartphone and social media use can be learned auto-didactically, but that using these media in the most advantageous way presupposed a variety of skills and knowledge that were very hard to learn by oneself. 190

As has been mentioned, the acquisition of these skills in the training course needs to be seen as an increase in the activists' embodied cultural capital. The participants of the training course, such as Coumba and Aziz, could enhance their embodied cultural capital in this context, which,

\footnotetext{
${ }^{189}$ Interview, 26/07/2019, Dakar - S.I.C.A.P. Sacré Cœur.

${ }^{190}$ As others have shown, also people who did not have the privilege of taking part in a specific training course have created content that reached a certain activist goal, for example disproving official, and potentially biased, media coverage by documenting evidence of police misconduct, or of the magnitude of protests (Tettey 2017, 688; Harsch 2012, 57). As demonstrated by Goggin and Torres (2014), footage and pictures taken on mobile devices can have massive political influence. Content of political relevance can take all kinds of forms - while it can be evidence of brutal misconduct, also humorous images can carry political messages, as demonstrated by Ncube $(2019,121)$ for the case of football memes. However, as will also be discussed in the next chapter, the activists I worked with considered having embodied cultural capitals in the form of skills at one's disposal when it came to practicing activism through smartphones important, with the expectation that activists who possessed more advanced skills would be more successful in the long run.
} 
as will be demonstrated in the next chapter, gives them opportunities to transform this embodied capital into other forms of capital. However, Coumba and Aziz both needed certain forms of capital to even be able to participate in this course. First, they were offered to participate because of the social capital they had acquired by engaging themselves in one of the organization's projects. The organization, through foreign funding, had the financial means to offer the activists engaged in their projects these trainings. Second, the course was held entirely in French ${ }^{191}$ and also presupposed good literacy in this language. Given that only about one quarter of Senegal's population is estimated to be fluent in French (B. Beck et al. 2018, 35), and that only about 52 percent of Senegal's population over the age of 15 are estimated to be literate (Kemp 2019), even the embodied cultural capital of these particular language and literacy skills cannot be considered to be available for everybody. And third, because the training course was entirely held on the premise that the activists owned smartphones, the necessary economic capital to own and maintain a smartphone was presupposed, along with basic medium-related and content-related skills in connection to using the smartphone.

\subsection{Communication}

In this section, I want to focus on communication, the second category of smartphone use in the activist context I identified during my research. I have already mentioned this use of smartphones in the first chapter, where it was analysed mostly under the lens of physical access. As I have outlined there, I observed that much of the communication within activist groups took place on social media platforms, particularly WhatsApp. I have also shown how not having access to these WhatsApp groups inhibited access to activism as such, particularly because it seemed a self-evident fact that everybody owned a smartphone and would be able to access the information shared in a group chat.

The distinction between the categories of 'communication' and 'publication,' which will be discussed in the following section, is not clear-cut, but I argue that they describe two inherently different phenomena. While "communication" entails contacting or sharing content with a certain person or a certain group of people, "publication" describes a voluntary loss of control of who receives the message or the respective content. There are different steps on the spectrum between the poles of one-to-one communication and publication for an uncontrollably big public. Sending certain content in a WhatsApp group with 200 members makes it harder to control who gets to see the content than sending it to one person. Posting content to a Facebook

\footnotetext{
${ }^{191}$ This was mostly due to the fact that Immanuel, who was not originally from Senegal, did not speak Wolof well enough to give the course in this language (Interview, 06/08/2019, Dakar - Plateau).
} 
page where restrictions have been put in place that limit who can access the content also makes it easier to control than to publish it without any restraints. As Villi (2013) has noted, sending content, such as pictures, only to a certain number of people in private chats is considered more secure and intimate than publishing content without restrictions.

WhatsApp and Facebook were the two most popular social media platforms among my group of interlocutors. ${ }^{192}$ While WhatsApp was, as already mentioned in the previous chapter, the most popular platform for communication, Facebook was used more often for publications. Aziz, ${ }^{193}$ for example, mentioned that he only used the Facebook chat function when contacting activists or groups he did not know, mostly after they caught his attention through content published there. In this first message, he would introduced himself, state his reason for writing, and ask for the person's phone number to be able to further communicate on WhatsApp.

WhatsApp, and in particular the option to communicate in group chats, was used extensively by the activists I worked with. Many of them were members in more than one WhatsApp group chat concerning their engagement. Cheikh, ${ }^{194}$ for example, also reported regularly sharing and transferring information he received between multiple WhatsApp groups, thereby spreading the content he received through one of them among his network of fellow activists. For example, he reported having reposted information on the anti-corruption protests which took place in June and July 2019 from a group to which he was added by somebody he got to know on one of these protests, to the group of the student movement. Apart from the publication of information - for example concerning protests on Facebook pages - the communication of this content through a network of WhatsApp groups thus seemed to be a widespread practice. Demarest (2016, $20 \mathrm{ff}$.) also noted that the dissemination of information via WhatsApp chat groups of activist movements was a more efficient way of gathering people for protests than publishing it online.

Cheikh ${ }^{195}$ told me that he used WhatsApp in the context of his activism both as a tool to communicate with fellow activists, as well as to contact other people in connection to his engagement, for example the press. Contacting the press and holding a press conference on a certain issue, either for television or radio stations, was one of Cheikh's ${ }^{196}$ strategies when

\footnotetext{
192 Alzouma $(2019,248)$ also noted that WhatsApp and Facebook were the two most popular social media platforms in West Africa.

${ }^{193}$ Interview, 02/07/2019, Dakar - Point E.

${ }^{194}$ Informal conversation, 05/08/2019, Dakar - Fann.

195 Informal conversation, 09/07/2019, Dakar - Cité Universitaire.

${ }^{196}$ Interview, 04/07/2019, Dakar - Cité Universitaire.
} 
university authorities would not fulfil what the students considered to be their responsibilities and would not react to the activists' demands. He thereby showed me ${ }^{197}$ how he had given an interview to a community radio station through WhatsApp, concerning the anniversary of the death of a student killed in protests on campus. The journalist had sent him questions through WhatsApp, and Cheikh answered them in two voice messages each - one in Wolof, and one in French. These voice messages were then aired in radio programs on the topic in these two languages.

Alzouma (2019, 251-52) also stated that WhatsApp and Facebook can be differentiated concerning the people who use the respective platform - while WhatsApp is used by people from all walks of life, including people living in poverty and with limited or no literacy skills, Alzouma sees Facebook as platform for "les citadins, les utilisateurs éduqués en langues française ou anglaise ainsi que la diaspora africaine" 198 Also Aziz ${ }^{199}$ told me that when he wanted to reach people from his home locality in relation to his political engagement, he tended to use the movement's different WhatsApp groups ${ }^{200}$ rather than the Facebook page. This was also due the fact, Aziz ${ }^{201}$ explained, that many people in his home locality did not have the necessary language skills to understand the content Aziz published on Facebook, which was mostly either in French or Wolof. Moreover, given that many had only limited literacy skills, the primarily text-based content published on Facebook would not necessarily reach everyone.

That literacy and language barriers are relevant aspects of the digital divide has been described by Steven Sam (2019) in the context of rural Sierra Leone. People who do not have proficient literacy, or who do not have language skills in a language in which content is made available, face particular difficulties concerning their access to and use of smartphones (Sam 2019, 217). These difficulties range from the acquisition of the objects, such as how to figure out which model to buy in order to be able to access all desired functionalities, to medium-related skills, such as how to change the device's settings or how to call somebody, to content-related skills, such as how to create an appealing profile on social media (Sam 2019, $226 \mathrm{ff}$.). ${ }^{202}$ In fact, much

\footnotetext{
${ }^{197}$ Participant observation, 09/07/2019, Dakar - Cité Universitaire.

198 "the city residents, the users who are educated in French and English, as well as the African diaspora".

${ }^{199}$ Interview, 12/07/2019, Dakar - Point E.

${ }^{200}$ As has been described in the previous chapter, Aziz managed the political movement's WhatsApp groups. The movement had one group for core members, several for people who worked in the movement but were not involved in important decisions, and even more for people who just wanted to be kept informed about the movement's activities.

${ }^{201}$ Interview, 12/07/2019, Dakar - Point E.

${ }^{202} \operatorname{Sam}(2019,231)$ could thereby identify three approaches of people with limited literacy and language skills to use their smartphone, namely the strategic use of icons and images, asking more educated individuals to do a certain activity for them, or organising informal schooling in order to acquire the most necessary skills.
} 
of the advantages predicted by the 'technology of freedom' discourse are null and void for illiterate people because the internet is foremost a text-based medium. While videos and audios are widely available, accessing them usually means typing text beforehand. ${ }^{203}$ While even people with limited literacy and language skills therefore overcome the first level of the digital divide and find strategies to operate them, their lack of this embodied cultural capital means that many uses of their smartphones and the internet are not accessible to them.

The activists I worked with possessed skills that enabled them to use their smartphones in a variety of ways in the context of their activist engagement. However, some, among them Aziz, ${ }^{204}$ encountered a struggle to overcome the second level of the digital divide on the part of their target group, in this case because of language and literacy barriers, which ultimately meant Aziz needed particular strategies to reach them. ${ }^{205}$

As mentioned, Aziz ${ }^{206}$ operated several WhatsApp groups for the political movement he was engaged in, as well as the movement's Facebook page. The Facebook page was kept entirely in French, because it was supposed to have an official appearance and because it acted as an official 'face' of the movement, where its different actions were to be documented not only for the people living in the locality, but any outsider who might be interested in following the goings-on. The publications on Aziz' WhatsApp account were made in different languages, mostly French, Wolof and Djola, depending on whom he wanted to address with the publication. Concerning his publications, Aziz ${ }^{207}$ said that he generally used pictures with little text, both because he found it more appealing this way, and because it was more accessible for people with limited literacy skills.

Aziz $^{208}$ explained that when the communication with his target group was intended to have a particular outcome, for example in late 2018 when he wanted as many people as possible to attend an election campaign event organized by the political movement, he needed to deploy certain strategies in his communications with them. There were two main aspects Aziz ${ }^{209}$ reported considering. First, the content to inform the inhabitants of his home locality of the

\footnotetext{
${ }^{203}$ While many smartphones enable voice input, this usually presupposes constant access to the internet. Also, the language selection for voice input software is usually limited and does not include many African languages.

${ }^{204}$ Interview, 12/07/2019, Dakar - Point E.

${ }^{205}$ Aziz also mentioned problems with physical access to smartphones or the internet as a phenomenon he had to take into consideration when communicating with his target group. However, in this section the focus will lie on aspects relating to the second level of the digital divide.

${ }^{206}$ Interview, 12/07/2019, Dakar - Point E.

${ }^{207}$ Interview, 12/07/2019, Dakar - Point E.

${ }^{208}$ Interview, 12/07/2019, Dakar - Point E.

${ }^{209}$ Interview, 12/07/2019, Dakar - Point E.
} 
upcoming event needed to be accessible to them, and second, he needed a strategy which would lead his communication efforts to a certain outcome, namely that people would show up to the event.

To inform people about the event he was planning and encourage them to attend, Aziz ${ }^{210}$ reported that he had first created a flyer, which stated the most important information about the event, such as where and when it would take place. He then posted this flyer as his WhatsApp status and encouraged people to repost it - both as a comment to his WhatsApp status, and by directly asking his boys ${ }^{211}$ living in the locality or with strong connections to the locality to do so in private WhatsApp chats.

$\mathrm{He}^{212}$ also recounted posting this picture to all the WhatsApp groups associated with the movement, together with a text message in which he gave details about the event and urged people to come. Because some people might not be able to read the longer text message, he explained that he also recorded voice messages in the different languages spoken in his locality and posted them to the WhatsApp groups. He first posted invitations about three weeks before the event, and then regularly reposted the same messages to remind people of it.

Aziz ${ }^{213}$ explained that he saw two main problems with this technique - first, he could not know who currently had effective access to the WhatsApp groups. Because he could not be sure that all the people he wanted to contact had physical access to the internet at that moment, Aziz could not know whether they received the messages he sent to those groups. And even if the person could access the message, Aziz said that he could not be sure people would show up to the event if they only received this rather impersonal message published as a WhatsApp status and in the WhatsApp groups of the movement.

Particularly when it came to people with a high standing in the village, or people he knew to not have a smartphone, Aziz ${ }^{214}$ thus reported employing different strategies to increase the liability of his invitation. If he knew they had a smartphone and were active on WhatsApp, he would send them the invitation in a private chat. In this way, Aziz could see whether they had seen the message by checking whether there were two blue checkmarks next to the message..$^{215}$

\footnotetext{
${ }^{210}$ Interview, 12/07/2019, Dakar - Point E.

211 The term boy was used as a term to describe people who were either younger than oneself, or lower in the social hierarchy for any other reason.

${ }^{212}$ Interview, 12/07/2019, Dakar - Point E.

${ }^{213}$ Interview, 12/07/2019, Dakar - Point E.

${ }^{214}$ Interview, 12/07/2019, Dakar - Point E.

${ }^{215}$ For WhatsApp, two grey checkmarks after the text of the message means the message could be delivered and two blue ticks means the message was viewed.
} 
In this way, Aziz ${ }^{216}$ believed to have proof that the person actually saw the message and would expect the person to come to the event. If the person did not have WhatsApp, but owned a phone, he would call them. Sending an SMS would also work, but then again Aziz could not be sure the person had read the message. In cases where the person did not have a phone, or was very high-standing in the village, Aziz said that he transferred money via a mobile app to one of his boys in the village to rent a motorcycle and drive to the person's homes to invite them in person.

Aziz' smartphone use in the context of communication with people from his home locality was thus influenced by difficulties in physical access to smartphones and the internet, by different levels of skills which could potentially serve as a barrier to accessing certain information, such as literacy, and by the valuation of communication through smartphones per se. Aziz thereby resorted to inviting people individually for two reasons. First, for practical reasons, because he could not know whether a specific person he wanted to join the event would be able to receive the message because of issues related to physical access. Second, for reasons related to the valuations of information shared through smartphones, because there seemed to be a difference in liability to accept Aziz' invitation with the different ways the invitation was delivered. Based on Aziz' strategies, it seems that a public post had the least liability, followed by an SMS where receipt cannot be verified, followed by a WhatsApp message where receipt is marked, followed by a call, and a personal visit, which carries most liability to attend.

The position of a certain person in the social hierarchy of the locality, relative to Aziz' own social standing, also seemed to influence the way Aziz communicated with them through his smartphone. When it came to his boys, Aziz expected them to attend the event because he invited them to it, even if just through a general publication or in a WhatsApp group with many members. Aziz put this down to the trust his boys had in him - If he posted an invitation, people would trust him that it was worthwhile to show up. When it came to people whom Aziz considered higher in the social hierarchy than himself, or who he knew to not have physical access to the internet, he launched particular invitations, because he did not consider publications and posts in the WhatsApp group as reliable enough in this case.

This example thus demonstrates that communication, which seems such a basic and easy-touse functionality of smartphones, is in fact not as simple as it may first appear. Particularly when the communication is aimed at a specific end, strategies need to be deployed which

${ }^{216}$ Interview, 12/07/2019, Dakar - Point E. 
account for a wide array of factors, including aspects of the digital divide, of the valuation of smartphones and the information passed on through them, and of local social hierarchies. Being able to develop such strategies and follow them presupposes both intricate knowledge of the local situation, and strategic skills to use one's smartphone in a certain way that considers this situation and leads to the achievement of one's aim. The strategic skills employed by Aziz also include the application of several other skills - among them communication skills to present himself as a trustworthy and involved leader in the locality. It is through making use of these communication skills that Aziz built up his symbolic capital as a trustworthy leader, which Aziz $^{217}$ considered to be one of the main reasons for his success as an activist.

\subsection{Publication}

As mentioned, I distinguish between communication and publication by the idea of how much control the activists retain of the content they share with others. While content posted in WhatsApp groups, where one knows either all or most of the members personally, is relatively easy to control, content published on a public Facebook page is potentially viewable by an unrestricted number of people.

The platforms which were used most frequently for publication by the activists I worked with were Facebook and the status function of WhatsApp. ${ }^{218}$ The status function of WhatsApp, in its most public setting, allows everybody who has the user's number saved in their phone to see the publication of the user. Thus, to view a publication on WhatsApp, some sort of contact already had to take place so that the viewer had the publisher's phone number. Also, the publication is only visible for 24 hours. Posts on a Facebook page, given that the page is set to public, can be found and seen even without prior contact and are online for as long as the publisher does not delete the post. On Facebook, there are thus more possibilities to see publications of people with whom no prior contact has been established - for example if a larger activist organization reposts the content or if a common friend shares it. To express it in Aziz,219 words: "WhatsApp, c'est un village, Facebook, c'est une metropole."220

As mentioned in the previous section, one-to-one communication or communication in smaller group chats was considered more private and personal than publication. The example of Aziz'

\footnotetext{
${ }^{217}$ Interview, 02/07/2019, Dakar - Point E.

${ }^{218}$ Aziz and Coumba told me that they both had accounts on Twitter and Instagram, which they had opened during the training course on smartphones and social media in activism, but at the time of my research these two platforms were not particularly popular (Interview, 02/07/2019, Dakar - Point E; Interview, 03/07/2019, Dakar - Plateau). ${ }^{219}$ Interview, 12/07/2019, Dakar - Point E.

220 "WhatsApp is a village, Facebook is a metropolis."
} 
organization of an event in his home locality has shown that more private chat rooms are connected with higher liability of the reader towards the person who sent the message. Publication, on the other hand, is considered less private and more public. A publication is not a private message, but a statement meant for as many people as possible. Because of this, I argue that the practices which fall into the category 'publication' are to be considered as activist acts in their own right. While the production and editing of content was more a step towards publication or communication, and communication was mostly used to organise other meaningful practices, such as events, publication was an end in its own right and considered impactful activism by the activists I worked with. ${ }^{221}$

There are two main practices the activists I worked with often referred to when it came to publication, of which I will each give an example in this section. The first one was sensibilisation, or awareness-raising, and usually involved providing certain information about an issue, usually in conjunction with a demand to change the current status quo concerning this issue. The second practice was denunciation, which describes the act of criticizing a certain condition or action and often involved the naming of the people or institutions the activists considered to be responsible for the respective condition. Publication in general entails both risks and opportunities for the activists who decide to practice it, as will be further elaborated on in the next chapter.

The example of awareness-raising which I will present was performed by Coumba ${ }^{222}$ during and following an event organized by the Senegalese Ministry of the Environment and Sustainable Development about single-use plastics. The day before the event, Coumba changed her Facebook profile picture to the official image of the campaign, ${ }^{223}$ which had been produced by the Ministry. Just before the event started, Coumba posted a message on her Facebook page $^{224}$ that she was attending an event about the dangers of plastics organized by the Ministry of the Environment and Sustainable Development. During the event, Coumba recorded two Facebook live streams of the speeches delivered by an activist dressed in a costume made out of plastic bags ${ }^{225}$ and an actress who performed a comedic play on the topic. ${ }^{226}$ While she was

\footnotetext{
${ }^{221}$ Mutsvairo (2016b, $9 \mathrm{ff}$.) only mentioned practices which involved the publication of content in his introductory chapter on digital activism.

222 Participant observation, 08/07/2019, Dakar - Hann.

223 Published as a Facebook profile picture on 07/07/2019 at 18:01, 21 likes, 1 comment, 1 time shared (documented on 15/07/2019).

${ }^{224}$ Published on Facebook on 08/07/2019 at 12:34, 14 likes (documented on 15/07/2019).

${ }^{225}$ Livestream on Facebook on 08/07/2019 at 13:24, 3 minutes 47 seconds, 214 views, 27 likes, 4 comments (documented on 15/07/2019).

${ }^{226}$ Livestream on Facebook on 08/07/2019 at 13:37, 2 minutes 15 seconds, 106 views, 16 likes, 8 comments (documented on 15/07/2019).
} 
not streaming, Coumba ${ }^{227}$ answered Facebook messages, wrote private messages to people who commented on her posts and videos, took pictures, shared two Facebook live streams of other people present at the event on her Facebook page and also sent messages to people with no direct connection to the event.

During the one-and-a half-hour event, Coumba always had at least one of her two smartphones in her hand and was occupied with one of the aforementioned activities. Shortly after the event, the minister went to talk to people who had stands just outside the building where the event took place, presenting three businesses who offered alternatives to products made out of plastic (plastic bags, plastic cups) or offered recycling possibilities for some plastic products (water cannisters and large plastic bottles). Coumba followed the minister, livestreaming how he looked at the stands and talked to the people presenting what the companies had to offer. ${ }^{228}$

In the evening of the same day, Coumba recorded another livestream at home, in which she first spoke about what she had learned about single-use plastic and its consequences for the environment, and then interviewed a fellow activist who worked more intensively on the topic. ${ }^{229}$ She asked him questions concerning the possibility of avoiding single-use plastics on an individual level and also asked two questions from the comments made by viewers during the livestream on plastic on an industrial level, as well as imported plastics.

For this practice of awareness-raising, Coumba thus employed a strategy spanning over more than 24 hours. She started by changing her profile picture the evening before the event, then livestreamed during the event, and followed up on it the same evening with a livestream she filmed together with a fellow activist, thereby integrating the questions people asked during the recording. When I asked her some time later whether she considered this instance of awarenessraising a success, Coumba ${ }^{230}$ said that she was very satisfied with the outcomes. Several of her friends hat contacted her to ask for more information on the topic, and she had also been contacted by other activists engaged for the environment who wanted to connect with her for possible future projects.

I will now come to the second practice often mentioned in the context of publication, namely denunciation. The following example stems from a Facebook page which was well-known as a

\footnotetext{
${ }^{227}$ Participant observation, 08/07/2019, Dakar - Hann.

${ }^{228}$ Livestream on Facebook on 08/07/2019 at 14:41, 8 minutes 39 seconds, 190 views, 11 likes, 5 comments (documented on 15/07/2019).

${ }^{229}$ Livestream on Facebook on 08/07/2019 at 19:54, 17 minutes 7 seconds, 674 views, 64 likes, 15 comments, 5 times shared (documented on 15/07/2019).

${ }^{230}$ Interview, 19/07/2019, Pikine.
} 
platform for denouncing in Senegal during my stay there. ${ }^{231}$ The main principle of the page was that followers could send in videos, images, or text in which they denounced misbehaviour by certain people, enterprises or institutions. The topics of denunciation ranged from irresponsible driving of bus drivers, poor hygiene standards of shops or restaurants, the poor living conditions of young talibé under the charge of influential marabouts, ${ }^{232}$ insufficient infrastructure caused by a lack of attention by the government, to police misconduct and corruption in government institutions.

Because of the popularity of the Facebook page and the large number of followers, denunciations published there were likely to have an impact and often, follow-up apologies or rectifications by the accused were published. Aliou, ${ }^{233}$ the founder of this page, and the six other people managing the page ${ }^{234}$ posted three denunciations every day, one at $10 \mathrm{am}$, one at $2 \mathrm{pm}$, and one at $5 \mathrm{pm} .{ }^{235}$ Posting at these particular times of the day followed a strategy which, according to Aliou, allowed the page and each of the posts to receive maximum attention. The first post of the day was to be read by people right after waking up. They then had the time to read, like and comment the post either on their way to work or during a short break at work in the morning. The second post of the day aimed at people's lunch breaks, where according to Aliou, they would read their Facebook feed again. The last post at 5 pm was, according to Aliou, the one that attracted most reactions, because people would take their time to read and react to it after work, which was also why he scheduled the most controversial denunciations for that slot. Aliou said that because he received so much content for publication, he usually planned the publications a few days in advance, using a function of Facebook that allows posts to be prepared in advance before being published automatically at a certain time.

\footnotetext{
${ }^{231}$ On 14/10/2019, the page had 132,245 likes and 138,841 followers.

${ }^{232}$ Many Senegalese children are sent to marabouts, Muslim religious leaders, to learn more about the Qu'ran and how to lead a pious life. However, abuse of the children, the talibé, has come to light in some cases. Because of the moral authority of marabouts, the denunciation of their misconduct is highly controversial in Senegal (see for example Seibert 2019).

${ }^{233}$ Interview, 25/07/2019, Dakar - Nord Foire.

${ }^{234}$ Aliou told me that seven people were engaged with the page. Two of them were jurists who consulted the other team members concerning legal aspects of the public denunciation of people on this Facebook page, one moderator who deleted comments including hate speech, one person responsible for public relations with, for example, sponsors or businesses who could provide material support for events, such as clean-up days, and two journalists, as well as Aliou himself (Interview, 25/07/2019, Dakar - Nord Foire).

${ }^{235}$ While many of the posts on the page do follow these time specifications, many do not. This could be due to not all publications being planned beforehand. However, the times of publication do mostly follow the pattern of one post in the morning, one around midday, and one in the evening, even though the exact times may vary.
} 
The example I will discuss was a denunciation published on this Facebook page which was directed towards a French restaurant chain that also sells baked goods in Senegal. ${ }^{236}$ The post denounced the hygiene standards of a particular branch of this restaurant chain in Dakar, because the baguette the writer had bought had two dead flies baked into it. The claims were proven with two pictures, showing the baguette and the dead flies as well as a wrapping with the restaurant chain's logo on it. The comments under the post included many further denunciations of the same nature, involving different restaurants of the same chain all over Senegal. On the same day, an apology by the manager responsible for hygiene for several restaurants of this chain, including the one originally denounced, was published. It stated that the hygiene regulations were strict and that he would take the claims seriously. ${ }^{237}$

Building up and maintaining a Facebook page with such a large social outreach required a number of skills from Aliou, as well as the other members of the team behind the page. Aliou ${ }^{238}$ said that he had learned most of these, including the strategic skills to set up the publication pattern of the website and build its reputation and outreach, as well as the medium-related skills to use the functions Facebook offers in a strategic way, ${ }^{239}$ while working for a radio station in the United States of America, where he had grown up.

This Facebook page fulfills in many ways what the 'technology of freedom' discourse portrays the internet to offer. Anybody with a smartphone can record evidence of certain negative behaviour, such as misconduct, and send it to the managers of the page to have it published. Because the page has a widespread audience, it is also not improbable that the publications receive attention which could ultimately lead to the demands of the publisher being taken seriously. The instance of the hygiene standard in the French restaurant chain exemplifies this. Due to the fact that the publications were always anonymous - the publishers' phone numbers were only ever listed in some cases when they wanted to be contacted - the parties responsible for publishing this denunciatory content were also somewhat protected from personal consequences. This will be discussed in more detail in the next chapter. The comments under

\footnotetext{
${ }^{236}$ Published on Facebook on 03/09/2019 at 14:34, 666 reactions (out of which 431 likes, 102 angry, 76 surprised, 29 sad, 26 laughing, two hearts), 433 comments, 122 times shared (documented on 14/10/2019).

${ }^{237}$ Published on Facebook on 03/09/2019 at 17:13, 864 reactions (out of which 784 likes, 66 hearts, nine laughing, two sad and two angry), 237 comments, 33 times shared (documented on 14/10/2019).

${ }^{238}$ Interview, 25/07/2019, Dakar - Nord Foire.

239 Aliou mainly spoke about two functions he regularly used. The first one was the function to schedule publications, which would then go online at a pre-set time. The second one was a function to 'boost' publications, which Aliou used to give particular posts an even greater outreach by paying Facebook to give this publication a higher priority in the followers' news feed (Interview, 25/07/2019, Dakar - Nord Foire).
} 
the publications were also often used for discussions on the respective topic, which would make this page a 'space for deliberation.' 240

However, the page was not a space where everybody could publish what they wanted. Rather, it was ultimately Aliou and the other team members behind the page who chose what to publish out of the content they received. It is true that Aliou's activist goal was exactly to give a platform to people of all walks of life, including the marginalized, to fight behaviour he deemed negative. However, the fact that he chose what was published, and not the actual producers of the content ultimately made him an intermediary that the ‘technology of freedom' discourse claims can be circumvented on the internet. While the followers of the page could simply publish the content on their own Facebook pages, they would not receive the same widespread reception, and probably also not the same success as they did by publishing on the page Aliou managed.

Moreover, the members of the activist student group hardly ever published content on Facebook, as has been mentioned in this chapter's introduction. Instead, they preferred to speak to the press if there was an issue they wanted to denounce, such as the late payout of scholarships, for example. Coumba and Aziz, on the other hand, mostly published content on their own Facebook pages, and in Aziz' case on the Facebook page of the political movement he was engaged in, too. The implications of this difference in using smartphone for publication, or 'digital activism' will be discussed in the next chapter.

\subsection{Chapter Conclusion: A Technology that 'Gives Voice' to Anybody?}

In this chapter, the focus lay on the different uses of smartphones in the activist context, and the different forms of capitals which certain uses demanded of the activists I worked with. The three sections thereby each discussed one category of practices in the context of activism which I could identify based on my research among Senegalese activists, namely the production and editing of content, communication, and publication.

Throughout the chapter and concerning all three categories of practices, I could show that performing activist practices presupposed certain forms of capitals from the activists I worked with. This included, for example, economic capital for specialized equipment. As I could show in the section on the production and editing of content that specific uses of smartphones require specific physical access, including, for example, a smartphone with a high-resolution camera.

\footnotetext{
${ }^{240}$ Bosch, Admire and Ncube $(2020,355)$ largely argued in the 'technology of freedom' discourse when stating that the internet offered a Habermasian public sphere were political issues could be discussed.
} 
Because the acquisition of equipment of high quality usually comes with higher costs, more economic capital is needed the more professional the content is expected to be.

A high-quality device alone will not, however, suffice to produce content of professional quality for a specific activist goal. The necessary skills, which Bourdieu would describe as embodied cultural capital, are equally important and must be acquired. In this chapter, I have described one space where these skills were acquired by some of the activists I worked with, namely a training course which the West African branch of an international organization had offered to the activists engaged in its projects, including to Coumba and Aziz. ${ }^{241}$ The skills learned in this course included both medium-related skills, such as which applications to use for picture or video editing, as well as content-related skills, such as the conceptualization and production of high-quality content, and the skill to build an overall strategy to evaluate and reconceptualize one's social media presentation in general. As has been shown, taking part in this course also presupposed a number of capitals on the site of the activists, including the social capital to be given the opportunity to take part in the course, the economic capital to own a smartphone with which to participate, as well as the embodied cultural capital of language and literacy skills which were required to participate.

Based on these insights from how the activists I worked with used their smartphone in the context of their activism, I argue that the internet is not a technology that 'gives voice' 242 to anybody who can access it. Rather, once physical access has been gained, and once the necessary skills have been acquired, the smartphone can be used to establish a space where one 'has voice.' An example of such a space named in this chapter would be Coumba's Facebook page. Because Coumba has established a Facebook page with a number of followers who see her publications, she has created a digital stage on which her publications will be visible. 'Voice,' in this sense, is therefore not a gift the internet offers to anybody who can access it, but needs to be established over time, with the precondition that one has the necessary technology and skills available to do so.

\footnotetext{
${ }^{241}$ As the examples of Coumba and Aliou have shown, work experience in traditional media, radio stations in both cases, were a space where these skills could be acquired. In Coumba's case, a university degree in journalism had equally provided her with the mentioned skills.

${ }^{242}$ As outlined in the theoretical framework of this thesis, the internet being a technology that 'gives voice' to anybody is one of the main claims of the 'technology of freedom' discourse.
} 


\section{The Perks of Being a Digital Activist - The Advantages Smartphones Bring and the Inequalities they (Re-)Create}

\subsection{Chapter Introduction}

In the previous chapters, I have discussed how the activists I worked with made use of their pre-existing capitals to firstly, gain physical access to one or even several smartphones and the internet, and secondly, use their smartphones for their activist purposes. These two aspects correspond to the first and the second level of the digital divide respectively. I have thereby shown that pre-acquired capitals provide certain advantages concerning the activists' access to smartphones and their use, which helped them overcome barriers which people who do not dispose of these capitals might find harder or impossible to overcome. The current chapter will now focus on the third level of the digital divide, which concerns the different outcomes, be they positive, negative, or neutral, which derive from ICT use. More exactly, this chapter will discuss the theory that smartphone use not only replicates existing social inequalities, but in fact reinforces them by providing ICT users with certain advantages. The context of analysis will thereby be limited on the practice of publication described in the previous chapter, which is more commonly called 'digital activism' (see for example Mutsvairo 2016a; Mwaura 2017; Schradie 2019). The questions that this chapter will thereby answer are whether a digital divide of the third level was observable among the activists I worked with, and how these findings relate to what I have called the 'technology of freedom' discourse.

In general, it can be said that the outcomes of ICT use, so the third level of the digital divide, largely depend on whether and to what degree the first and second level of the digital divide have been overcome (see for example Ragnedda and Ruiu 2018; L. Ncube 2019, 124). As mentioned before, access can also be partial and the lower the quality of the device and the internet connection, and the more limited the skills, the fewer positive outcomes are to be expected (see for example Tettey 2017, 691; van Dijk 2020, 96 ff.).

As already shown in the last chapters, the activists' engagement was interwoven with their use of smartphones. However, because their smartphones also played a role in many other aspects of their lives, the separation in activist and non-activist smartphone use was often not clear-cut. It therefore follows that the outcomes of digital activism are equally hard to separate into outcomes for the individual activist on the one hand, and outcomes for the activist cause on the other. Nevertheless, I will conceptually separate these two aspects in the first and second section of this chapter, in order to highlight the influence of (potential) personal outcomes for the activists on their digital activism. 
The section "The risks and chances of "being exposed" will focus on the personal outcomes of practicing activism through smartphones for the activists I worked with. Particularly the strategy to balance the degree of association of the publications with them personally, and the controversy of the content, will be discussed. The section "Digital activism and its outcomes" will then discuss the outcomes of practicing activism online concerning the respective activist goal. Particular attention will be put on the criteria the activists reported of how to determine the success of a publication, and what it takes to achieve this particular outcome. The section "Reinforcing inequalities?" will then discuss the outcomes of digital activism, both personal and regarding the activist goals, for four of the activists I worked with, and discuss whether it can be argued that smartphone use indeed reinforces existing inequalities.

\subsection{The Risks and Chances of 'Being Exposed'}

When I asked Coumba ${ }^{243}$ about the consequences, both positive and negative, of practicing digital activism for her personally, she said that both positive and negative outcomes were connected with the fact that she was very exposé, or exposed, on her social media accounts. ${ }^{244}$ Particularly on Facebook, so she ${ }^{245}$ explained, her profile showed a lot of personal information, including her full name, numerous pictures of her and a large documentation of her personal, professional and activist life events.

This exposure led to the phenomenon that the content she published on this Facebook page was associated with her personally, and reactions to publications would often be both about the content, and about her. Coumba ${ }^{246}$ appreciated this fact when she received positive feedback for her publications and her skills of producing and editing content. After all, this association of her being skilled in these aspects resulted in positive outcomes such as her being contacted by colleagues, by future informants for reports, by fellow activists and by organizations. Because of the good reputation Coumba had accrued over time, she was considered an expert on the topics she worked on, which also resulted in her receiving offers from international organizations and media institutions to create content for them.

\footnotetext{
${ }^{243}$ Interview, 03/07/2019, Dakar - Plateau.

${ }^{244}$ Coumba's explanation that being "exposed" increased her vulnerability for both positive and negative outcomes is shared by Alzouma $(2019,263)$, who also noted that it is mostly people who are particularly visible and possess high symbolic capital who are the victims of negative outcomes such as hate speech.

${ }^{245}$ Interview, 19/07/2019, Pikine.

${ }^{246}$ Interview, 19/07/2019, Pikine.
} 
Being exposed on her Facebook page had thus led to Coumba build up the reputation of a highly skilled activist and journalist. ${ }^{247}$ This brought her both the advantages of increasing her social capital, through the new contacts she made through her publications, as well as economic capital if she was commissioned to create content for large institutions. I argue that Coumba's prominent reputation in the field, which is partially due to her advanced skills concerning all aspects of maintaining her Facebook page, it was easier for her to acquire social capital, both in the form of Facebook friends, and in the form of potential partners for her future projects. Using Bourdieu's (1983) concept of the field, it can be argued that Coumba increased her own position through her publications which, as will be shown in the section "Reinforced inequalities?" offered benefits for her and for the achievement of her activist goals equally.

However, being exposed also led to negative outcomes for Coumba, ${ }^{248}$ including being a victim of insults and hate speech. This was particularly the case following the publication of content which treated controversial topics, such as the dangers illegal migrants face on their way to Europe. ${ }^{249}$ Coumba $^{250}$ also reported having experienced sexual harassment online, such as in the form of unsolicited pornographic content being sent to her.

For Coumba, and also for Aziz who was similarly 'exposed,' it was of the utmost importance to carefully choose which content to publish in order to avoid these negative personal outcomes. Coumba $^{251}$ thereby placed high value on her publications living up to her professional standards, concerning both the validity of the content she published as well as its presentation. Insults or poorly researched content, including misinformation, were out of the question for her, also because her followers expected Coumba's publications to live up to these standards. Keeping up her reputation was thus important for Coumba to maintain or increase her forms of capital. Publishing content which did not meet those criteria expected by Coumba's followers, or publishing content that was too controversial, could thereby have a negative effect on her symbolic capital, which could likewise entail a loss of other forms of capital.

The observation that some topics and some kind of content were deliberately avoided in someone's publications contradicts another aspect of what I have called the 'technology of

\footnotetext{
247 That Facebook pages can be considered the 'face' of institutions, such as political parties, has been noted before (Bosch 2018, 149). Also some of the activists I worked with used their Facebook pages in this sense.

${ }^{248}$ Interview, 19/07/2019, Pikine.

${ }^{249}$ In this particular case, Coumba recounted being insulted as a collaborator with France, because by thematizing the dangers of the migrant routes she would act in France's interest to exclude Senegalese migrants from the wealth they expected to find there.

${ }^{250}$ Interview, 19/07/2019, Pikine.

${ }^{251}$ Interview, 03/07/2019, Dakar - Plateau.
} 
freedom' discourse, namely the claim that the internet provides an autonomous space for free deliberation, where opinions can be shared without having to fear the consequences. My own findings suggest that this is not the case, especially when the activists are very 'exposed.' Rather, as Skjerdal $(2016,77)$ also suggests, the social and political environment is very influential when it comes to what can be said and done online, as well as to the consequences certain online behaviour can entail. ${ }^{252}$

At the time of my research, Aziz ${ }^{253}$ had similar concerns as Coumba about the content he published - after all, publishing overly controversial content could damage his reputation. Since he had only been active for less than a year in the political movement, he was still seeking to increase his social capital within the movement's ranks, and ultimately within the ranks of the ruling party this movement was associated with. At the time, he thus actively avoided publishing controversial content to build a strong reputation, which, as the following episode Aziz $^{254}$ told me shows, had not always been the case.

One night in June 2017, shortly after returning to Dakar from a trip to his home locality, Aziz could not sleep because he was angry about the fact that a town hall in his home locality, which should have been finished by then, was in fact not and that there was no money left to finish building it. In the middle of the night, Aziz decided to voice his anger in a long publication on his Facebook page, enumerating the different grievances in his locality, calling the responsible authorities 'cockroaches' and tagging the Facebook pages of the mayor and the vice-mayor in the post.

The next morning at around $9 \mathrm{am},{ }^{255}$ people started calling him. They included, among others, family members on his father's side, who themselves had been called by family members of the mayor and wanted Aziz to delete the publication to maintain good relationships between the two families. A cousin on his mother's side also called him, crying and begging Aziz to delete the post because she was afraid he would be killed because of it. Aziz refused to delete it, but instead posted another message, saying that he would not be on Facebook for a few days because of the threats he had received, and thanking his friends and family for their support.

\footnotetext{
${ }^{252}$ Also the social standing of the person in question plays a role in what can and cannot be said online - as Schradie $(2019,16)$ has observed in her study on activist groups in the USA, African American activists were less likely to publish on controversial topics than white Americans for fear of negative consequences, such as job loss. ${ }^{253}$ Interview, 12/07/2019, Dakar - Point E.

${ }^{254}$ Interview, 12/07/2019, Dakar - Point E.

${ }^{255}$ Because this incident had happened two years prior to my research, I could not confirm the time specifications Aziz gave me. They should thus rather be viewed as an indicator of the temporal sequence, rather than exact times.
} 
Together with the message, he published a picture of himself sitting on a flight of stairs, gesticulating as if he was passionately giving a speech. ${ }^{256}$

The same day, Aziz was contacted by a member of the ruling party whom Aziz had not known prior to this first contact. This man congratulated him on his honesty and said that he was in contact with the local prosecutor, just in case the authorities would file a complaint against Aziz based on the publication. Three days later, the imam of the locality called Aziz to ask him to delete the post saying that it had created unrest among the community. Aziz thus deleted it. However, after the publication had been taken down, a new wave of calls and messages arrived, this time from people who had supported his act of denunciation and defended Aziz against voices from elders who would call him "indiscipliné." ${ }^{257}$

Aziz' publication thus caused a crisis in several aspects. First, the publication threatened his, as well as his family's, social capital, as the publication threatened to break the good relations Aziz' family had with the mayor's family. The pressure on Aziz was thereby not asserted by any officials or the people directly implicated, but by his own family, a phenomenon also observed elsewhere (see for example Bruijn 2016, 98). The reason he finally took the publication down was the call from the local imam. This is particularly interesting against the background that many of my interlocutors ${ }^{258}$ said that criticizing or opposing politicians had become widely accepted in Senegal, whereas criticizing or opposing religious authorities had not.

Because of the ambivalent reactions to his publication, with some people strongly condemning it and others supporting it, Aziz was faced with the dilemma of deciding whose expectations he wanted to live up to and thus whom he wanted to maintain as social capital. Through this controversial act, he could also gain new social capital in the form of the party member who later founded the movement Aziz was engaged in. The act of publishing this post through his smartphone thus influenced his future activist engagement through this new contact.

\footnotetext{
${ }^{256}$ Publication on Facebook, 17/06/2017, 69 reactions (66 likes, 2 surprised, one heart), 14 comments (documented on $14 / 10 / 2019)$.

When Aziz told me about this incident, he described this second publication as including the statement that he did not want to hurt anybody's feelings, but that he wanted to continue on the way to true change, which was sometimes rough (interview, 12/07/2019, Dakar - Point E). When I found this publication on his Facebook account after the end of my research stay, Aziz confirmed through WhatsApp that it was in fact the publication he had referred to. 257 "undisciplined".

${ }^{258}$ Some of the interlocutors who mentioned this include Aziz (informal conversation, 07/08/2019, Dakar - Fann; Cité Universitaire), Cheikh (informal conversation, 05/08/2019, Dakar - Fann), and also Immanuel, the trainer of the course on the use of smartphones in activism (interview, 06/08/2019, Dakar - Plateau).
} 
Second, the post brought Aziz into a dilemma concerning his symbolic capital. On the one hand, Aziz wanted to be considered an honest person who stood his ground and was not afraid to say what he had to say, which would rather speak for keeping the publication online. On the other hand, Aziz wanted to be considered a responsible, trustworthy and esteemed person, and not 'undisciplined' which would have meant to take the publication down.

As this example illustrates, publishing controversial content, either because it contains a provocative message or is formulated and presented provocatively, can lead to various outcomes, which the activist can only partially predict. Aziz experienced both positive outcomes, such as the contact to the party member which would be of advantage for him later on, or the reputation of being a strong 'leader' among his supporters, as well as negative outcomes, such as being considered 'undisciplined' by the local authorities. He also reported receiving threats, to which he responded by not logging in to Facebook for a few days.

In order to avoid these negative outcomes, many of the activists I worked with had specific strategies in place. I have previously mentioned that Coumba and Aziz, who are both very 'exposed' on their Facebook pages, follow the strategy to avoid publishing controversial content that could harm their social or symbolic capitals or provoke negative outcomes such as insults or threats. Another strategy I could observe during my research was to not avoid controversial content, but instead reduce the degree of 'exposure' on the Facebook page where the content was published. A particularly clear example of this strategy would be the Facebook page managed by Aliou and his fellow team members which I have already mentioned in the previous chapter.

The Facebook page was opened some time after Aliou $^{259}$ first had the idea to denounce what he considered negative behaviour online. Aliou started to publish denunciatory content on his private Facebook page, which also featured information about him and his private life. The first video he published in the context of his activism was taken when one day just outside his home he saw a driver going the wrong way, blocking the lane completely. Aliou took his smartphone and filmed the incident and later put it on his private Facebook page, denouncing the act of wrong-way driving. Because it got so much attention, he decided to open a Facebook page on which his personal details were not 'exposed,' to which he continued to post denunciatory content he had produced in his everyday life without having to face the possible negative outcomes of being personally associated with the content. The page gained popularity and

${ }^{259}$ Interview, 25/07/2019, Dakar - Nord Foire. 
people started to send in their own denunciatory content, which Aliou published instead of content he had produced himself.

By creating a Facebook page on which he was not 'exposed,' Aliou avoided the possible negative outcomes he could have faced personally. Aliou ${ }^{260}$ also reported having asked two jurists to join the team behind the page with the intention to avoid possible legal consequences based on the denunciations that were published. However, as will be discussed in the third section of this chapter, he managed to get quite a few positive outcomes, both for himself and for the cause he was engaged in.

The fact that the activists needed to follow certain strategies to avoid negative personal outcomes, among them refraining from publishing controversial content, ultimately also influenced the topics about which content would be published. ${ }^{261}$ When I met Immanuel, ${ }^{262}$ the trainer of the course on activist smartphone use, he told me that a project on LGBT+ rights for which he had also given this specific training course had to be closed earlier than planned because the great majority of activists and organizations had stopped their cooperation with the project. Most of those who ultimately decided not to participate had told Immanuel that they did so because they feared for their personal safety. Far from being an 'autonomous space,' the internet is thus a space where social pressures are exercised similar to, or even more than, in the offline realm (see for example Hußenöder 2014, 5).

\subsection{Digital Activism and its Outcomes}

As I have shown in the last section, smartphone use in the activist context can have positive as well as negative consequences for the activists, particularly if they are 'exposed' in connection with their content, and particularly if the content is controversial. As Aziz' story has demonstrated, these consequences are not always foreseeable - he could not have known to what extent the denunciatory publication would influence his future engagement. Even though personal risks and opportunities were an intrinsic part of the activist practices among the activists I worked with, it was the outcomes in connection to their activist goals which were at the centre of the activists' attention and motivation.

Because my research focussed on the activists who published the content, and not so much on the people who later consumed it, the question of the exact impact of the publications cannot

\footnotetext{
${ }^{260}$ Interview, 25/07/2019, Dakar - Nord Foire.

261 Tettey $(2017,689)$ also concluded that people were not motivated to denounce corruption if they themselves might face negative consequences in the case of Ghana.

${ }^{262}$ Interview, 06/08/2019, Dakar - Plateau.
} 
be answered in this thesis. Other research has found that digital activists have a large influence on the national political discourse, both offline and online, as for example Ogola and Owuor $(2016,234)$ have shown for the case of Kenya. Bosch et al. $(2020,354)$ have shown that the influence of young people whose content is very visible online also extends into offline debates. While, as mentioned, I cannot make any statements about the exact outcomes of the digital activism, this section will focus on the structures the activists put in place to get the desired outcomes for their respective activist goals.

First, however, it needs to be established what these desired outcomes are. When I asked Awa, ${ }^{263}$ the leader of one of the projects by the West African branch of the international organization previously mentioned in this work, when she considered a certain publication to be a success, she said that it depended mostly on the number of views, comments and reactions to the publication. The main idea was that the more people saw a certain publication, reacted to it or shared it, the more people would either become aware of a certain issue, or would see a certain denunciation. The case of the Facebook page managed by Aliou mentioned in the last chapter is a good example of this - because so many people saw the denunciations published on the site, denounced people and businesses were often under pressure to justify their actions or pledge improvements in the future. Also the activists I worked with ${ }^{264}$ expressed reaching a widespread audience as their main goal when publishing certain content. It will thus be assumed in the remainder of this thesis that the largest number of views, reactions and comments possible are the main goal sought when publishing content. The higher this number is, the greater the activists consider the impact of the publications.

So what is required to achieve this desired outcome? In the last two chapters, I have argued that there are two main preconditions to achieve this seemingly easy task: The first one is gaining and maintaining physical access to a smartphone and the internet, which relates to overcoming the first level of the digital divide, and the second one is having the motivation and the necessary skills to use a smartphone and the internet in a beneficial way, which relates to overcoming the second level of the digital divide. I have shown that overcoming these levels of the digital divide presupposes a number of capitals, particularly economic capital to overcome the first level, and (embodied) cultural capital to overcome the second.

\footnotetext{
${ }^{263}$ Interview, 26/07/2019, Dakar - S.I.C.A.P. Sacré Cœur.

${ }^{264}$ Some of the activists who expressed this were Aziz (interview, 02/07/2019, Dakar - Point E), Coumba (informal conversation, 08/07/2019, Pikine) and Aliou (interview, 25/07/2019, Dakar - Nord Foire).
} 
However, as Immanuel ${ }^{265}$ explained, there are more prerequisites to achieve the desired outcome of obtaining a large number of views, reactions and reposts. He said that firstly, it depended on the quality of the content. The quality of the content depended on the person's skills in producing and editing content, as well as the equipment the person had available. ${ }^{266}$ Immanuel $^{267}$ also emphasized that it was not only about getting these aspects right for one single publication, but for the entire strategy pursued by an activist. All publications, and other activist practices carried out, needed to follow a certain concept in order to be successful to a maximum degree. The activists thus needed to have strategic skills which allowed them to build up symbolic capital among their followers. This symbolic capital was important for the activists, and the content associated to their personas, to be considered trustworthy. This was true either for individual activists who chose to be 'exposed,' or for activist groups or other themed pages, such as the one managed by Aliou. Immanuel called these skills to build up symbolic capital 'marketing skills,'268 which included an intricate knowledge of the target group of one's publications, as well as an overall strategy of publication which fit the likings of this target group. What played a role, according to Immanuel, ${ }^{269}$ was not only what somebody did when using their smartphone, but who their target group believed them to be because of these actions. A certain message could thus have a greater or lesser impact depending on who published it, or in other words, how high this particular individual's symbolic capital is.

Because production and publication processes, just like consumption processes, can shape people's identities and sense of belonging (see for example Ragnedda and Mutsvairo 2017, 6), these strategic practices are not only to be seen as a calculated means to an end. Rather, the practices involved in digital activism are a part of who the activists I worked with saw themselves to be. The reputation built online, for example in the case of $\mathrm{Aziz}^{270}$ as a trustworthy, involved and approachable person, formed part of his identity, as well as an important basis for his digital activism.

Another important aspect in relation to the success of a publication, according to Immanuel, ${ }^{271}$ was to have a strong network of social media contacts, who preferably also had a high number of contacts themselves, and who would share the content in order to gain a large number of

\footnotetext{
265 Interview, 06/08/2019, Dakar - Plateau.

266 See the section "Production and editing of content" of the previous chapter for a more detailed description.

${ }^{267}$ Interview, 06/08/2019, Dakar - Plateau.

268 According to van Dijk's categorization, these skills would fall under 'strategic skills.'

${ }^{269}$ Interview, 06/08/2019, Dakar - Plateau.

${ }^{270}$ Interview, 02/07/2019, Dakar - Fann.

${ }^{271}$ Interview, 06/08/2019, Dakar - Plateau.
} 
views, reactions and comments. In this context, Immanuel gave the example of the \#Bringbackourgirls campaign, to which he had contributed when working for an international human rights organization in Nigeria in 2014. He said that this campaign had been successful because a number of well-known activist groups and advocates - including Michelle Obama had used the hashtag and shared related content. It was thus pre-existing structures which promoted the movement and made it known internationally. In West Africa, Immanuel said, international and local organizations had used the hashtag and made it well-known in the region. The chances for published content to go 'viral' and potentially start a revolution, Immanuel claimed, were higher if existing structures and organizations shared the content to reach a maximum number of people. ${ }^{272}$ If a person was not connected to any large scale organizations or other people with a large number of followers, who would share the content, it was very unlikely that this person could publish a post that would go on to be shared widely.

This view thus contradicts another aspect of what I have called the 'technology of freedom' discourse, namely the image of a standalone activist changing the world through a tap on his smartphone. Rather, as Immanuel's ${ }^{273}$ assessment suggests, social capital in the form of established groups and organizations is hugely beneficial, if not necessary, to attract a large number of views and reactions on one's publications and ultimately to come closer to achieving one's activist goal. ${ }^{274}$

\subsection{Reinforced Inequalities?}

In this section, I want to answer the question of whether inequalities are reinforced by the activists' smartphone use by taking a closer look at the links between the activists' biographies, the capitals at their disposal in the context of their activism, as well as their smartphone use. What were the advantages the individual activists took out of their smartphone use in the activist context, and do these advantages present a reinforcement of existing inequalities? Echoing the last two sections, the positive outcomes the activists described will be separated in two different

\footnotetext{
${ }^{272}$ Harsch $(2012,53)$ came to a similar conclusion concerning the online campaigns involved in the protests widely referred to as the 'Arab Spring,' where he found that pre-existing activist structures were at the root of the protests. ${ }^{273}$ Interview, 06/08/2019, Dakar - Plateau.

274 Other literature has come to similar conclusions, including Schradie (2019, 18-20) who concluded that digital activism was still very much centred on traditional group structures in North Carolina, USA, and that hierarchical structures within those groups, including a strict allocation of responsibilities, have a positive correlation with high internet presence. Also Volpi and Clark (2019, 12-13), in their research on activist groups in the Middle East and North Africa, have found that the internal structure of an organization, its interaction with other political and social institutions, as well as the symbolic capital of the organization in relation to the reason of protest were important features in the activist group's success when it came to organizing protests through social media. The opportunities the organizations can offer the individual activists were thereby also found to be relevant - if the movement could offer activists particular positive outcomes for their engagement, such as career opportunities or similar benefits, the movements were more likely to be successful in the long run (Volpi and Clark 2019, 7).
} 
domains. The first domain will be advantages smartphone use brought for the personal lives of the activists, including aspects such as job opportunities or contacts that could also be of advantage in non-activist contexts. The second domain will be advantages for the achievement of activist goals, which, as has been shown in the last section, also depended on the forms of capitals the activists had at their disposal. While negative outcomes were, as I have previously shown in this chapter, relevant in the context of activism, they will not be considered in this section.

I will start this analysis with Cheikh, the speaker of the activist student movement which previously featured in this thesis. As has been shown through his experience and the experiences of some of the student movement's members, having a smartphone was essential to take part in the organizational processes of activist groups. Communication through WhatsApp had not only become the norm within this particular group but also, Cheikh ${ }^{275}$ experienced, in WhatsApp groups associated with larger movements in Senegal, such as the one associated to $Y$ en a marre to which Cheikh had been added by somebody he met at a large anti-corruption protest in June 2019.

$\mathrm{Cheikh}^{276}$ chose not to be affiliated with either a political party or an international organization with foreign funding, because he considered both options to be collaboration with either a corrupt political elite, or neo-colonising Western actors. He was not particularly 'exposed' on Facebook and hardly ever published there, even less so in the context of his activist engagement. While the student movement also had its own Facebook page, the publications hardly ever featured controversial topics or even activist content, and focused instead on music and arts created by the movement's members.

The main advantages Cheikh's engagement brought were contacts to influential people, which he maintained mainly over his phone. These contacts included media representatives, as well as university staff and authorities. Having this social capital at his disposal served him mostly in the activist context, in that he could contact the media or university staff and authorities if there was an issue on campus that he wanted to solve.

Through his engagement, Cheikh also accumulated symbolic capital, not so much because of his publications on social media, but because he regularly appeared on television or radio programmes as the speaker of the student movement. Most of these appearances were organized

\footnotetext{
275 Informal conversation, 09/07/2019, Dakar - Cité Universitaire.

${ }^{276}$ Informal conversation, 09/07/2019, Dakar - Cité Universitaire.
} 
by him and other members of the movement on specific occasions, through their smartphones. Because of his engagement, Cheikh ${ }^{277}$ had already received the offer to join a political movement, which, as he said, would have meant greater personal gains. Cheikh also told me that some of his family members had asked him to stop making controversial speeches on TV in which he voiced critic of university authorities, and to join a political movement that could offer him more opportunities in the future.

Aziz $^{278}$ started his activist engagement in an apolitical movement he founded with the goal of improving infrastructure in his home locality, and only decided to join a political movement with the same goal after being contacted by the political movement's founder and asked to join. The contact with this leader was established after a controversial publication Aziz posted on his Facebook page about a year prior, as has previously been outlined. The contact to this leader proved very profitable for Aziz, ${ }^{279}$ for example when his smartphone had been stolen and the leader decided to provide him with the financial means to purchase a new one. Aziz ${ }^{280}$ also attributes his finding a job with a long-term contract in a culture institution in Dakar to his political engagement.

For Aziz, the possibility to switch from apolitical to political engagement thus came as a result of a practice performed through his smartphone - the publication of a controversial post. This step signified an enhancement of different forms of capital for him personally, including economic and social capital. The use of his smartphone in the context of his apolitical engagement thus turned out to be a stepping stone towards a more rewarding membership in a political movement, as was also expected to be Cheikh's future by some of his family members.

Joining the political movement was also beneficial for the achievement of his activist goal because it was better funded than the apolitical one had been. This allowed the movement to purchase equipment for his home locality, including expensive assets like ambulances.

Aziz could also enhance some of his capitals through his apolitical engagement in the West African branch of an international organization, such as the skills he learned in the training course given by Immanuel. This embodied cultural capital served Aziz' activist goals, and brought him a higher reputation within the political movement he was engaged in, as he was granted the task of managing the movement's Facebook page and WhatsApp groups because

\footnotetext{
277 Informal conversation, 09/07/2019, Dakar - Cité Universitaire.

278 Interview, 02/07/2019, Dakar - Fann.

${ }^{279}$ Interview, 12/07/2019, Dakar - Fann.

${ }^{280}$ Informal conversation, 26/09/2019, Dakar - Fann Hock.
} 
of his expertise in this area. ${ }^{281}$ For his future, Aziz $^{282}$ could imagine a career in the local politics of his home locality, possibly running for elections within the political movement he was engaged in.

Coumba was engaged in several organizations at the time of my research, most of which received foreign funding, and also held high-up positions in some of the projects of these organizations. Through her engagement, but equally through her career as a journalist, Coumba accumulated several forms of capital, from which she profited both personally and in the context of her activist goals. These include both cultural capital, as for example the skills she learned when taking part in the course taught by Immanuel, and economic capital, for example when radio stations bought the rights to air Coumba's content or when international organizations commissioned certain content from her.

Most importantly, however, Coumba accumulated large social capital, as she was relatively well-known in Dakar's media landscape as well as among international organizations, and high symbolic capital, as has previously been described. Both these capitals expressed themselves in her high number of Facebook friends and followers, among them social media channels of wellknown Senegalese and international organizations. This meant that her publications reached a relatively large number of people, particularly if they were shared on accounts with a large outreach. For her activism, these forms of capital have helped engage in much co-operation with organizations, both local and international, in addition to other activists.

Her activist engagement also brought some benefits for Coumba personally. These include, for example, trips to Europe, where Coumba ${ }^{283}$ participated in training courses and conferences. ${ }^{284}$ Furthermore, because her profession in journalism and her activist engagement sometimes overlapped, a high symbolic capital in her activist engagement often meant her being consulted as a journalist, which also helped Coumba accumulate economic capital.

Aliou, unlike Aziz or Coumba, was not 'exposed' on the Facebook page where he and his team members published the often controversial denunciatory content. As previously discussed, this meant that on the one hand, he avoided many of the negative outcomes that, for example,

\footnotetext{
${ }^{281}$ Bourdieu (1983) also noted that embodied cultural capital, in case it was not common among the social environment, could easily be transformed into other forms of capital.

${ }^{282}$ Informal conversation, 07/08/2019, Dakar - Fann.

${ }^{283}$ Interview, 02/07/2019, Dakar - Plateau.

284 This is noteworthy because accumulating the necessary funds to fly to Europe, or even just obtaining the visa, seemed out of reach for many of the people I met in Senegal.
} 
Coumba faced. On the other, he also did not enhance his symbolic capital through his publications.

However, because the Facebook page was so well-known in Senegal, Aliou ${ }^{285}$ at some point decided to be associated with the page by giving interviews to the press about his engagement. Aliou ${ }^{286}$ thereby told me that his social capital had increased manifold through his engagement, including politicians who had contacted him and asked whether he was interested in a political career. Similarly to Cheikh, Aliou ${ }^{287}$ insisted on not ever joining a political movement for his own personal gain, also claiming that he would publish any attempts to corrupt him on the Facebook page. However, he said that he did not generally reject the idea of becoming politically active in the future.

The Facebook page also featured one of Aliou's phone numbers, under which he regularly posted WhatsApp statuses. The content he published there was both in connection with the Facebook page he managed, but equally often advertisement for his businesses, which were in car rentals and private security. In this way, Aliou not only enhanced his symbolic and social capital through the page, given that he got in contact with many people through it and that he featured in quite a few news reports, but also his economic capital by advertising his business ventures through his WhatsApp account which featured on the Facebook page.

The large social capital accumulated through the Facebook page facilitated the achievement of Aliou's activist goals. Because so many people followed the page, those who had been denounced faced the pressure of reacting to it, either by rectifying the claim, or by apologizing. In this way, the publications launched a discourse on what behaviour was acceptable, which was ultimately Aliou's activist goal. Also, Aliou and his fellow team members regularly organized clean-up actions of beaches or streets, as well as fundraising campaigns, for example before the religious holiday Tabaski. Aliou ${ }^{288}$ reported that because of the large number of followers of the Facebook page, many people regularly participated in these events.

It can thus be said that several factors influence the outcomes of digital activism for the activists personally, but equally for their respective activist cause. These factors include the type of organization they were engaged in and the opportunities the organization could offer. These opportunities differed based on the organization's position in the local and global power

\footnotetext{
${ }^{285}$ Interview, 25/07/2019, Dakar - Nord Foire.

${ }^{286}$ Interview, 25/07/2019, Dakar - Nord Foire.

${ }^{287}$ Interview, 25/07/2019, Dakar - Nord Foire.

${ }^{288}$ Interview, 25/07/2019, Dakar - Nord Foire.
} 
structure - movements associated to a political party or groups which received foreign funding could offer the activists more than movements that had none of these affiliations. Also the overall strategy of the digital activism envisaged by the activist, such as the degree to which the activists decided to be 'exposed,' influenced how much they could enhance their capitals through their engagement. And, as has been discussed throughout this thesis, the degree to which they have overcome the digital divide was a particularly relevant aspect.

The benefits the activists could reap from their engagement, which could ultimately be described as various enhancements of different forms of capital, add to the privilege the activists initially had. As was shown in the last two chapters, all the activists I worked with already disposed of capitals in various forms, which were a prerequisite for them to be able to use their smartphones for activism. I also argued that the more capital the activists initially had at their disposal, the better they could master the digital divide and the higher the outcomes they could expect from their smartphone use.

The capitals the activists had at their disposal, and the capitals they gained through the ways they used their smartphones in activism, thus worked in a circular logic - the higher the initial capital, the more capital would most probably be gained, which translated into even higher capital. It is in this way that smartphones do not flatten social inequalities, as the 'technology of freedom' discourse argues, but instead reinforces them. Those who previously had much, gained more.

\subsection{Chapter Conclusion: A Revolution through a Tap on the Touchscreen?}

As a conclusion to this chapter, it can be said that differences in the outcome of internet use, which relate to the third level of the digital divide, were observable among my interlocutors. Based on different ways of using their smartphones, and on different kinds of groups the activists were affiliated with, the activists experienced different outcomes. As was shown, for example through Aziz' story, smartphone use and the opportunities to gain affiliation to a certain group which might offer better personal outcomes can be interconnected.

The chapter thereby distinguished between two types of outcomes. First, the outcomes for the activists personally, and second, the outcomes in relation to the pursued activist goal. In regards to the personal outcomes the activists faced because of their activism, I showed how different strategies were employed to avoid potential negative consequences. These negative outcomes, which can be seen as a loss in capital of different forms, meant that the activists sometimes avoided controversial topics, or avoided being personally associated with the content. This had 
the effect that particularly controversial topics, such as homosexuality, were hardly ever addressed in published content. Contrary to what the 'technology of freedom' discourse suggests, my findings show that the internet is a space which is just as subject to social and political norms as other, 'offline' spaces.

Concerning the outcomes in relation to the activist goal, I could show that the activists drew on different forms of capital to achieve their desired outcomes, including social capital, symbolic capital, and cultural capital. I thereby argued that the image of a standalone activist who can create a huge impact through a tap on the touchscreen, as portrayed by the 'technology of freedom' discourse, is not tenable, but that existing activist group structures play an important role in the success of published content.

I then described for four of the activists I worked with how the personal positive outcomes they experienced from their engagement added up to the capitals they had previously had at their disposal. Because these positive outcomes, which can be described as an increase in different forms of capital, are added to the previously available ones in a circular way, inequalities are in fact reinforced because of a digital divide. 


\section{Conclusion}

In the very beginning of this thesis, I described a scene which took place during my three-month ethnographic fieldwork in Dakar, the capital of Senegal. In this scene, Oumar, a young man engaged in an activist student movement, became emotional when telling me about the theft of his iPhone, which had taken place two months prior to the meeting. He expressed feelings of anger and despair for having been robbed of his smartphone, which he had enjoyed a lot and felt proud of, and which had served him in a variety of domains, his education and activist engagement among them. As a conclusion I would like to revisit this scene. Can smartphones be considered a 'technology of freedom' in Oumar's situation, or are they a 'technology of inequality?'

Before answering this question, I will first reintroduce the approach of this thesis. In the chapter "Setting the scene," I have defined 'activism' as the passionate pursuit of one or more activist goals, which were often in connection to changing a certain status quo, and often pursued together with fellow activists in more or less formal groups and organizations. I have thereby highlighted that the local and global power structures in which the activists and the groups and organizations the activists were affiliated with were entangled highly influenced the field of activism. The affiliation to either a political party or an institution from the Global North provided certain resources for the activists, which directly translated into the ways they used their smartphones in the activist context. For example, as elaborated in the chapter "The stuff (digital) activism is made of - The materiality of smartphones and their role in the everyday lives of Senegalese activists", Aziz received money from the political movement he was engaged in to buy a new smartphone when his was stolen. Also, both Aziz and Coumba had taken part in a training course on the activist use of smartphones and the internet organized by an organization that received funding from the Global North, equipping them with various skills they considered essential for their smartphone use.

I have further elaborated what I described as the 'technology of freedom' discourse, namely the view taken both in popular opinion and science that smartphones ultimately simplify becoming an activist by reducing the impact of social inequalities. The main argument of this discourse is that by providing users with the possibility to publish content without gate-keeping intermediaries, such as traditional media, also marginalized groups are 'given voice.'

What this discourse largely ignores is the well-researched phenomenon that access to the internet and ICTs, as well as their use and outcomes derived from this use, are not equally 
available to everybody. This phenomenon of unequal access, which has been shown to correlate with pre-existing inequalities, is usually referred to as the 'digital divide.' This thesis has used a three-level model of the digital divide, which differentiates between physical access to the internet (first level), differences in the ways the internet is used (second level), and the outcomes which the user experiences from their internet use (third level). These different levels of the digital divide are not to be seen as entirely different phenomena, but as different focuses on the ways pre-existing inequalities carry into the interaction between a person and the internet through an ICT.

To theoretically substantiate this analysis I have used Bourdieu's (1983) conceptualization of different forms of capitals, as well as van Dijk's (2020) conceptualization of skills in relation to internet use in order to be able to analyse this specific aspect in more detail. I have chosen Bourdieu's concepts, rather than, for example Ragnedda's (2018) concept of 'digital capital' which was developed on the basis of the three-level digital divide, because it allowed me to view activist practices performed through smartphones as meaningful practices in both the physical and the digital sphere. Ragnedda's (2018) concept, similar to other concepts adapted to the digital sphere, separates the digital and physical sphere to an extent that, in my opinion, masks the multiple ways in which those spheres are interconnected. Ultimately, concepts that stipulate a strict separation between the two spheres feed into the narrative that online interactions follow an entirely different logic than offline interactions, which is the root of the 'technology of freedom' argumentation and clearly not what my research has shown. Rather, both spheres are intricately interconnected and materialize through the relationship between people, such as the activists I worked with, and their ICTs, such as the activists' smartphones.

Using the three-level model of the digital divide as a framework, I have elaborated aspects of physical access to the internet and smartphones (first level), different uses of the internet in the specific context of activism, as well as the skills and other resources required for these uses (second level), and the outcomes derived from this use (third level), each one in a corresponding chapter.

In the chapter "The stuff (digital) activism is made of - The materiality of smartphones and their role in the everyday lives of Senegalese activists," I showed that physical access to the internet was an ongoing process that many of the activists I worked with struggled with. This was due to a lack of financial means to afford buying a smartphone, for example after the previous one broke or was stolen, as well as to afford paying the ongoing costs for airtime and mobile data. Overcoming this first level of the digital divide was, however, important both 
because the activists experienced negative feelings when not being able to access the internet through their smartphones at any given time, and because not owning a smartphone seriously hampered their activist engagement. I exemplified the latter through the case of the activist student group, which organized most discussions in a WhatsApp group chat. This ultimately meant that not having a smartphone limited members in their abilities to participate in the group. Moreover, because many of the activists found it important to be considered responsible leaders who could always be reached through their smartphones in case of need, not having physical access to the internet led to a crisis in the way these activists built their identity and their reputation. The entanglement of the device in local and global discourses, as well as a notion of 'good' and 'bad' use of smartphones, equally influenced the way the devices and their use were viewed by the activists.

Particularly the valuation of uses as 'good' or 'bad,' which acknowledges that smartphones can be used in a variety of ways, is a counter-argument against the 'technology of freedom' discourse. It is not the mere access to the internet through smartphones that leads to more freedom in a society, as the 'technology of freedom' discourse suggests, but rather the morally valued choices of users to interact with their smartphones in a way that could eventually lead in this direction.

The chapter "Practicing activism through smartphones - Communication, and the production and publication of content" focussed on the way smartphones were used in the context of activism. I could thereby identify three main ways in which smartphones were used, namely the production and editing of content, communication, and publication. Concerning the production and editing of content, I have shown how different usage requires different technologies to overcome the first level of the digital divide. While a low-quality smartphone might already give access to a variety of uses, more professional equipment is needed for specific uses, for example a device with a high-resolution camera to take high quality pictures. Because these more advanced devices are linked to a higher cost, a lack of economic capital can hamper overcoming the first level of the digital divide for specific uses. Also, skills are needed to produce and edit content in a professional way, which need to be acquired somewhere. In the case of the activists I worked with, it was particularly social capital in connection to the activist's affiliation with specific organizations through which an acquisition of these skills was made possible.

I further discussed communication both within activist groups, and with the target group as the second category of smartphone use I could identify. My analysis focussed on the strategies the 
activists employed to successfully reach their target group, and the resources they required to do so. I could thereby show that the digital divide not only affected the activists themselves, but that they also encountered it in their communication with target groups, particularly if the target group had fewer resources at their disposal. Factors such as problems with physical access to the internet, or illiteracy, needed to be integrated into the activists' strategies of communication. Concerning the practice of publication, which is often referred to as 'digital activism,' I could identify two different forms, namely awareness-raising and denunciation. The examples for the two practices showed how skills, particularly strategic skills, were needed to accomplish them.

The chapter "The perks of being a digital activist - The advantages smartphones bring and the inequalities they (re-)create" focussed on the outcomes of using smartphones in activism, particularly concerning the practice of publication. I differentiated between outcomes for the activists personally, and outcomes concerning the pursued activist goals. I could show how balancing the level of exposure on the platform of publication and the controversy of the content was strategically used to avoid negative personal consequences. I then argued that achieving the desired outcome for publications, namely a large number of views and reactions, required certain resources from the activists. These included cultural capital in the form of skills and a long-term strategy, and particularly social capital in the form of online contacts who could repost and share the content. I then discussed whether and how the capitals of four of the activists whose examples have featured most prominently in this thesis were increased through their online activist practices. The main conclusion was that all of these activists could increase different forms of capitals through their engagement. The position of the activist organization in the global power structure thereby influenced the outcomes of the activist practices.

I would now like to come back to the student room in which Oumar told me that his smartphone had been stolen, with the line of argumentation of this thesis in mind. The question of whether for him smartphones were a 'technology of freedom' or a 'technology of inequality' could be answered as follows:

If Oumar had had a smartphone, it would have offered him a number of functionalities which could have facilitated his everyday life. Theoretically, he could have published activist content through his smartphone that might have helped Oumar achieve his activist goal, or even spark a large social movement. As I could show, producing, editing and publishing activist content is not simple. While it is not impossible to start a large movement with a tap on a smartphone's touchscreen, Oumar's chances of doing so were relatively small unless he had a large amount of resources at his disposal. These resources include equipment that would be adequate to 
produce and edit content of high quality, as well as the skills and strategies to do so. Also the publication of this content would have required resources, for example in the form of data volume to upload it, as well as in the form of skills to publish it in the most advantageous way. Additionally, Oumar would have needed contacts who would then share and repost the content to give it a greater impact, preferably including large organizations who can reach many people. However, even if all these preconditions were met, Oumar would have to face the possibility of a number of outcomes, both positive and negative, for him personally and for his activist engagement. Unless Oumar had the skills to apply specific strategies to avoid negative outcomes, publishing activist content, particularly if it was controversial, could render him vulnerable.

However, all these theoretical considerations did not apply in Oumar's case, because he did not have a smartphone, not even after saving for two months. Oumar could, at least during my stay in Senegal, not overcome the first level of the digital divide to gain physical access to the internet. ${ }^{289}$ His friends and fellow activists, however, did own smartphones and could physically access the internet through them, to the extent that the activist student movement was organized around the presupposition that everybody did. In this context, smartphones thus became a material manifestation of the economic inequalities between Oumar and his fellow activists, and not owning one, being on the 'wrong side' of the digital divide, physically excluded Oumar from practicing activism within this group. While a smartphone that is owned thus offers possibilities of activist practices, and can be considered a 'technology of freedom' in that sense, the lack of a smartphone needs to be seen as a manifestation of inequality. Because the difference between owning and not owning a smartphone is, in this case and as research on the digital divide has shown in many others, ${ }^{290}$ a symptom of pre-existing inequalities, the implication is that also activism as such is not more accessible for the less-privileged through a wide availability of smartphones.

Because the activists who had more capitals at their disposal generally expected higher impact of their content and often increased their capitals through their activist practices, my observations suggest that inequalities are in fact increased through smartphone use because of the digital divide. Rather than flattening the barriers to become an activist independently of one's social standing, it seems that the barrier is reinforced through this vicious cycle. The gap

\footnotetext{
289 Oumar was 'partially' connected through computers in the university library. However, he could not access WhatsApp on these computers, which, as I have shown, meant he could not participate in the Whats App group chat mainly used for discussions by the activist student movement.

${ }^{290}$ See the section on the digital divide.
} 
between those who do not own a smartphone, like Oumar, and those who do increases. The internet and smartphones do offer a number of functionalities which facilitate activism, but only for those who are privileged to have the specific capitals at their disposal to make respective use of them. The supposed 'technology of freedom' thus turned out to be a 'technology of inequality.' 


\section{References}

Aker, Jenny C, Paul Collier, and Pedro C. Vicente. 2017. "Is Information Power? Using Mobile Phones and Free Newspapers During an Election in Mozambique." The Review of Economics and Statistics 99 (2): 185-200.

Alozie, Nicholas O., and Patience Akpan-Obong. 2017. "The Digital Gender Divide: Confronting Obstacles to Women's Development in Africa." Development Policy Review 35 (2): 137-60.

Alzouma, Gado. 2005. "Myths of Digital Technology in Africa." Global Media and Communication 1 (3): 339-56.

Alzouma, Gado. 2019. “Du désert technologique au paradis digital: L'Afrique dans le discours numérique au XXIe siècle.” In L'Afrique en discours: Littératures, Médias Et Arts Contemporains, edited by Bernard Ambassa Fils and Jean-Claude Abada Medjo, 247-68. Saint-Denis: Connaissances et savoirs.

Anyanwu, Chika. 2019. "Digital Divide or Information Divide: Interrogating Telecommunication Penetration Measurements in Communal African Societies." In Mapping Digital Divide in Africa, edited by Bruce Mutsvairo and Massimo Ragnedda, 173-94. Amsterdam: Amsterdam University Press.

Archambault, Julie Soleil. 2017. Mobile Secrets: Youth, Intimacy, and the Politics of Pretense in Mozambique. Chicago: The University of Chicago Press.

Barbosa Neves, Barbara, and Geoffrey Mead. 2018. "The Interpretive and Ideal-Type Approach: Rethinking Digital Non-Use(s) in a Weberian Perspective.” In Theorizing Digital Divides, edited by Massimo Ragnedda and Glenn W. Muschert 2018, 48-60. New York: Routledge.

Barry, Céline. 2017. “Die Bedeutungen von Tubaabité. Rassismuskritische Perspektiven auf das postkoloniale Dakar.” Peripherie 37 (2): 162-91.

Beck, Baptiste, Richard Marcoux, Laurent Richard, and Alexandre Wolff. 2018. "Estimation des Populations Francophones dans le Monde en 2018: Sources et Démarches Méthodologiques." Accessed August 10, 2020. https://www.odsef.fss.ulaval.ca/sites/odsef.fss.ulaval.ca/files/odsef-lfdm-2018.pdf.

Beck, Linda. 2008. Brokering Democracy in Africa. New York: Palgrave Macmillan US. 
Bernardini, Flavia. 2018. "Senegal: Bastion of Democracy, Migration Priority for the EU." Accessed May 05, 2020.

http://www.europarl.europa.eu/RegData/etudes/IDAN/2018/570490/EXPO_IDA(2018)570 490_EN.pdf.

Bosch, Tanja Estella. 2016. "Twitter and Participatory Citizenship: \#FeesMustFall in South Africa.” In Participatory Politics and Citizen Journalism in a Networked Africa, edited by Bruce Mutsvairo, 159-73. London: Palgrave Macmillan UK.

Bosch, Tanja Estella. 2018. "Digital Media and Political Citizenship: Facebook and Politics in South Africa." In Perspectives on Political Communication in Africa, edited by Bruce Mutsvairo and Beschara Karam, 145-58. Cham: Springer International Publishing.

Bosch, Tanja Estella, Mare Admire, and Meli Ncube. 2020. "Facebook and Politics in Africa: Zimbabwe and Kenya." Media, Culture \& Society 42 (3): 349-64.

Bourdieu, Pierre. 1983. “Ökonomisches Kapital, Kulturelles Kapital, Soziales Kapital.” In Soziale Ungleichheiten, edited by Reinhard Kreckel, 183-98. Göttingen: Schwartz.

Bourdieu, Pierre. 1998. Practical Reason: On the Theory of Action. Cambridge: Polity Press. Bourdieu, Pierre, and Loïc Wacquant. 1994. An Invitation to Reflexive Sociology. Chicago: University of Chicago Press.

Brouwer, Sara. 2019. “Kenya's 'Mobile Agriculture’ Discourse: Unpacking Notions of Technology, Modernisation, and Development." In Mapping Digital Divide in Africa, edited by Bruce Mutsvairo and Massimo Ragnedda, 257-76. Amsterdam: Amsterdam University Press.

Carolus, Astrid, Jens Binder, Ricardo Muench, Catharina Schmidt, Florian Schneider, and Sarah Buglass. 2019. "Smartphones as Digital Companions: Characterizing the Relationship between Users and their Phones.” New Media \& Society 21 (4): 914-38.

Castells, Manuel. 2017a. Der Aufstieg der Netzwerkgesellschaft: Das Informationszeitalter. Wirtschaft. Gesellschaft. Kultur. Band 1. Wiesbaden: Springer Fachmedien Wiesbaden.

Castells, Manuel. 2017b. Jahrtausendwende: Das Informationszeitalter. Wirtschaft. Gesellschaft. Kultur. Band 3. Wiesbaden: Springer Fachmedien Wiesbaden.

Castells, Manuel, Mireira Fernández-Ardèvol, Jack Linchuan Qiu, and Araba Sey. 2009. Mobile Communication and Society: A Global Perspective ; a Project of the Annenberg 
Research Network on International Communication. Cambridge, Mass., London: MIT Press.

Chitanana, Tenford. 2019. "From Global to Local, Metropolitan to Village: A Case for a Definitional and Context-Oriented Approach to Examining the 'Digital Divide'." In Mapping Digital Divide in Africa, edited by Bruce Mutsvairo and Massimo Ragnedda, 4564. Amsterdam: Amsterdam University Press.

Chuma, Wallace. 2016. “Between 'Bottom-up' Journalism and Social Activism in Unequal Societies: The Case of GroundUp in South Africa." In Participatory Politics and Citizen Journalism in a Networked Africa, edited by Bruce Mutsvairo, 202-14. London: Palgrave Macmillan UK.

Cisse, Mamadou. 2005. “Langues, État et Société au Sénégal.” Accessed August 05, 2020. http://www.sudlangues.sn/spip.php?rubrique26.

Cover, Rob, and Steven Doak. 2015. "Identity Offline and Online.” In International Encyclopedia of the Social \& Behavioral Sciences, edited by Neil Smelner and Paul Baltes, 547-53. Amsterdam: Elsevier.

Crossouard, Barbara, and Máiréad Dunne. 2015. "Politics, Gender and Youth Citizenship in Senegal: Youth Policing of Dissent and Diversity." International Review of Education 61 (1): 43-60.

Currier, Ashley, and Julie Moreau. 2016. "Digital Strategies and African LGBTI Organizing." In Participatory Politics and Citizen Journalism in a Networked Africa, edited by Bruce Mutsvairo, 231-48. London: Palgrave Macmillan UK.

Curtin, Nicola, and Craig McGarty. 2016. "Expanding on Psychological Theories of Engagement to Understand Activism in Context(s).” Journal of Social Issues 72 (2): 22741.

Daniels, Glenda. 2016. "Scrutinizing Hashtag Activism in the \#MustFall Protests in South Africa in 2015: What Role Did Media Play in Hasthag Activism during the \#RhodesMustFall and \#FeesMustFall Protests in South Africa in 2015?” In Participatory Politics and Citizen Journalism in a Networked Africa, edited by Bruce Mutsvairo, 175-93. London: Palgrave Macmillan UK. 
De Bruijn, Mirjam. 2016. "Citizen Journalism at Crossroads: Mediated Political Agency and Duress in Central Africa." In Participatory Politics and Citizen Journalism in a Networked Africa, edited by Bruce Mutsvairo, 90-104. London: Palgrave Macmillan UK.

Demarest, Leila. 2016. "Staging a "Revolution": The 2011-12 Electoral Protests in Senegal." African Studies Review 59 (3): 61-82.

Direction des Statistiques Démographiques et Sociales. 2020. "Population Du Sénégal 2019." Accessed July 07, 2020. http://www.ansd.sn/ressources/publications/Rapport\%20population_final\%2006mai2020.p df.

Dudenhöffer, Kathrin, and Michael Meyen. 2012. "Digitale Spaltung im Zeitalter der Sättigung.” Publizistik 57 (1): 7-26.

Etzo, Sebastiana, and Guy Collender. 2010. “The Mobile Phone 'Revolution' in Africa: Rhetoric or Reality?" African Affairs 109 (437): 659-68.

Fantaw, Setargew Kenaw. 2013. Technology-Culture Dialogue. Universität Bayreuth: LIT Verlag.

Ferguson, James. 1996. The Anti-Politics Machine: “Development”, Depoliticization, and Bureaucratic Power in Lesotho. Minneapolis, London: University of Minnesota Press.

Frassinelli, Paolo. 2018. "Hashtags: \#RhodesMustFall, \#FeesMustFall and the Temporalities of a Meme Event." In Perspectives on Political Communication in Africa, edited by Bruce Mutsvairo and Beschara Karam, 61-76. Cham: Springer International Publishing.

Fredericks, Rosalind. 2018. Garbage Citizenship: Vital Infrastructures of Labor in Dakar, Senegal.

Geser, Hans. 2004. “Towards a Sociological Theory of the Mobile Phone.” Accessed August $12,2020$. http://www.geser.net/mobile/t_geser1.pdf.

Goggin, Gerard, and César Albarrán Torres. 2014. "Political and Mobile Media Landscapes in Mexico: The Case of \#yosoy132." Continuum 28 (1): 28-42.

Göpfert, Mirco. 2019. “Überlegungen zu einer politischen Ethnologie des Nicht-Politischen, Oder: Jetzt mal Butter bei die Fische!'. In Zugehörigkeiten: Erforschen, Verhandeln, Aufführen im Sinne von Carola Lentz, edited by Jan Beek, Konstanze N'Guesson, and Mareike Späth, 73-83. Köln: Köppe. 
Gottlieb, Jessica, and Horacio Larreguy. 2015. “An Informational Theory of Electoral Targeting: Evidence from Senegal." Accessed July 12, 2020. http://cpd.berkeley.edu/wp-content/uploads/2016/01/GL_SenegalElectoralBehavior-1.pdf.

Greijdanus, Hedy, Carlos A. de Matos Fernandes, Felicity Turner-Zwinkels, Ali Honari, Carla A. Roos, Hannes Rosenbusch, and Tom Postmes. 2020. "The Psychology of Online Activism and Social Movements: Relations Between Online and Offline Collective Action." Current opinion in psychology 35: 49-54.

GSM Association. 2019. “The Mobile Economy West Africa 2018.” Accessed August 07, 2020.

https://www.gsma.com/subsaharanafrica/wp-content/uploads/2018/11/2018-04-11e568fe9e710ec776d82c04e9f6760adb.pdf.

GSM Association. 2020. “The Mobile Economy West Africa 2019.” Accessed August 07, 2020.

https://www.gsma.com/mobileeconomy/wpcontent/uploads/2020/03/GSMA_MobileEconomy2020_West_Africa_ENG.pdf.

Hahn, Hans Peter. 2011. “Antinomien kultureller Aneignung: Einführung.” Zeitschrift für Ethnologie 136 (1): 11-26.

Hahn, Hans Peter, and Ludovic Kibora. 2008. "The Domestication of the Mobile Phone: Oral Society and New ICT in Burkina Faso.” The Journal of Modern African Studies 46 (1): 87109.

Hames, John. 2017. "Language Activism on the Airwaves: Pulaar Radio Broadcasting in the Senegal River Valley.” Communication, Culture \& Critique 10 (4): 657-74.

Hargittai, Eszter, and Amanda Hinnant. 2008. "Digital Inequality.” Communication Research 35 (5): 602-21.

Harsch, Ernest. 2012. “An African Spring in the Making: Protest and Voice Across a Continent." Whitehead Journal of Diplomacy and International Relations, 13 (1): 45-62.

Heeks, Richard. 2018. Information and Communication Technology for Development (ICT4D). New York: Routledge.

Howcraft, Debra, and Brian Fitzgeralt. 1998. From Utopia to Dystopia: The Twin Faces of the Internet. Boston: Kluwer Academic Publishers. 
Hußenöder, Felix Sebastian. 2014. "Social Capital Sites: Understanding Digital Networks from a Resource Perspective.” Accessed September 02, 2020.

https://www.researchgate.net/publication/276069720_Social_Capital_Sites_Understanding _digital_Networks_from_a_Ressource_Perspective.

Ignatow, Gabe, and Laura Robinson. 2017. "Pierre Bourdieu: Theorizing the Digital." Information, Communication \& Society 20 (7): 950-66.

Ihlen, Øyvind. 2018. “Symbolic Capital.” In The International Encyclopedia of Strategic Communication, edited by Robert L. Heath and Winni Johansen, 1-4: Wiley.

Karam, Beschara. 2018. "Theorising Political Communication in Africa.” In Perspectives on Political Communication in Africa, edited by Bruce Mutsvairo and Beschara Karam, 2744. Cham: Springer International Publishing.

Karam, Beschara. 2019. “The Digital Divide and Film.” In Mapping Digital Divide in Africa, edited by Bruce Mutsvairo and Massimo Ragnedda, 153-71. Amsterdam: Amsterdam University Press.

Keja, Roos, and Kathrin Knodel. 2019. "Mistrust and Social Hierarchies as Blind Spots of ICT4D Projects." TATuP 28 (2): 35-40.

Kemp, Simon. 2019. "Digital 2019: Senegal.” Accessed June 27, 2020. https://datareportal.com/reports/digital-2019-senegal.

Kohnert, Dirk, and Laurence Marfaing. 2019. "Senegal: Presidential Elections 2019: The Shining Example of Democratic Transition Immersed in Muddy Power-Politics." EconStor Open Access Articles, 355-66.

Kusiak, Pauline. 2010. “'Tubab’ Technologies and 'African' Ways of Knowing: Nationalist Techno-politics in Senegal." History and Technology 26 (3): 225-49.

Lachenmann, Gudrun. 1993. "Civil Society and Social Movements in Africa: The Case of the Peasant Movement in Senegal.” The European Journal of Development Research 5 (2): 68100.

Lancaster, Harry. 2020. "Senegal: Telecoms, Mobile and Broadband - Statistics and Analyses.” Accessed July 23, 2020.

https://www.budde.com.au/Research/Senegal-Telecoms-Mobile-and-Broadband-Statisticsand-Analyses. 
Ling, Rich, and Heather A. Horst. 2011. "Mobile Communication in the Global South." New Media \& Society 13 (3): 363-74.

Malisa, Mark, and Phillippa Nhengeze. 2018. "Pan-Africanism: A Quest for Liberation and the Pursuit of a United Africa." Genealogy 2 (3): 28.

Mare, Admire. 2016. "Baba Jukwa and the Digital Repertoires of Connective Action in a 'Competitive Authroitarian Regime': The Case of Zimbabwe.” In Participatory Politics and Citizen Journalism in a Networked Africa, edited by Bruce Mutsvairo, 45-68. London: Palgrave Macmillan UK.

Mare, Admire, Hayes Mawindi Mabweazara, and Dumusani Moyo. 2019. “"Fake News” and Cyber-Propaganda in Sub-Saharan Africa: Recentering the Research Agenda." African Journalism Studies 40 (4): 1-12.

Medie, Peace A. 2016. "Women's and Feminist Activism in West Africa.” In The Wiley Blackwell Encyclopedia of Gender and Sexuality Studies, edited by Angela Wong, Maithree Wickramasinghe, Renee Hoogland, and Nancy A. Naples, 1-4. Singapore: John Wiley \& Sons, Ltd.

Ministère de l'économie numérique et des télécommunications. 2019. “Salon Du Digital VIVATECH À Paris : «L'Afrique se développera par le numérique » Selon Madame Le Ministre Ndéye Tické Ndiaye Diop.” Accessed May 05, 2020. http://www.numerique.gouv.sn/actualites/salon-du-digital-vivatech-\%C3\%A0-paris\%C2\%AB-1\%E2\%80\%99afrique-se-d\%C3\%A9veloppera-par-le-num\%C3\%A9rique$\% \mathrm{C} 2 \% \mathrm{BB}-$ selon.

Mossberger, Karen, Caroline Tolbert, and Mary Stansbury. 2003. Virtual Inequality: Beyond the Digital Divide. American governance and public policy series. Washington, DC: Georgetown Univ. Press.

Musa, Muhammed. 2019. "Technology and the Democratic Space in Africa: A ReExamination of the Notion of 'Digital Divide'." In Mapping Digital Divide in Africa, edited by Bruce Mutsvairo and Massimo Ragnedda, 65-88. Amsterdam: Amsterdam University Press.

Mutsvairo, Bruce, ed. 2016a. Digital Activism in the Social Media Era: Critical Reflections on Emerging Trends in Sub-Saharan Africa. Cham: Springer International Publishing. 
Mutsvairo, Bruce. 2016b. "Dovetailing Desires for Democracy with New ICT's Potentiality as Platform for Activism." In Participatory Politics and Citizen Journalism in a Networked Africa, edited by Bruce Mutsvairo, 3-23. London: Palgrave Macmillan UK.

Mutsvairo, Bruce. 2016c. "Recapturing Citizen Journalism: Processes and Patterns.” In Participatory Politics and Citizen Journalism in a Networked Africa, edited by Bruce Mutsvairo, 1-15. London: Palgrave Macmillan UK.

Mutsvairo, Bruce, and Massimo Ragnedda. 2019a. "Comprehending the Digital Disparities in Africa." In Mapping Digital Divide in Africa, edited by Bruce Mutsvairo and Massimo Ragnedda, 13-26. Amsterdam: Amsterdam University Press.

Mutsvairo, Bruce, and Massimo Ragnedda, eds. 2019b. Mapping Digital Divide in Africa. Amsterdam: Amsterdam University Press.

Mwaura, Job. 2017. "Digital Activism in the Social Media Era: Critical Reflections on Emerging Trends in Sub-Saharan Africa.” African Journalism Studies 38 (1): 152-55.

Ncube, Lyton. 2019. “Online Football Fandom as a Microcosm of the Digital Participation Divide in Zimbabwe.” In Mapping Digital Divide in Africa, edited by Bruce Mutsvairo and Massimo Ragnedda, 113-30. Amsterdam: Amsterdam University Press.

Ndiaye, Sergine. 2000. "Student Activism and the Repressive State: Reflections on the Political History of Senegal since Independence." Ufahamu: A Journal of African Studies 28 (1): $125-38$.

Ndlovu-Gatsheni, Sabelo. 2014. "Global Technologies of Domination: From Colonial Encounters to the Arab Spring." In Civic Agency in Africa: Arts of Resistance in the $21^{\text {st }}$ Century, edited by Ebenezer Obadare and Wendy Willems, 27-48. Suffolk: Boydell \& Brewer.

Nissenbaum, Asaf, and Limor Shifman. 2017. "Internet Memes as Contested Cultural Capital: The Case of 4chan's /b/ Board." New Media \& Society 19 (4): 483-501.

Ogola, George, and Mike Owuor. 2016. "Citizen Journalism in Kenya as a Contested 'Third Space'." In Participatory Politics and Citizen Journalism in a Networked Africa, edited by Bruce Mutsvairo, 229-43. London: Palgrave Macmillan UK.

Oyedemi, Toks. 2019. “The Partially Digital: Internet and South African Youth.” In Mapping Digital Divide in Africa, edited by Bruce Mutsvairo and Massimo Ragnedda, 91-111. Amsterdam: Amsterdam University Press. 
Paccoud, Ivana, James Nazroo, and Anja Leist. 2020. "A Bourdieusian Approach to ClassRelated Inequalities: The Role of Capitals and Capital Structure in the Utilisation of Healthcare Services in Later Life.” Sociology of health \& illness 42 (3): 510-25.

Prentice, Alessandra. 2019. "Senegal Police Detain Protesters Amid Outcry over Gas Deal." Accessed May 07, 2020.

https://www.reuters.com/article/us-senegal-politics-protest/senegal-police-detainprotesters-amid-outcry-over-gas-deal-idUSKCN1TF2O4.

Ragnedda, Massimo. 2017. The Third Digital Divide. New York: Routledge.

Ragnedda, Massimo. 2018. "Conceptualizing Digital Capital.” Telematics and Informatics 35 (8): $2366-75$.

Ragnedda, Massimo. 2019. “Conceptualising the Digital Divide.” In Mapping Digital Divide in Africa, edited by Bruce Mutsvairo and Massimo Ragnedda, 27-43. Amsterdam: Amsterdam University Press.

Ragnedda, Massimo, and Glenn W. Muschert. 2018a. “Introduction.” In Theorizing Digital Divides, edited by Massimo Ragnedda and Glenn W. Muschert 2018, 1-8. New York: Routledge.

Ragnedda, Massimo, and Bruce Mutsvairo. 2017. "Demystifying Digital Divide and Digital Leisure." In Digital Leisure Cultures: Critical Perspectives, edited by Sandro Carnicelli, David McGillivray, and Gayle McPherson, 107-19. London: Routledge.

Ragnedda, Massimo, and Maria Laura Ruiu. 2018. "Social Capital and the Three Levels of Digital Divide.” In Theorizing Digital Divides, edited by Massimo Ragnedda and Glenn W. Muschert 2018, 21-34. New York: Routledge.

Ragnedda, Massimo, Maria Laura Ruiu, and Felice Addeo. 2020. "Measuring Digital Capital: An Empirical Investigation.” New Media \& Society 22 (5): 793-816.

Robinson, Laura. 2009. “A Taste for the Necessary.” Information, Communication \& Society 12 (4): 488-507.

Rudolph, Steffen. 2019. Digitale Medien, Partizipation und Ungleichheit. Wiesbaden: Springer Fachmedien Wiesbaden.

Salgado, Susana. 2016. "Political Participation, Alternative Media and Citizen Journalism in Lusophone Africa." In Participatory Politics and Citizen Journalism in a Networked Africa, edited by Bruce Mutsvairo, 178-201. London: Palgrave Macmillan UK. 
Sam, Steven. 2019. "Bridging the Digital Gap in Sub-Saharan Africa: A Critical Analysis of Illiteracy and Language Divide." In Mapping Digital Divide in Africa, edited by Bruce Mutsvairo and Massimo Ragnedda, 215-55. Amsterdam: Amsterdam University Press.

Schneider, Mindi. 2008. “"We Are Hungry!”: A Summary Report of Food Riots, Government Responses, and States of Democracy in 2008.” Accessed July 14, 2020.

https://www.researchgate.net/publication/237113525_We_Are_Hungry_A_Summary_Rep ort_of_Food_Riots_Government_Responses_and_States_of_Democracy_in_2008.

Schradie, Jen. 2011. "The Digital Production Gap: The Digital Divide and Web 2.0 Collide." Poetics 39 (2): 145-68.

Schradie, Jen. 2019. The Revolution That Wasn't: How Digital Activism Favors Conservatives. Cambridge, MA: Harvard University Press.

Seibert, Lauren. 2019. “There Is Enormous Suffering”: Serious Abuses Against Talibé Children in Senegal, 2017-2018. New York: Human Rights Watch.

Seto, Ario. 2017. Netizenship, Activism and Online Community Transformation in Indonesia. Singapore: Palgrave MacMillan.

Selwyn, Neil. 2004. "Reconsidering Political and Popular Understandings of the Digital Divide." New Media \& Society 6 (3): 341-62.

Sey, Araba, and Manuel Castells. 2004. "From Media Politics to Networked Politics: The Internet and the Political Process." In The Network Society: A Cross-Cultural Perspective, edited by Manuel Castells. Cheltenham, UK, Northampton, MA: Edward Elgar Pub.

Skjerdal, Terje. 2016. "Why the Arab Spring Never Came to Ethiopia.” In Participatory Politics and Citizen Journalism in a Networked Africa, edited by Bruce Mutsvairo, 77-89. London: Palgrave Macmillan UK.

Sneyd, Lauren, Alexander Legwegoh, and Evan Fraser. 2013. "Food Riots: Media Perspectives on the Causes of Food Protest in Africa." Food Security 5 (4): 485-97.

Soumaré, Marième. 2019. "Sénégal : Le Collectif Aar Li Ñu Bokk, Objet Politique Non Identifié.” Accessed August 10, 2020. https://www.jeuneafrique.com/861978/politique/senegal-le-collectif-aar-li-nu-bokk-objetpolitique-non-identifie/.

Stafford, Casey. 2013. University Student Agency, Representation, and Activism: A Case Study of Students Studying English at Université Cheikh Anta Diop (Dakar, Sénégal). 
University of Minnesota Digital Conservancy. Accessed August 10, 2020.

https://hdl.handle.net/11299/159931.

Tettey, Wisdom. 2017. "Mobile Telephony and Democracy in Ghana: Interrogating the Changing Ecology of Citizen Engagement and Political Communication."

Telecommunications Policy 41 (7-8): 685-94.

Thioune Diop, Moustapha. 2017. Entwicklungspolitik und Partizipation in Senegal.

Wiesbaden: Springer Fachmedien Wiesbaden.

Trkulja, Violeta. 2010. Die Digitale Kluft. Wiesbaden: VS Verlag für Sozialwissenschaften.

Trzciòski, Krzysztof. 2005. "Origins of Armed Separatism in Southern Senegal.” Africana Bulletin 53: 169-208.

Uimonen, Paula. 2012. Digital Drama: Teaching and Learning Art and Media in Tanzania. New York: Routledge.

Uimonen, Paula. 2015. "Internet and Social Media: Anthropological Aspects.” In International Encyclopedia of the Social \& Behavioral Sciences, edited by Neil Smelner and Paul Baltes, 600-605. Amsterdam: Elsevier.

Van Deursen, Alexander, Jan van Dijk, and Peter Klooster. 2015. "Increasing Inequalities in What We Do Online: A Longitudinal Cross Sectional Analysis of Internet Activities Among the Dutch Population (2010 to 2013) Over Gender, Age, Education, and Income." Telematics and Informatics 32 (2): 259-72.

Van Dijk, Jan. 2005. The Deepening Divide: Inequality in the Information Society. Thousand Oaks, Calif.: Sage.

Van Dijk, Jan. 2020. The Digital Divide. Cambridge, UK: Polity Press.

Van Zomeren, Martijn. 2015. "Collective Action as Relational Interaction: A New Relational Hypothesis on How Non-Activists Become Activists." New Ideas in Psychology 39: 1-11.

Villi, Mikko. 2013. "Visual Mobile Communication on the Internet: Patterns in Publishing and Messaging." In Mobile Media Practices, Presence and Politics, edited by Kathleen M. Cumiskey and Larissa Hjorth, 214-27. Hoboken: Taylor and Francis.

Volpi, Frédéric, and Janine Clark. 2019. "Activism in the Middle East and North Africa in Times of Upheaval: Social Networks’ Actions and Interactions." Social Movement Studies 18 (1): $1-16$. 
Wachanga, D. Ndirangu. 2012. "Participatory Culture in an Emerging Information Ecosystem: Lessons from Ushahidi." Communicatio 38 (2): 195-212.

Waltinger, Michael. 2019. Das Mobiltelefon im Alltagsleben des urbanen Kenia. Wiesbaden: Springer Fachmedien Wiesbaden.

Wane, Birane. 2010. L'islam au Sénégal: Le poids des confréries ou l'émiettement de l'autorité spirituelle. Accessed August 28, 2020.

https://tel.archives-ouvertes.fr/tel-00660670/document.

Warschauer, Mark. 2003. Technology and Social Inclusion: Rethinking the Digital Divide. Cambridge, Mass: MIT Press.

Wasserman, Herman. 2011. "Mobile Phones, Popular Media, and Everyday African Democracy: Transmissions and Transgressions." Popular Communication 9 (2): 146-58.

Wasserman, Herman. 2016. "Foreword." In Participatory Politics and Citizen Journalism in a Networked Africa, edited by Bruce Mutsvairo, v-vii. London: Palgrave Macmillan UK.

Wei, Kwok-Kee, Hock-Hai Teo, Hock Chuan Chan, and Bernard Tan. 2011.

"Conceptualizing and Testing a Social Cognitive Model of the Digital Divide." Information Systems Research 22 (1): 170-87.

Willems, Wendy, and Ebenezer Obadare. 2014. "Introduction: African Resistance in an Age of Fractured Sovereignty." In Civic Agency in Africa: Arts of Resistance in the $21^{\text {st }}$ Century, edited by Ebenezer Obadare and Wendy Willems, 1-23. Suffolk: Boydell \& Brewer.

Wittmann, Frank. 2008. "Politics, Religion and the Media: The Transformation of the Public Sphere in Senegal." Media, Culture \& Society 30 (4): 479-94.

Yang, Guobin. 2009. The Power of the Internet in China: Citizen Activism Online. New York: Columbia Univ. Press.

Zillien, Nicole, and Mirko Marr. 2013. “The Digital Divide in Europe.” In The Digital Divide, edited by Massimo Ragnedda and Glenn Muschert, 55-66. Abingdon, Oxon: Routledge. 